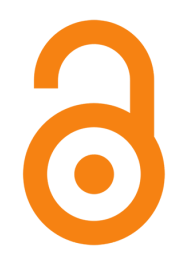

(C2020 The Author(s)

This is an Open Access book distributed under the terms of the Creative Commons Attribution-NonCommercial-NoDerivatives Licence (CC BY-NC-ND 4.0), which permits copying and redistribution in the original format for non-commercial purposes, provided the original work is properly cited.

(http://creativecommons.org/licenses/by-nc-nd/4.0/). This does not affect the rights licensed or assigned from any third party in this book.

This title was made available Open Access through a partnership with Knowledge Unlatched.

IWA Publishing would like to thank all of the libraries for pledging to support the transition of this title to Open Access through the KU Select 2019 program.
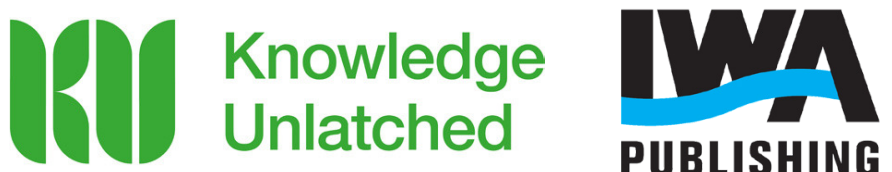

PUBLISHING 
Seventeen years of scientific research - A new paradigm proposed

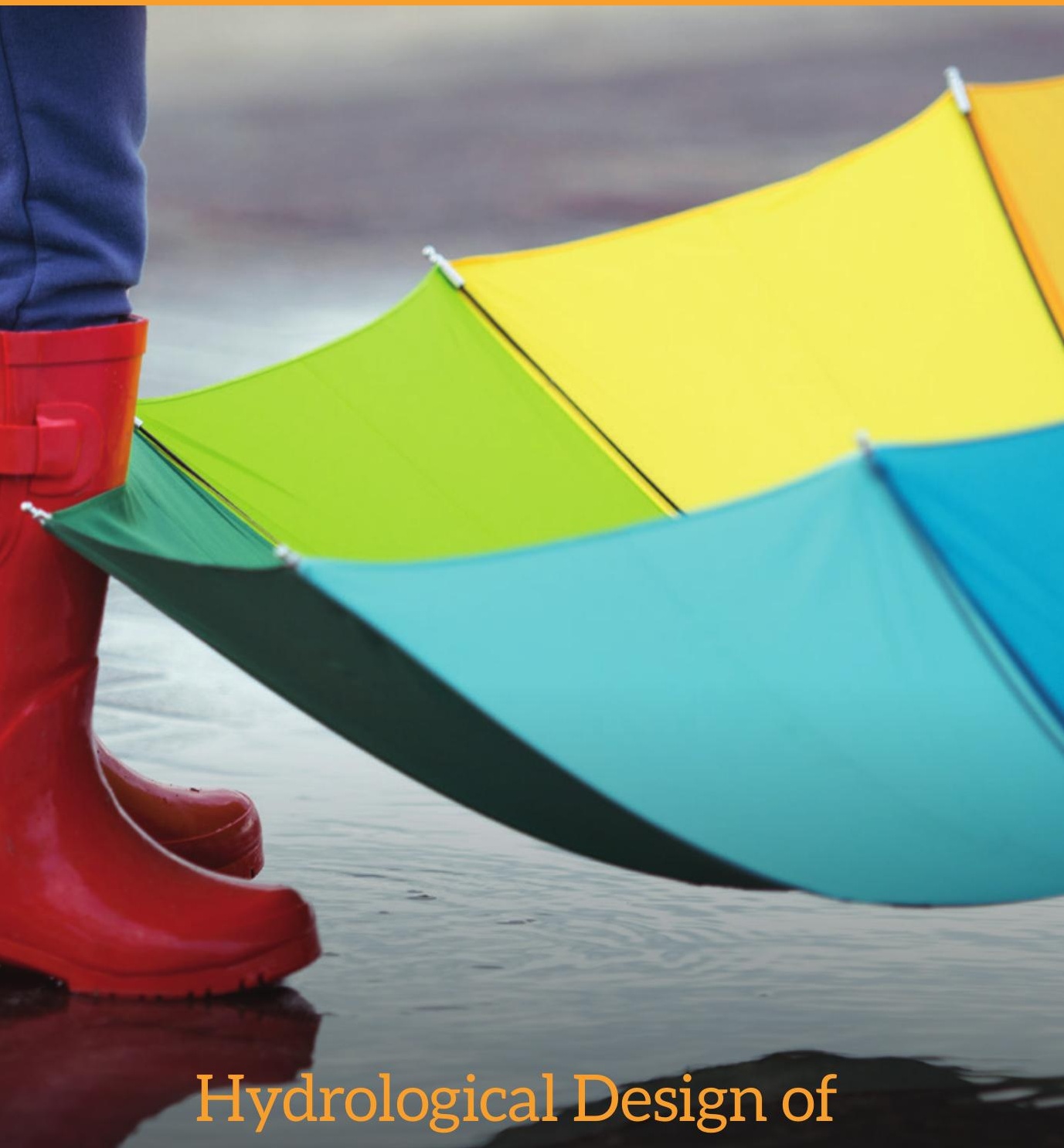

Multipurpose Micro-catchment Rainwater Management 


\section{Hydrological Design of Multipurpose Micro-catchment Rainwater Management}


Downloaded from https://iwaponline.com/ebooks/book-pdf/651202/wio9781780408712.pdf

by IWA Publishing publications@iwap.co.uk 


\section{Hydrological Design of Multipurpose Micro-catchment Rainwater Management}

\section{Mooyoung Han and Duc Canh Nguyen}


Published by

First published 2018

(c) 2018 IWA Publishing
IWA Publishing

Alliance House

12 Caxton Street

London SW1H 0QS, UK

Telephone: +44 (0)20 76545500

Fax: +44 (0)20 76545555

Email: publications@iwap.co.uk

Web: www.iwapublishing.com

Apart from any fair dealing for the purposes of research or private study, or criticism or review, as permitted under the UK Copyright, Designs and Patents Act (1998), no part of this publication may be reproduced, stored or transmitted in any form or by any means, without the prior permission in writing of the publisher, or, in the case of photographic reproduction, in accordance with the terms of licenses issued by the Copyright Licensing Agency in the UK, or in accordance with the terms of licenses issued by the appropriate reproduction rights organization outside the UK. Enquiries concerning reproduction outside the terms stated here should be sent to IWA Publishing at the address printed above.

The publisher makes no representation, express or implied, with regard to the accuracy of the information contained in this book and cannot accept any legal responsibility or liability for errors or omissions that may be made.

\section{Disclaimer}

The information provided and the opinions given in this publication are not necessarily those of IWA and should not be acted upon without independent consideration and professional advice. IWA and the Editors and Author will not accept responsibility for any loss or damage suffered by any person acting or refraining from acting upon any material contained in this publication.

\section{British Library Cataloguing in Publication Data}

A CIP catalogue record for this book is available from the British Library

ISBN: 9781780408705 (Print)

ISBN: 9781780408712 (eBook)

ISBN: 9781780409351 (ePUB) 


\section{Contents}

About the authors $\ldots \ldots \ldots \ldots \ldots \ldots$ ix

Preface from the chief author ........... xi

\section{Chapter 1}

A new paradigm of rainwater management ...... 1

1.1 Rainwater: Drain or Collect? . . . . . . . . . . . . . 1

1.1.1 Cities draining rainwater $\ldots \ldots \ldots \ldots \ldots .2$

1.1.2 A new paradigm of rainwater management ... 4

1.2 Challenges of Drain City $\ldots \ldots \ldots \ldots \ldots \ldots \ldots$

1.3 Rain City as a Solution $\ldots \ldots \ldots \ldots \ldots \ldots \ldots$

1.4 From Drain City to Rain City $\ldots \ldots \ldots \ldots \ldots \ldots \ldots$

1.5 Summary $\ldots \ldots \ldots \ldots \ldots \ldots \ldots \ldots \ldots \ldots \ldots \ldots \ldots$

\section{Chapter 2}

Modeling of micro-catchment hydrology . . . . . 15

2.1 Introduction ........................ 15

2.2 Comparison of Conventional Hydrology and Micro-Catchment Hydrology $\ldots \ldots \ldots \ldots \ldots \ldots . . \ldots 17$ 
vi Hydrological Design of Multipurpose Micro-catchment RWM

2.3 Review of Conventional Hydrology $\ldots \ldots \ldots \ldots \ldots 19$

2.3.1 Rainfall modeling $(i) \quad \ldots \ldots \ldots \ldots \ldots \ldots$

2.3.2 Runoff modeling $(Q) \ldots \ldots \ldots \ldots \ldots \ldots \ldots$

2.3.3 Discharge modeling $(D) \ldots \ldots \ldots \ldots \ldots \ldots 28$

2.3.4 Verification from field data . . . . . . . . . 28

2.4 Considerations for Micro-Catchment Hydrology

Modeling .................... 29

2.4.1 Rainfall modeling $(i) \quad \ldots \ldots \ldots \ldots \ldots \ldots . \ldots 29$

2.4.2 Runoff modeling $(Q) \ldots \ldots \ldots \ldots \ldots \ldots \ldots$

2.4.3 Discharge modeling $(D) \ldots \ldots \ldots \ldots \ldots .33$

2.5 Case Study of Micro-Catchment Hydrology

Modeling .................... 36

2.5.1 Design rainfall hyetograph for micro-catchment RWMS ........... 36

2.5.2 Verification of the runoff equation ....... 42

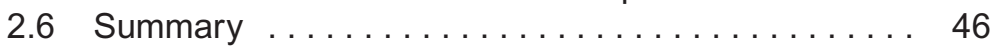

References ..................... 46

\section{Chapter 3}

\section{Hydrological design of multipurpose} micro-catchment rainwater management . . . . 49

3.1 Introduction .................... 49

3.1.1 Development of rainwater management (RWM) models ............... 50

3.1.2 Procedure of hydrological modeling ...... 52

3.1.3 Other considerations in micro-catchment

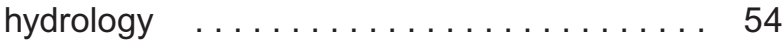

3.2 Rainfall-Discharge (R-D) Model $\ldots \ldots \ldots \ldots \ldots \ldots 5$

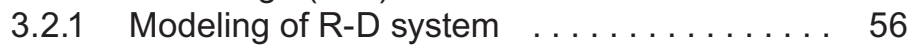

3.2.2 Results and discussion ............ 58

3.3 Rainfall-Storage-Discharge (R-S-D) Model . . . . . 60

3.3.1 Modeling of R-S-D system . . . . . . . . 61

3.3.2 Results and discussion ............ 64

3.4 Rainfall-Storage-Pump-Discharge (R-S-P-D)

Model .........................68 
3.5 Rainfall-Storage-Utilization-Discharge (R-S-U-D) Model . . . . . . . . . . . . . . . . . 71

3.5.1 Modeling of R-S-U-D system . . . . . . . 72

3.5.2 Results and discussion . . . . . . . . . . 75

3.6 Rainfall-Storage-Infiltration-Discharge (R-S-I-D) Model . . . . . . . . . . . . . . . . . . . . . . . 79

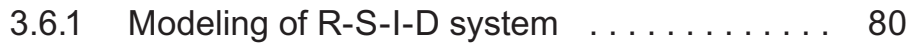

3.6.2 Results and discussion ........... 83

3.7 Rainfall-Storage-Utilization-Infiltration-Discharge

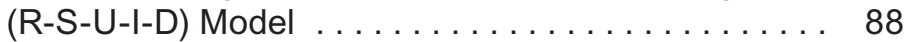

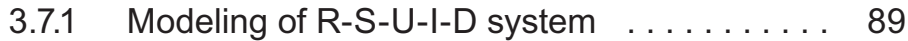

3.7.2 Results and discussion ............ 93

3.8 Design Example of RWMS for Seoul City, Korea . . . 98

3.8.1 Design procedure ... . . . . . . . 98

3.8.2 Example calculation ............. 99

3.9 Summary ... . . . . . . . . . . . . . . . . . . . 102

References ............................ 105

\section{Chapter 4}

Hydrological design of rainwater harvesting

system for water supply . . . . . . . . . . . 107

4.1 Introduction . . . . . . . . . . . . . . . 107

4.2 Daily Rainfall Data Model . . . . . . . . . . . . . 110

4.2.1 Modeling method ................. 110

4.2.2 Design example for daily rainfall data model ... 113

4.3 Monthly Rainfall Data Model (When Rainfall

Data is Insufficient) . . . . . . . . . . . . . . . 115

4.3.1 Modeling method .............. 116

4.3.2 Design example for monthly rainfall data model ...................... 118

4.4 How to Improve the Performance of RWHS . . . . . 121

4.4.1 Variable demand model . . . . . . . . . . . 122

4.4.2 Design example for RWHS performance improvement ................... 124

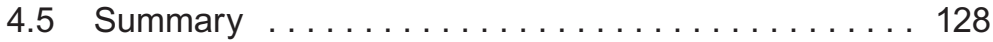

References . . . . . . . . . . . . . . . . . . . . . . 129 
viii Hydrological Design of Multipurpose Micro-catchment RWM

\section{Chapter 5}

\section{Case studies}

5.1 Design and Operation of a Multipurpose RWHM

Project in an Urban Area - Case Study in Star City,

South Korea . . . . . . . . . . . . . . . . . . . . . . . . . 131

5.1 .1 Introduction . . . . . . . . . . . . 131

5.1.2 Materials and methods ............. 133

5.1.3 Results and discussion ............ 134

5.2 Design and Operation of a Rainwater for Drinking

(RFD) Project in a Rural Area - Case Study in

Cu Khe Elementary School, Vietnam . . . . . . . 139

5.2 .1 Introduction . . . . . . . . . . . . . 139

5.2 .2 Materials and methods ............. 140

5.2.3 Results and discussion ............. 142

5.3 Effect of Flood Reduction by Decentralized Rainwater

Management System (DRWMS) - A Case Study

in Suwon City, South Korea . . . . . . . . . . . . . . . . 147

5.3 .1 Introduction . . . . . . . . . . . . . . 147

5.3.2 Materials and methods ............. 148

5.3.3 Results and discussion ... . . . . . . . . 149

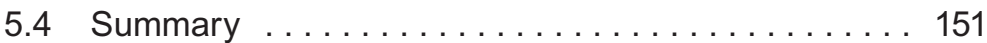

References ......................... 152

Index . . . . . . . . . . . . . . . . . . . . 155 


\section{About the authors}

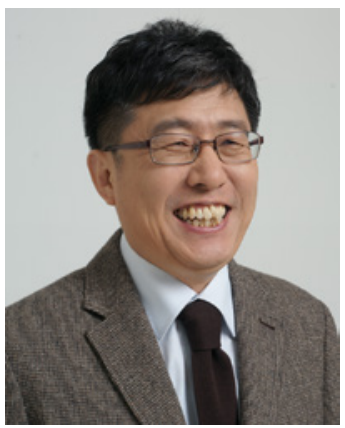

Professor Mooyoung Han is Director of the Rainwater Research Center, Seoul National University, in Korea, and Chairman of the International Water Association's Rainwater Harvesting and Management Specialist Group.

Department of Civil and Environmental Engineering \#35-302, Seoul National University

1, Kwanakro, Kwanakgu, Seoul 151-742

Republic of Korea

E-mail: myhan@snu.ac.kr

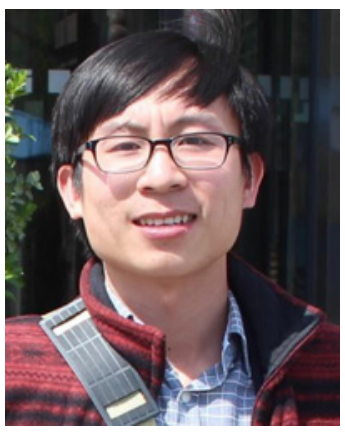

Dr. Duc Canh Nguyen got his PhD from the Department of Civil and Engineering, Seoul National University in 2017 then joined the Faculty of Environmental and Labour Safety, Ton Duc Thang University the same year.

C125, Faculty of Environment and Labour Safety Ton Duc Thang University

19 Nguyen Huu Tho Street, Tan Phong Ward District

7, Ho Chi Minh City, Vietnam

E-mail: nguyenduccanh@tdt.edu.vn 
Downloaded from https://iwaponline.com/ebooks/book-pdf/651202/wio9781780408712.pdf

by IWA Publishing publications@iwap.co.uk 


\section{Preface from the chief author}

\section{RAINWATER AND ME}

My journey with rainwater started almost 17 years ago. Since then, I have published and reported several successful rainwater harvesting demonstration projects including one at Seoul National University's Dormitory and also the world-famous Star City Rainwater System at Seoul, Korea. Rainwater has become one of the main agendas in the field of sustainable water management.

In 2004, I became the Chairman of IWA (International Water Association) Rainwater Harvesting Management (RWHM) Specialist Group and organized seven International Rainwater Harvesting Workshops and three RWHM international conferences. In addition, I installed and operated several tens of rainwater harvesting systems in several developing countries such as Vietnam, Solomon Islands, Tanzania, Ethiopia, and the Philippines, ranging from individual household to community scales. During the process, of course, mistakes were countless and unavoidable. Yet thanks to such mistakes and failure, I was able to equip myself with precious experiences which became the basis for the development of highly sustainable systems.

The first and foremost motivation of my rainwater research was simply to collect rainwater and use it for non-drinking purposes, 
thus reducing demands on the water supply. As I continued my research on the water quality, I realized that we can produce very high quality drinking water with little or even no treatment. Moreover, by collecting rainwater, great extra benefits can be obtained such as flood mitigation, groundwater recharge, storage for emergency, and so on.

As all water problems are site-specific, so too are the solutions. Therefore, the solution should start from indigenous wisdom. Although a rainwater system is relatively small and requires simple technology, the philosophy for how to deal with water is of most importance for successful implementation. For example, Korea has been suffering from both drought and flooding in the same year due to the Monsoon climate and mountainous geology. Therefore, rainwater management was of utmost concern and the responsibility of the highest level officials such as the king for the country or a respected leader of a village. Under these circumstances, it is not surprising that the world's first rain gauge was developed in 1441 and rainfall has been recorded ever since then. Some 250 years of continuous rainfall record is available for Seoul. Perhaps by understanding the importance of managing rainfall over the centuries we could also find important knowledge for sustainable water management for the future.

Ecologists say that when there are shocks or stresses in the ecosystem, the response to that change in conditions follows three stages: resistance, adaptation and transformation. Because the concept of collecting rainwater in the city and using it instead of draining it might have been a shocking change to most of the society, it is likely that adoption of this 'new' old idea might follow the same three stages.

\section{RESISTANCE}

The first response from the people and experts regarding rainwater management was resistance. Many people doubted the rainwater quality for any use including drinking. Some experts 
said that the rainwater harvesting system is not cost-effective, because the water rate is too low. They also questioned the flood mitigation effect. They believed that large dams are preferred to small rainwater systems because of their scale merit. In South Korea, in particular, there was (and still is) an exaggerated fear of acid rain.

Ironically, the strongest resistance came from the experts. They resisted against any new idea not supported by references and scientific and engineering data. They wanted to see the scientific data and references which require a lot of money, time, endurance, cooperation of citizens, and publication of scientific papers as well as the wide promotion of the results to the public and law makers.

Now, after 17 years of research and practice, most of the answers to the commonly asked questions concerning rainwater management are ready and available. Addressing the scientific and engineering questions improved our approach. I have to say thank you to all the experts and citizens who raised many hard questions. Now they have access to well thought-out and reasonable answers, it is time for them to promote rainwater.

\section{ADAPTATION}

This book is prepared with the mind of a little boy who sees from the shoulders of a giant: it builds on the existing theories and practices of hydrology and water quality management. Care was taken to make certain that all aspects of rainwater harvesting were consistent with broader theory and methodology. The fit and efficiency of the newly suggested system is proven from the operational data of actual rainwater systems. Therefore, contemporary hydrology experts may choose to adapt the theory and methodology presented in this book and hopefully become proponents of rainwater management.

In many ways this change is already underway. As a result, in South Korea in 2016, 59 local governments declared their intention 
xiv Hydrological Design of Multipurpose Micro-catchment RWM

to join Rain City in which citizens recognize the importance of rainwater and develop regulations to subsidize and offer financial incentives for rainwater systems. It is my expectation that 'Rain City' and 'Rain Village' will be expanded not only in South Korea but also in the wider world.

\section{TRANSFORMATION}

This book is written to give hope to those who seek to transform their community from Drain City to Rain City. Readers of this book will have the tools to address the reasonable concerns of experts and the ability to overcome the same resistance that I have encountered in the last 17 years. It has been prepared to answer most of the questions and clear the ambiguity regarding rainwater management and transform the experts as well as the citizens into active proponents of rainwater. I believe that this can be achieved, because the goal of the 'Rain City' concept can make everybody happy. Together with the following publication on 'Rainwater for Drinking,' this publication can be a guide to transform the world into a Rain City, which may become a viable solution toward SDG6 (Water and Sanitation for all).

\section{BOOK CONTENTS}

This book contains five chapters. Chapter 1 proposes a New Paradigm of Rainwater Management. The conventional Drain City concept is challenged, and a new Rain City concept is suggested as a solution. Chapter 2 reviews the conventional hydrology and compares it with micro-catchment hydrology. Chapter 3 introduces hydrological modeling for micro-catchments which incorporates various measures of rainwater management for multiple benefits. Chapter 4 introduces the hydrological method for the design of a rainwater system for a water supply especially where the rainfall data is limited. Finally, Chapter 5 introduces 
three case studies that support the validity of micro-catchment hydrology modeling and practice.

\section{THANK YOU NOTE}

I am grateful to international rainwater experts who firstly made me open my eyes and convinced me of a new water management paradigm and continuously encouraged me whenever I lost my way: Dr. Makoto Murase (Japan), Klaus Koenig (Germany), Dr. Michael Kravich (Slovakia), Prof. Viet Anh Nguyen (Vietnam), Steve Moddemeyer (USA), Brita Forssberg (Sweden) and Paul Reiter (IWA). I also thank those who encouraged and supported me to design, build and operate the rainwater systems. Without their financial and emotional support, I could not have come this far.

Special thanks to my 'Rain Doctors' who wrote their Ph.D. dissertations on rainwater from my lab, including Dr. Kim Youngjin, Dr. Muhammad Tahir Amin, Dr. Mun Jungsoo, Dr. Kim Sangrae, Dr. Kim Mikyoung, Dr. Lee Juyoung, Dr. Tulinave Mwamila and Dr. Duc Canh Nguyen (who is the co-author of this book). Dzung Ahn Dao and Kwak Dongeun are almost close to join Rain Doctor group. Many Master and Bachelor students from the Department of Civil and Environmental Engineering at Seoul National University joined me in the voluntary rainwater harvesting installation activities in Vietnam. My deep appreciation goes to the IWAP, who agreed to publish this book and Lis Stedman, Thu Hoai Thi Do and Khue Dieu Do who helped with English editing.

Professor Mooyoung Han

Director, Rainwater Research Center,

Seoul National University

Chairman, IWA Rainwater Harvesting and Management Specialist Group 
Downloaded from https://iwaponline.com/ebooks/book-pdf/651202/wio9781780408712.pdf

by IWA Publishing publications@iwap.co.uk 


\section{Chapter 1}

\section{A new paradigm of rainwater management}

\subsection{RAINWATER: DRAIN OR COLLECT?}

Recently, there have been several global water problems, such as flooding, drought, water shortage, water pollution, and groundwater depletion. All of these issues are related to rainwater: flooding occurs because of excessive rainwater; drought and water shortage are results of a reduced rainfall; non-point source pollution occurs during rainfall; and groundwater depletion results from reduced rainwater infiltration in areas where the number of impermeable surfaces has increased. Therefore, proper rainwater management (RWM) is required to mitigate most of these global water issues, thus ensuring sustainability and enhancing the resilience of the existing water infrastructure. The fundamental questions regarding RWM are: 'Rainwater-Drain or Collect?' and 'How do we make everybody happy?'

C IWA Publishing 2018. Hydrological Design of Multipurpose Micro-catchment Rainwater Management Mooyoung Han, Duc Canh Nguyen doi: 10.2166/9781780408712_001 


\subsubsection{Cities draining rainwater}

Traditionally, most cities have been designed to drain rainwater as rapidly as possible. This can be easily recognized by observing old and new buildings in Europe, the Americas, or Asia. Rainwater from the rooftop is drained through downpipes and discharged to the road surface or sewer system. Rainwater from the streets is also discharged to the sewers. Flooding occurs when the flow rate increases beyond the sewer capacity. Rainwater will mix with the contaminants on roads, resulting in the pollution of surface water. A drained city can experience heat wave problems due to the loss of the evaporative cooling effect of water. All of the present cities in which none of the citizens recognizes the importance of rainwater while all participate in draining it are defined as Drain Cities. This stems from several scientific misunderstandings about rainwater.

\section{Q1: Is acid rain safe?}

Most people believe that rainwater is acidic and therefore, dangerous. The $\mathrm{pH}$ of pure and uncontaminated rainwater is 5.6 due to the chemical equilibrium with $\mathrm{CO}_{2}$ in the atmosphere. In the past, air pollution has caused severe acid rain. However, due to the development of treatment technology and regulations to inhibit air pollution emission, such harmful acid rain events seldom occur nowadays under ordinary conditions, although rain is naturally in the weakly acidic range.

A simple $\mathrm{pH}$ measurement can prove that while rainwater is acidic during precipitation, the rain collected following contact with rooftops covered with some dust is alkaline. Following one day of storage, it becomes neutral (Figure 1.1). Therefore, rain is not dangerous in an uncontaminated or slightly contaminated area. It is interesting to know that the $\mathrm{pH}$ of healthy human skin is approximately 5.6, which is close to the $\mathrm{pH}$ of (acid) rain. 


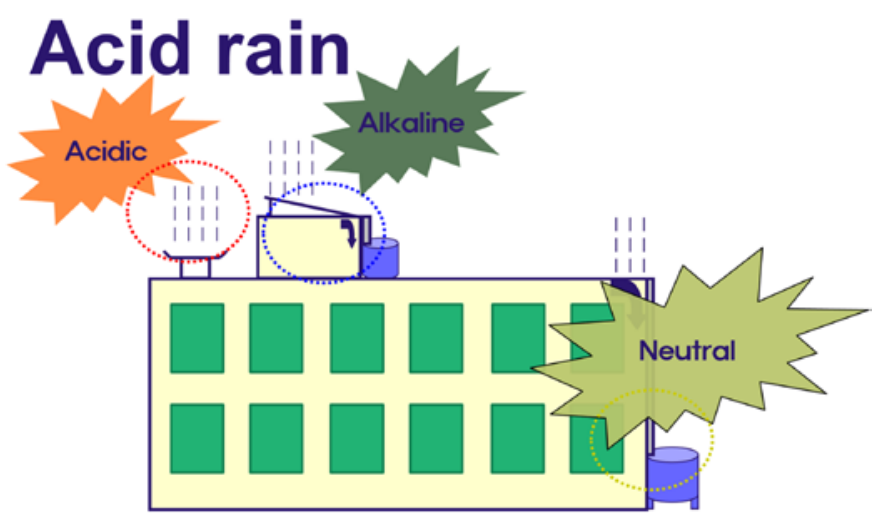

Figure 1.1 Acid rain neutralizes after falling on a surface and being stored for a day thereafter.

\section{Q2: Is rainwater clean?}

Figure 1.2 shows the natural water cycle: rainwater that has fallen on mountains flows through cities and rivers, eventually reaching the sea. The originally-clean rainwater becomes contaminated as it travels. The degree of contamination depends on the distance it has moved after touching down on the ground and the duration of contact with the surface or contaminants. The numbers in the figure show the trend of the total dissolved solids (TDS) concentration of the water: the higher the mileage of the water, the more contaminated it is. Based on the concept of 'mileage of water', rainwater from the building rooftop has zero mileage, thus making it the cleanest.

\section{Q3: Is rainwater safe to drink?}

Many people ask me 'Is it safe to drink rainwater?' Before I answer, I ask them back, 'Is it safe to drink river water?' The 
4 Hydrological Design of Multipurpose Micro-catchment RWM answer is no. We must treat the river water before drinking it. It is the same with rainwater. We must treat it to make it drinkable. Therefore, a more appropriate question might be: 'Is river water or rainwater more economical to treat?' The answer is certainly rainwater.

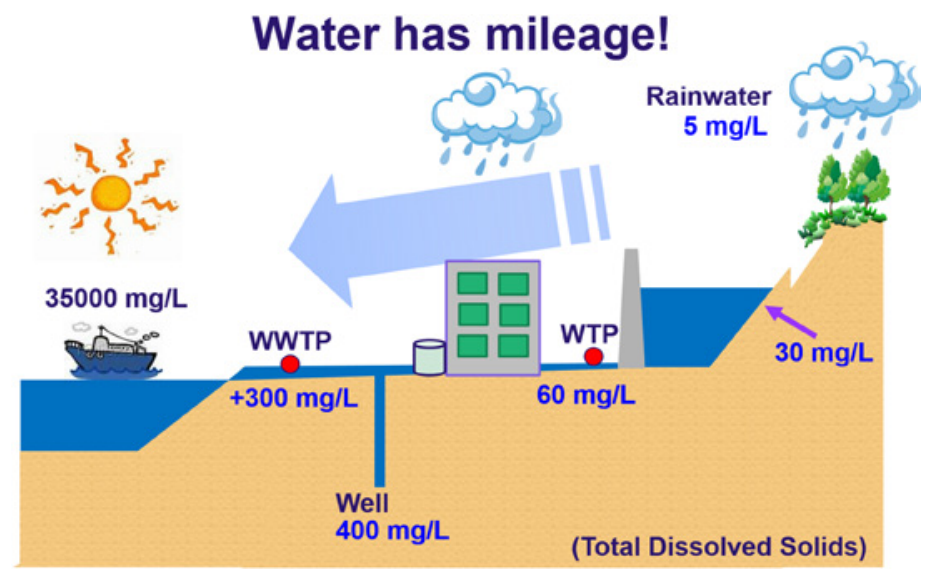

Figure 1.2 Quality of water in the natural water cycle (WTP: Water Treatment Plant; WWTP: Waste Water Treatment Plant).

\subsubsection{A new paradigm of rainwater management}

We must think about rainwater differently from the traditional concept. Once we clarify the scientific misunderstandings about rainwater, we need to ensure that rainwater is collected where it falls, before it gets contaminated, and use it subsequently for multiple purposes. Our cities should be changed or developed according to the new paradigm of rainwater management.

\subsection{CHALLENGES OF DRAIN CITY}

The traditional and currently accepted concept of managing rainwater in cities is to drain it as quickly as possible, considering 
it a menace, rather than an asset. People ignore the importance of rainwater, draining it thoughtlessly. Architects design buildings to drain rainwater. Land planners plan cities while considering rainwater a nuisance, draining it while constructing infrastructure such as pumping stations, and storm water retention basins. The design codes developed by experts are based on the concept of draining rainwater. The regulations and laws are also made to drain rainwater as quickly as possible. Therefore, the only purpose of managing rainwater in a city with a sewer system or a 'Drain City' is to drain it, so as to prevent flooding in ' $\mathrm{MY}$ ' area. It is interesting to note that the rainwater drained from upstream will eventually cause damage downstream and lead to the requirement for further investment in water infrastructure downstream.

This can be shown conceptually, as in Figure 1.3, using a palm. Here, the hand and lines represent the city or country and sewer or river, respectively. While rain falls at any location within the given area, people drain the rainwater to a sewer or river (the line), attempting to manage it along the line. This is called 'management by line'. The runoff flow increases downstream. It is not possible to design and maintain the sewer and river systems to ensure safety because the rainfall may be heavier than expected due to climate change compared to the designed capacity.
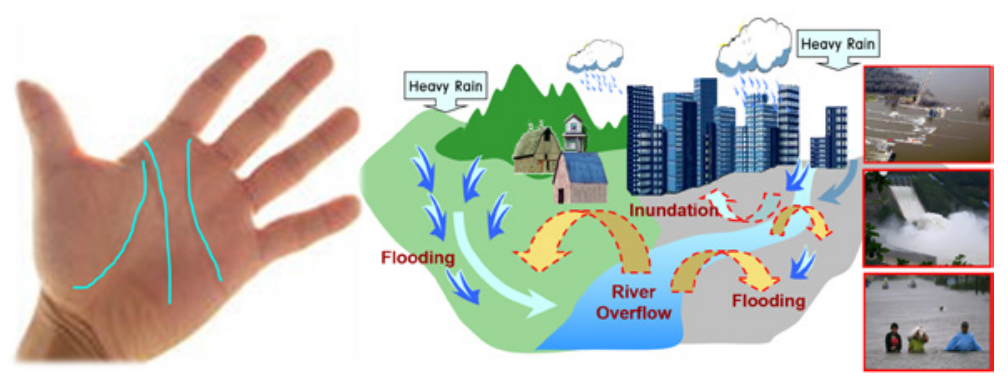

Figure 1.3 Rainwater management by line. 
The inherent design concepts of a Drain City are as follows:

(1) Rainwater is a waste: Rainwater is considered to be contaminated and a nuisance. Therefore, all the rainwater should be drained assuming that it is a waste, instead of collecting it as a resource.

(2) Combine the rain flow, increasing its momentum: In the design of the sewer system, all the rainwater is combined downstream. This causes the quantity to gradually increase, requiring an increase in the capacity of the sewer system. When the volume of flow is higher than the sewer capacity, flooding occurs.

According to elementary physics, the momentum of a body is proportional to the product of mass and velocity. If the rainwater from each street is combined while moving downstream, the momentum increases. Therefore, the sewer system or river bank system needs to be strengthened to resist the higher momentum.

(3) Collect rain downstream on a large scale: Rainwater has always been collected downstream, such as near the river, where the potential energy of the water is lost. In other words, energy is required to send the water back to the upper region. In a traditional storm water management system, since rainwater is collected downstream from a large catchment area, the system should be constructed on a large scale. Since the damage may be significant in case of an adverse event, a storm water basin should be built with a higher safety factor, requiring extra investment. Although it is expensive, it is used for only a short period in a year, if at all. Furthermore, since it is intended for flood prevention, it must remain empty for most of the time to store rainwater in the event of an unexpected heavy rainfall.

(4) Do it for a single purpose: Since the sole purpose of rainwater management in line is flood prevention, all the 
rainwater needs be drained. There is no reason to collect rainwater from the roof or road surfaces. Instead, the rainwater is expected to be removed as soon as possible.

(5) Social responsibility of rainwater management: Most architects or land developers assume that they can design a building or landscaping, while disregarding adequate rainwater management. Their only concern regarding rainwater is to drain it downstream. They do not seem to consider it their responsibility to manage the rainwater in the design area. Moreover, they do not seem to be concerned about the consequences of draining rainwater on the people or environment downstream. Increased runoff from buildings and cities damages the area downstream, requiring extra investment in water infrastructure. With decreased infiltration due to paved surfaces, the groundwater level will be depleted, gradually destroying the environment.

\section{PHILOSOPHY OF A DRAIN CITY}

People drain rainwater, ignoring the fact that draining it can adversely affect the people downstream due to increased runoff and pollution. The philosophy of a Drain City is to focus only on self-comfort. It does not consider others, including people, nature, and the future generation.

\subsection{RAIN CITY AS A SOLUTION}

A 'Rain City' can solve most challenges faced in a Drain City. This can be shown conceptually (Figure 1.4), as an example of rainwater management by area. Since rainfall covers the entire area, if all the buildings and small sites were designed to collect rainwater at site on a small scale by storing or infiltrating it, then the amount of runoff would be reduced. This solution can cope with even major rainfall events without increasing the current 
sewer capacity. Additional benefits can be expected by using the collected rainwater for water supply, emergency storage, or groundwater recharge.
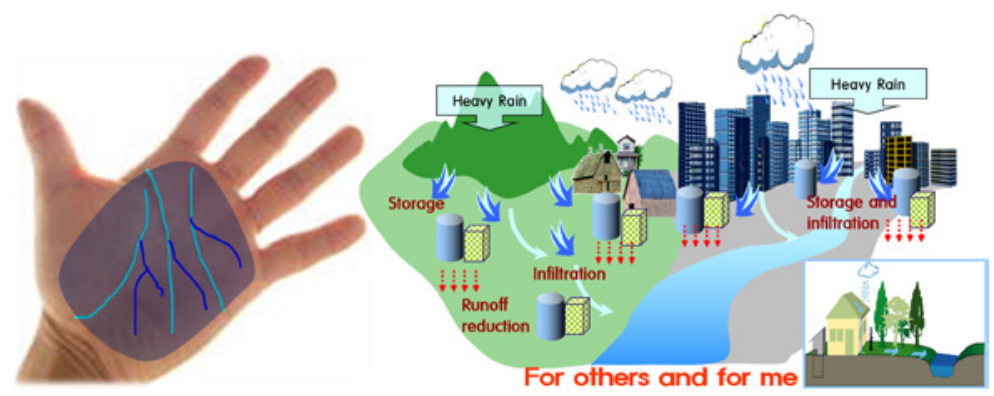

Figure 1.4 Rainwater management by area.

The inherent design concepts of a Rain City are as follows:

(1) Rain is money: In our building at Seoul National University (Seoul, Korea), a $250 \mathrm{~m}^{3}$ rainwater tank was included from the design stage. When it rains, the tank is filled with rainwater, which is used for flushing toilets, thus saving the money otherwise used to pay for tap water. Therefore, we believe that 'rainwater is money'. If people realize that rainwater is like money, they will collect it. Rainwater is the origin of all water sources, such as surface water and groundwater. Rainwater harvesting and utilization can not only save the money and energy required for water treatment and transportation, but also enhance resilience against damage due to flooding, water shortage, pollution, or fire.

(2) Distribute and manage rainwater: By distributing rainwater using small-scale rainwater storage and infiltration, the flow 
rate can be reduced, along with the investment in building and operating water infrastructures. If we distribute the rainwater runoff by collecting it on site, its mass will decrease, along with its momentum. Soil erosion will be reduced as well. By distributing rainwater, we can control its mass and momentum, thus managing it, instead of being managed by it.

(3) Collect rainwater upstream on a small scale: If we collect rainwater where it falls, we can obtain good water quality with relatively less treatment. An additional benefit of reducing the volume of runoff by direct storage or ground infiltration is the reduced threat of flooding at a local level. After collection, the stored water can be used for various purposes. Moreover, if we collect upstream, we can make use of the potential energy: it can be transported downstream by gravity. Instead of a largescale centralized system, several decentralized systems, coupled with proper management, will not only improve the runoff reduction effect, but also reduce the cost and energy requirements.

(4) Make it multipurpose: The value of a rainwater management system increases if it is designed as a multipurpose system. Considering that many water-related problems, such as flooding, drought, water pollution, heat island effect, groundwater depletion, and mountain fires are related to rainwater, several problems can be solved simultaneously. Multipurpose rainwater management can be a good option, solving these existing problems more efficiently.

(5) Social responsibility of rainwater management: It is the responsibility of architects and land developers to manage the extra rainwater that is discharged from the properties they develop. 
Some countries, like Germany, charge a rainwater tax based on the property area. Alternatively, the tax is reduced when a rainwater management system is installed at the site. In ancient Korea and Vietnam, traditionally, when a large building or palace was constructed, ponds were built on or near the site as a sign of social responsibility of rainwater management, while enjoying the multiple benefits of these ponds. There remain several good examples, including the ponds at Gyeongbokgung Palace (Figure 1.5), which was built in the 14th century at the beginning of the Chosun Dynasty (a kingdom before the Republic of Korea).

\section{PHILOSOPHY OF A RAIN CITY}

The philosophy of a Rain City, which collects rainwater upstream using many small storage systems or infiltration, can satisfy people both downstream and upstream. This benefits the environment and the future generation, as the sustainability of the system is maintained.

\section{Ponds at Gyeongbokgung Palace in Seoul} (since 1395: Chosun Dynasty)

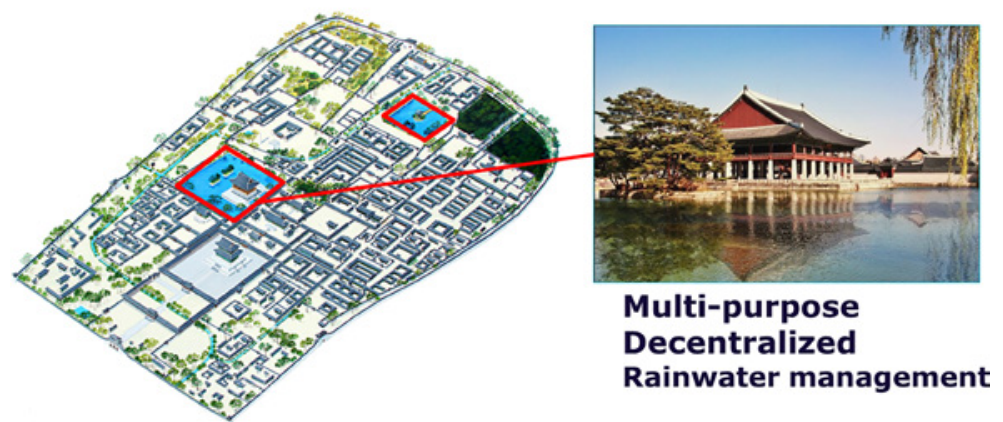

Figure 1.5 An example of multipurpose decentralized rainwater management in ancient Korea. 


\subsection{FROM DRAIN CITY TO RAIN CITY}

A Rain City is a city in which all the citizens understand that rainwater is valuable, introducing regulations to promote rainwater by offering subsidies or incentives for people implementing a rainwater system.

There is a good example of this in the Republic of Korea. Through continuous promotions in the mass media and appropriate education, by October 2016, 59 cities declared themselves Rain Cities. These cities focused on two objectives: (1) increasing their water independency ratios, and (2) trying to maintain their original water status. Achieving these objectives involves the cooperation of all stakeholders, which is gained by offering financial incentives, while imposing compulsory requirements and technical guidelines for rainwater management facilities.

The success of a Rain City is founded on reminding residents of what the word 'village' (洞, pronounced 'Dong') means in the Korean language. It is worth mentioning that the names of all local districts in Korea end with the word 'Dong', such as Myoung Dong, Insa Dong, and Pyungchang Dong, etc. The literal meaning is water (水) + same (同) (Figure 1.6). This implies that the first thing to be considered in a city or village should be water because it is the most important. The second meaning is that it reminds all villagers that they depend on the same water, thus encouraging them to conserve water and reduce pollution. The third definition is that the water status should be kept in the same condition after development (no impact), which is a more reasonable and advanced philosophy than Low Impact Development (LID). The fourth meaning is that rainwater that falls at each site should be managed as the major source of water. This means that a high water independency ratio can be maintained for each village. The philosophy embedded in 'Dong' provides important insights for sustainable water management.

Climate change adaptation to protect against flooding and drought, while providing safe drinking water, will be a significant 
challenge to water experts and politicians. Rainwater management can partly solve these problems. Rainwater that is collected on a building or a site is a relatively clean water source that can reduce the energy used to treat and transport the water, as well as reducing the flood risk in local sewers. A decentralized, multiple rainwater tank system, with the associated IT-based decision-making tools, will be the only solution to localized heavy rainfall in congested cities, where increasing the sewer capacity is technically and financially not feasible.

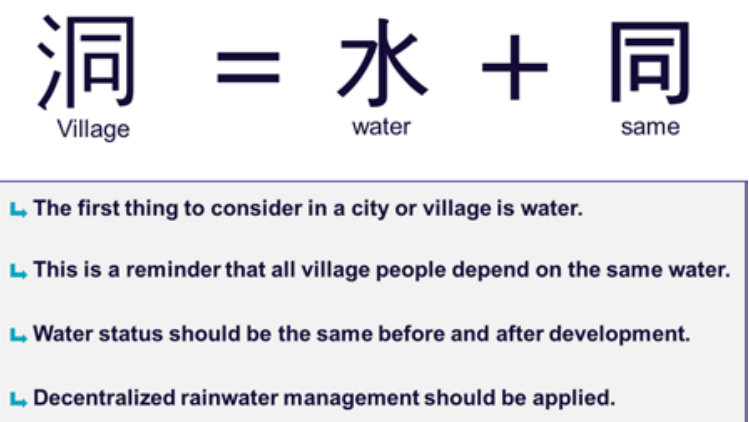

Figure 1.6 Philosophy of rainwater management.

Innovative job opportunities in designing, operating, maintaining, and promoting Rain Cities can be offered. Modeling tools can be developed to design a system of decentralized rainwater tanks, while predicting the effects of flooding, water conservation, and energy conservation. Products for collecting, treating, and storing rainwater on various scales, in accordance with the existing urban planning and water infrastructure, will be made available. Based on new types of rainwater management, the water industry is expected to grow.

The techniques and the engineering of small-scale decentralized rainwater systems are more straightforward than the large-scale centralized storm water systems. People working 
in water management may be reluctant to adopt the concept as they might be concerned about losing their jobs or being unsuccessful in their first attempt. The most challenging thing is changing people's mindset and misconceptions regarding rainwater management through education. The most important thing is to make the approach multipurpose by adding more value, while eliminating the sources of conflict. The approach should be both top-down and bottom-up. By changing the voters' mindsets and influencing decision makers with engineering data, appropriate regulations can be introduced.

Since current climate-change-related water issues such as floods, drought, and water shortages are related to rainwater, proper rainwater management is essential. On-site, decentralized rainwater management has significant potential for water conservation, energy conservation, and flood mitigation. It can be an excellent supplement to the existing centralized water systems. Both technical data and public education are required to change the mindset of ordinary citizens and the regulations of a city. The primary slogan of this movement is:

'Revolution of Rainwater: From Drain City to Rain City by Training Brain Citizens'.

\subsection{SUMMARY}

In this chapter, the fundamental question about rainwater ('Drain or Collect?') has been raised and addressed. Traditionally, rainwater has been managed using the Drain City concept, which promotes draining rainwater as rapidly as possible, while considering it a nuisance. It is managed by the sewer and river systems, using some significant measures for the sole purpose of flood prevention. The philosophy of a Drain City is self-comfort, without considering others' needs. 
14 Hydrological Design of Multipurpose Micro-catchment RWM

Some scientific misconceptions regarding rainwater have been clarified, while a new paradigm of rainwater management by area using the Rain City concept has been proposed. According to this concept, rainwater is collected where it falls, with several small measures to make it multipurpose. The philosophy of a Rain City involves considering everyone's requirements, including people downstream, the environment, and the future generations. This concept coincides exactly with the win-win strategy in the field of world business and negotiation. It is also based on Hongik Ingan, which is the original founding philosophy of Korea teaching us to live and work for the benefit of all mankind. In addition, some examples of multipurpose rainwater management systems from historical and modern eras have been presented. 


\section{Chapter 2}

\section{Modeling of micro-catchment hydrology}

\subsection{INTRODUCTION}

During the last century, many hydrological models have been developed and applied to predict the behavior of rainfall and runoff, which can be used in designing various types of hydraulic structures. While all of the models have been developed for a large area $\left(10^{5} \sim 10^{10} \mathrm{~m}^{2}\right)$ as a centralized system, rainwater management systems (RWMSs) are designed on a decentralized basis, as the area of a rooftop is small (less than $2000 \mathrm{~m}^{2}$ ). While hydrological behaviors such as the flow rate and time of a centralized system are not controllable, those of RWMSs are controllable due to their decentralized nature. While the conventional systems calculate the case of maximum flow rate for flooding prediction, decentralized RWMSs can carry out multiple functions such as flooding mitigation, water saving and groundwater recharge, and so on (Figure 2.1).

C IWA Publishing 2018. Hydrological Design of Multipurpose Micro-catchment Rainwater Management Mooyoung Han, Duc Canh Nguyen doi: 10.2166/9781780408712_015 
16 Hydrological Design of Multipurpose Micro-catchment RWM

\section{Conventional Sewer System}

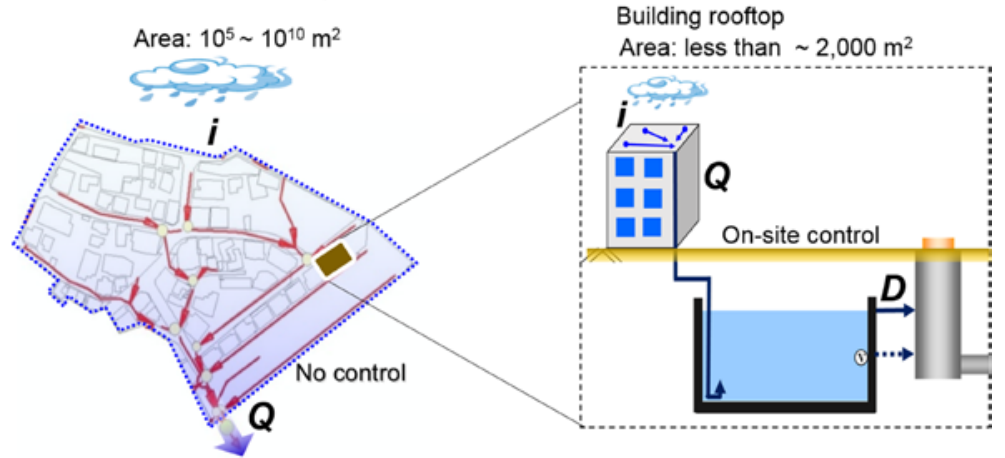

Figure 2.1 Conventional sewer system and micro-catchment RWMS.

When we want to design and predict the hydrological behaviors of rooftop catchment and RWMSs, several basic questions arise:

(1) Can we use the rainfall and runoff equations developed for conventional hydrologic models, which are based on a very large area as compared to the area of a rooftop?

(2) While we can design the control measures in RWMS such as storage volume, utilization, pump to discharge, and infiltration, how can we model such system?

In this chapter, the assumptions and conditions of conventional and micro-catchment hydrology systems are compared (Section 2.2). The conventional hydrology is reviewed, and then developed to model the rainfall and runoff from different regions and time periods (Section 2.3). The method to model micro-catchment RWMS is suggested after careful consideration (Section 2.4). Finally, an example for micro-catchment modeling is presented for the case of Seoul city (Section 2.5). 


\subsection{COMPARISON OF CONVENTIONAL HYDROLOGY AND MICRO-CATCHMENT HYDROLOGY}

To predict overflow to the sewer system, we need to carry out the following: (1) rainfall prediction modeling (to find $i$ ), (2) runoff modeling (to find $Q$ ), and (3) discharge modeling after controlled hydraulic structures (to find $D$ ). Figure 2.2 demonstrates the flow chart for hydrology modeling.

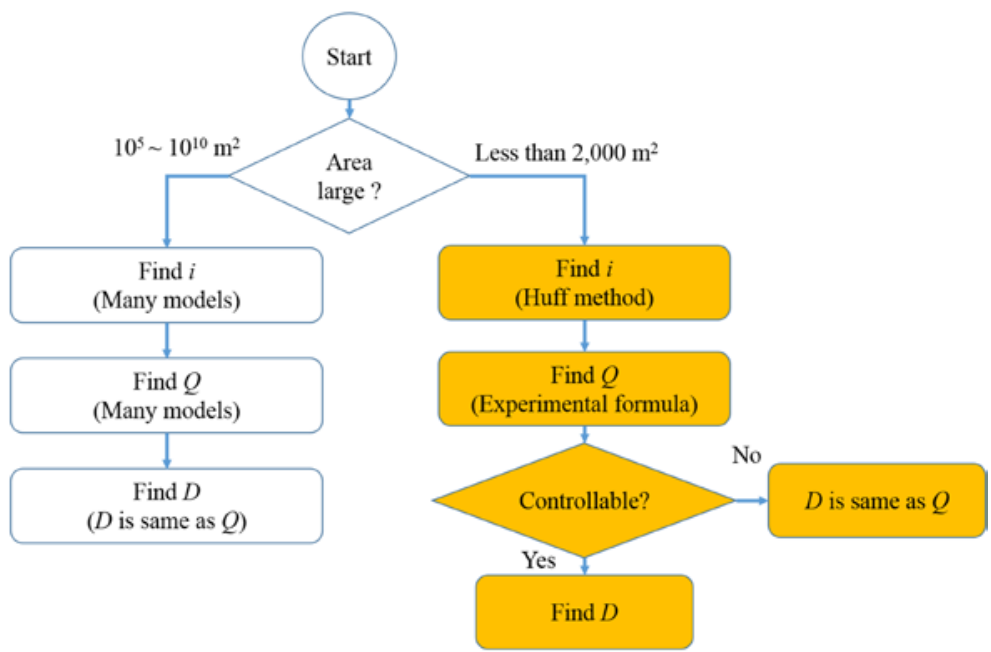

Conventional Hydrology

Micro-catchment Hydrology

Figure 2.2 Flow chart for hydrology modeling.

Various rainfall, runoff, and discharge models have been developed for conventional hydrology based on their specific conditions. However, due to the specific assumptions of the conventional hydrology theories, they face limitations in application, especially for specific design of micro-catchment 
rainwater management. The detailed reasons for this are listed as follows:

- Area: Conventional sewer systems are constructed and designed for areas of larger scale in the range of $10^{5} \sim 10^{10} \mathrm{~m}^{2}$. Meanwhile, micro-catchment RWMSs have small catchment areas of building rooftops usually ranging from 100 2000 $\mathrm{m}^{2}$.

- Time of concentration: Due to the large scale of areas, conventional sewer systems have runoff paths with long durations (30 min to a few hours). Meanwhile, the time required for rainwater to travel from the roof to the rainwater tank inlet in micro-catchment RWMSs is assumed inconsiderable. According to Kim et al. (2009), the actual time measured is usually around 5 to 10 minutes.

- Position: The conventional sewer systems are a regional runoff control system that manages downstream flows at the end-of-pipe of drainage networks using large channelization and underground detention basins. Micro-catchment RWMSs are regarded as a type of on-site source control as it collects rainwater at a place close to where it falls.

- Purpose: Discharge of rainwater was the main philosophy of the conventional hydrology which focused on flood mitigation only. The ideal of 'micro-catchment' is that the rainwater can be safely collected and utilized on site for multiple purposes: as a source of water with good quality with minimum treatment, saving energy and cost.

- Controllable operation: The conventional sewer systems are huge. Therefore, it is difficult, or almost impossible, to control the runoff if something goes wrong. The microcatchment RWMSs are small and easy to handle at extreme (rainfall) events. It is possible to control the discharge overflow easily by simple controllable measures (i.e., storage tank, utilization, pump to discharge, infiltration) and thus increase the system's resilience. 
The most critical differences between conventional sewer systems and micro-catchment RWMSs are summarized in Table 2.1.

Table 2.1 Comparison of conventional sewer system and microcatchment RWMSs.

\begin{tabular}{lll}
\hline Factor & $\begin{array}{l}\text { Conventional } \\
\text { Sewer System }\end{array}$ & $\begin{array}{l}\text { Micro-catchment } \\
\text { RWMS }\end{array}$ \\
\hline Drainage area & $10^{5} \sim 10^{10} \mathrm{~m}^{2}$ & Less than $2000 \mathrm{~m}^{2}$ \\
Time of concentration & 30 min $\sim$ hours & $\sim 0(5 \sim 10 \mathrm{~min})$ \\
Position & End-of-pipe & On-site \\
Purpose & Flood mitigation & Multipurpose \\
Controllable operation & Difficult to control & Controllable \\
\hline
\end{tabular}

\subsection{REVIEW OF CONVENTIONAL HYDROLOGY 2.3.1 Rainfall modeling (i)}

In the design of hydraulic structures and prediction of hydrological behavior, the most crucial task is to logically model the rainfall pattern, that is, to properly manage the time-rainfall intensity relationship at the design site. In reality, this task has been achieved by simply assuming uniform distribution and applying a rigorous stochastic approach. In this section, we briefly review the development of rainfall models. The final selection of a proper model depends on site-specific conditions. For further details of rainfall models, hydrology textbooks should be referred to including Mays (2001).

\subsubsection{Uniform distribution}

Uniform distribution is the simplest method which assumes that rainfall is constant over the duration of the storm event as shown in Figure 2.3. This method is generally used in conjunction with the Rational method for runoff modeling. However, 
20 Hydrological Design of Multipurpose Micro-catchment RWM

many researchers believe that this assumption is unsuitable to use in hydrograph modeling. It is important to note that this method assumes that the storm duration should be the time of concentration.

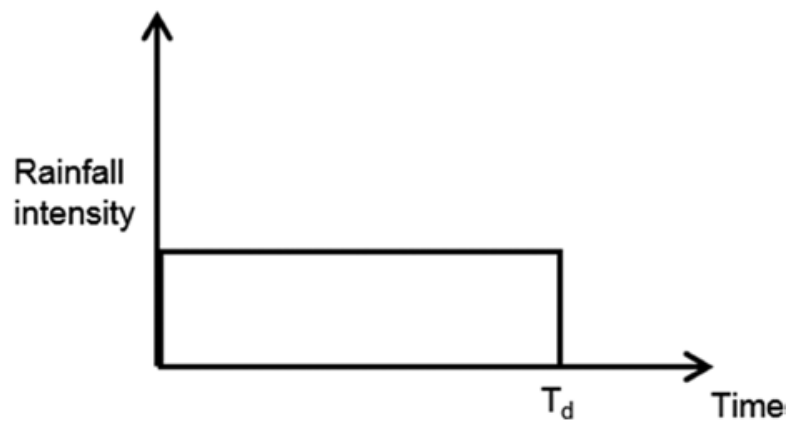

Figure 2.3 Uniform distribution.

\subsubsection{Alternating block method}

The Alternating block method (Figure 2.4) is a simple method to develop a design of storm from Intensity-Duration-Frequency (IDF) curves. In particular, the precipitation depth occurring in $n$ successive time includes intervals of duration $\Delta t$ over a total duration $T_{d}$. The intensity equation is derived from:

$$
i=\frac{c}{\left(T_{d}\right)^{e}+f}
$$

$i=$ rainfall intensity, $\mathrm{mm} / \mathrm{h}$, for all given storm durations of an IDF curve

$T_{d}=$ total duration of rainfall, $\mathrm{h}$

$c, e, f=$ coefficient

The method is proposed for use in most of the cases where storm duration time is less than 24 hours. However, naturally 
occurring storms do not occur in this manner, and computed results have relatively high peak discharges (Wilson, 1992).

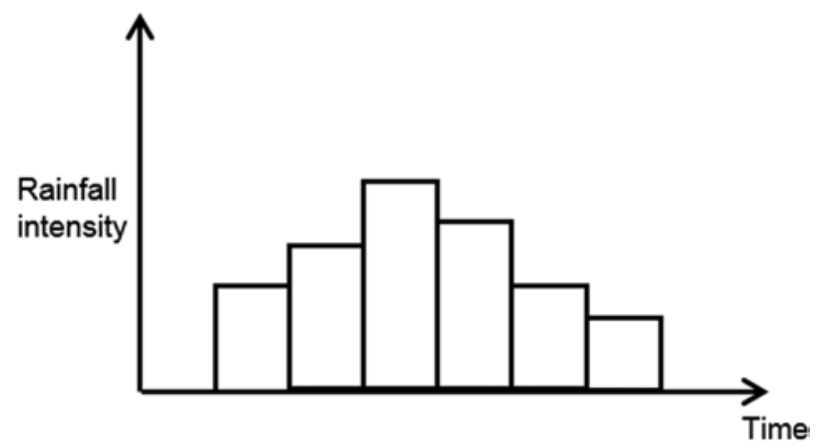

Figure 2.4 Alternating block method.

\subsubsection{Chicago method}

Kiefer and Chu (1957) suggested a procedure which is generally known as the Chicago method (Figure 2.5). The method has been extensively applied in the hydrology literature. However, this method is only investigated with storm durations of up to 3 hours. The method provides equations for calculating peak intensity, and then redistributes the rainfall before and after the peak with appropriate equations. It presupposes an IDF relation of the form:

$$
i=\frac{a}{\left(T_{d}^{b}+c\right)}
$$

$i=$ rainfall intensity, $\mathrm{mm} / \mathrm{h}$, for all given storm durations of an IDF curve

$T_{d}=$ total duration of rainfall, $\mathrm{h}$

$a, b, c=$ shape and location parameters, dimensionless obtained by fitting an IDF curve for a given frequency 
22 Hydrological Design of Multipurpose Micro-catchment RWM

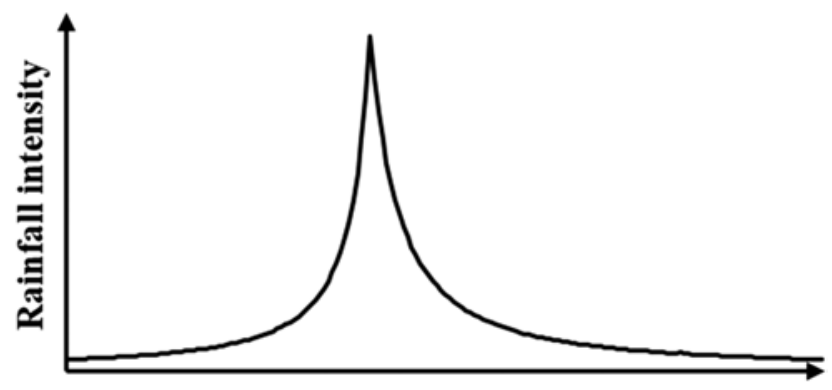

Time

Figure 2.5 Chicago method.

\subsubsection{Yen and Chow method}

The method initiated by Yen and Chow (1980) was originally developed for use with the design of small drainage structures. Due to its simplicity, the method has been utilized in other applications as well. Statistical analysis is carried out based on the method of moments, resulting in a triangular hyetograph. Figure 2.6 shows a sample hyetograph that illustrates this method. The basic parameters needed are:

$i_{p}=\frac{2 P}{T_{d}}$

$i_{p}=$ peak intensity, $\mathrm{mm} / \mathrm{h}$

$P=$ total depth of rainfall, $\mathrm{mm}$

$T_{d}=$ total duration of rainfall, $\mathrm{h}$

It is important to note that there is no restriction on the storm duration. However, the method was only investigated with storm durations of up to 6 hours.

\subsubsection{Huff method}

The Huff method (1967) was developed with a consideration of heavy storms with durations ranging from 3 to 48 hours. The derived 
distributions are grouped based on the quartiles in which the rainfall is considered the heaviest. The quartiles describe when the time of peak intensity occurs during a given storm (i.e., in the first, second, third or fourth quartile). Furthermore, the Huff method focuses on showing the time distribution with probability terms from $10 \%$ to $90 \%$ based on the great variability of the distribution's characteristics from different rainfall events. Figure 2.7 shows an example of Huff distribution curves.

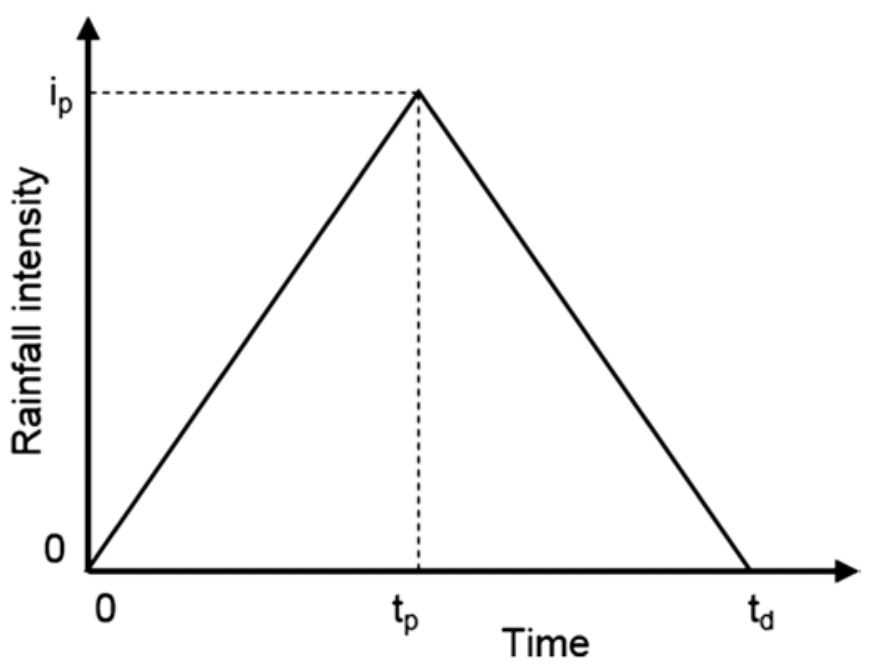

Figure 2.6 Yen and Chow rainfall hyetograph.

The Huff method is becoming more and more popular in field works since it is informative and sensitive to the duration time. It is especially recommended for runoff computations related to the design and operation of runoff control structures. Bonta and Rao (1988) concluded that Huff curves exhibited a high degree of flexibility, and that their temporal distributions were developed according to objective criteria. Also, they better approximated 
24 Hydrological Design of Multipurpose Micro-catchment RWM naturally occurring temporal variability of storm rainfall due to their multiple-peaked nature.

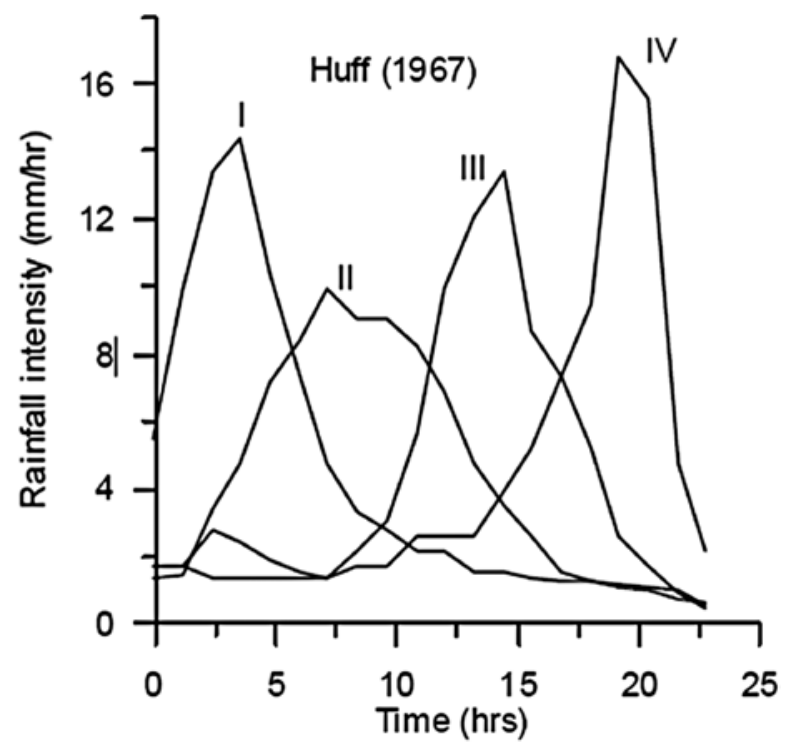

Figure 2.7 Huff distribution method.

\subsubsection{Runoff modeling (Q)}

The next step after the rainfall $(i)$ modeling is to estimate the runoff $(Q)$ modeling in the design of hydraulic structures. The runoff with time $\left(Q_{t}\right)$ or peak runoff $\left(Q_{p}\right)$ should be predicted based on the characteristics of catchment, which include the area, shape and surface condition. The final discharge flow rate becomes the inflow rate for hydrological structures.

After a French engineer named Mulvaney proposed that the volume of runoff could be calculated by the product of the intensity $\times$ runoff area (Huggins \& Burney, 1982), various runoff analyses and models were developed over the last century based 
on their specific conditions with different assumptions. Some of the most commonly used methods are briefly reviewed in this section. For more details, hydrology textbooks should be referred to including Dingman (2015).

\subsubsection{Rational method}

The most popular theory is the Rational method, which was developed by introducing a runoff coefficient (Lloyd et al. 1906). The concept is attractive and easy to understand. If rainfall occurs over a basin at a constant intensity for a period of time which is sufficient to produce steady runoff at the outlet or designed point, then the peak outflow rate will be proportional to the product of rainfall intensity and basin area (Eq. 2.4):

$$
Q=C i A
$$

$Q=$ peak flow, $\mathrm{m}^{3} / \mathrm{h}$

$C=$ runoff coefficient used to adjust for abstractions from rainfall

$i=$ rainfall intensity for a duration that equals time of concentration of the basin, $\mathrm{mm} / \mathrm{h}$

$A=$ basin area, $\mathrm{m}^{2}$

In practice, the Rational method is mostly used in small urban areas to design storm sewer system. Linsley et al. (1982) and Ponce (1989) have reviewed and recommended the reliable area for the application of the Rational method as 40-500 ha while noting that there are still a number of practical limitations of this approach.

\subsubsection{Unit hydrograph method}

For areas where rainfall and runoff data are not available, the Unit hydrograph can be developed based on physical basin 
26 Hydrological Design of Multipurpose Micro-catchment RWM

characteristics. The Unit hydrograph introduced by Sherman (1932) is defined as the discharge produced by a unit volume of effective rainfall of a given duration.

Clark (1945) and Snyder (1983) have recommended a reliable large scale of areas ranging 400-500,000 ha to apply the Unit hydrograph. The basic hypothesis of this approach is that the basin responds linearly to effective rainfall. Linearity implies that if

$$
i=a i_{1}+b i_{2}
$$

then

$$
Q=a Q_{1}+b Q_{2}
$$

where $i_{i}$ and $Q_{i}$ are corresponding inputs and outputs.

It is recommended that a flood hydrograph can be calculated with the help of even a very short record of data, and that the unit hydrograph procedure can be computerized easily to facilitate calculations.

\subsubsection{Time-area method}

Time-area methods are developed to address non-uniform rainfall in larger areas. One of the most common time-area techniques was introduced by Clark (1945). The method is based on the concept that the translation of flow through the watershed can be described by runoff isochrones; and that the corresponding histogram of contributing area is a function of travel time. Isochrones are lines of equal travel time; they describe the fraction of watershed area contributing runoff to the watershed outlet as a function of travel time (Figure 2.8). In the other words, a larger area is divided into smaller areas whose durations of rainfall concentration are similar. 

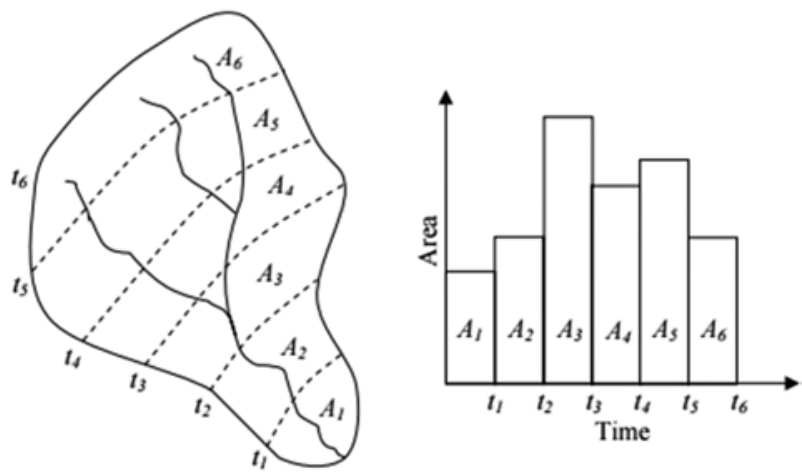

Figure 2.8 Time-area isochrones and histogram for Clark's method.

\subsubsection{Comparing applicable area range of runoff models}

Figure 2.9 compares the applicable area range of runoff models in a logarithmic scale. While all of the existing models are developed to predict the peak flow (for flood routing for a relatively large area), there is currently no model designed to predict multipurpose behaviors (flooding mitigation and water resource management) for a very small catchment area, such as a building rooftop of less than $2000 \mathrm{~m}^{2}$.

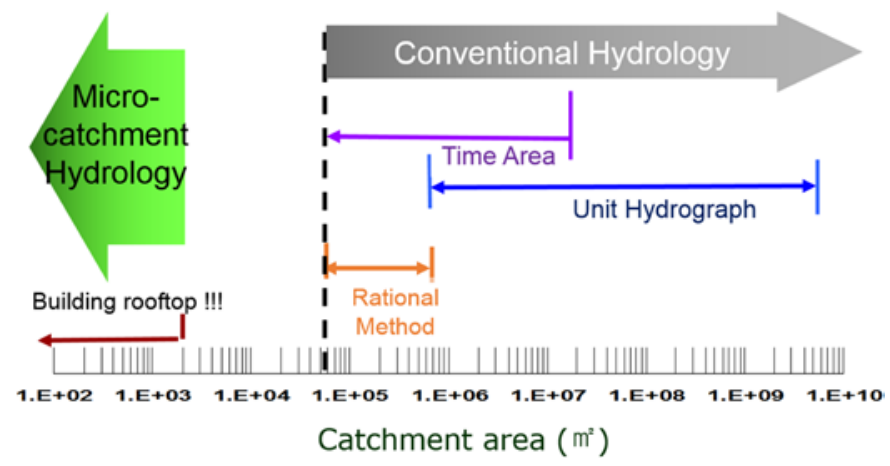

Figure 2.9 Applicable area range of runoff models. 
28 Hydrological Design of Multipurpose Micro-catchment RWM

\subsubsection{Discharge modeling $(D)$}

In most cases of conventional hydrology calculation, there is no difference between the amount of runoff and discharge. When designing a hydraulic structure, we assume that flow rate $(Q)$ predicted from the runoff model will be the inflow to the structure and the same flow rate will be discharged $(D)$, that is, something that comes in will go out without changing the flow rate $(D=Q)$. Due to the large volume during a short time, controlling the runoff flow may not be easy, except when it is specifically designed to be controlled. However, the control of runoff flow in a microcatchment RWMS can be easily achieved by using storage, utilization, pump to discharge and infiltration, so that the discharge will be less than the runoff flow from the roof $(D<Q)$.

\subsubsection{Verification from field data}

In fact, the verification of the prediction model to actual field measurement is not always easy due to the large volume of water and short time, and many unknown factors involved in the actual hydraulic behavior. Therefore, the models inherently tend to produce large errors. There are many uncertainties inherent in the prediction of conventional hydrology modeling due to several reasons. First, the rainfall model is too simplified to accurately consider the spatial and temporal distribution, especially in a large area with limited rainfall data. Second, the runoff model is not able to include heterogeneity in soil hydraulic properties, landscape structural properties (e.g., hydrogeological layering, compaction of soil horizons and soil organic content, roots, and pores), soil moisture profile, surface-subsurface interaction, interception by plants, and storm properties. Vegetation growth may also influence the surface characteristic and, as a result, affect runoff due to climate, infiltration, soil water and even evapotranspiration. Third, because the main purpose of conventional hydrology modeling is to find the maximum flow 
rate, it is not easy to verify the modeling result, as the volume is too large to measure during that time. So far, no model has been reported to have succeeded in generally verifying the field measurement and modeling prediction.

\subsection{CONSIDERATIONS FOR MICRO-CATCHMENT HYDROLOGY MODELING}

\subsubsection{Rainfall modeling (i)}

In order to predict the runoff from a very small area such as a rooftop of less than $2000 \mathrm{~m}^{2}$, a proper rainfall modeling method should be used. A uniform rainfall model which assumes that the duration of rainfall is equal to the concentration time is not suitable to apply for a micro-catchment whose time of concentration is near to zero. Also, the alternating block method is not good to use because naturally occurring storms result in relatively high peak discharges. The Chicago method and Yen and Chow method can be used to investigate cases with 3-6 hour durations. The application of the most conventional method of duration determination requires that the duration of the design rainfall event be equal to the time of concentration in the basin (30 min to a few hours). In a micro-catchment, the time of concentration is inconsiderable. Therefore, all types of rainfall events with the 24-hour system operation time should be taken into account.

Huff distribution is suitable to apply for a micro-catchment RWMS modeling because it uses all range duration times during 24 hours. The Huff method is becoming more popular in field works and is recommended as a reasonable method for designed rainfall analysis of South Korean metrological conditions (Ministry of Construction and Transportation [MOCT], 2000). Since the rainfall characteristic is site specific, rainfall data should be used differently for each specific area. In this section, the discussion is limited to the designed rainfall analysis following 
the Huff method for the case of Seoul, South Korea, and uses the data of the Korean Meteorological Administration (KMA).

Table 2.2 shows the procedure for the design of rainfall hyetograph construction following the Huff method. The first and second steps are concerned with the engineering strategies and the structural characteristics of the flood-control infrastructure. The rainwater harvesting system is a type of retention tank which can hold inflow water from the runoff until it reaches the maximum capacity and overflows as shown in Figure 2.10. Therefore, the tank must be able to hold a full cumulative quantity of inflow as well as to control the peak flow. That is, a reasonable tank retention volume which is safe enough for the peak runoff needs to be determined by using a designed hyetograph with the heaviest cumulative water quantity at the time of the peak flow. Therefore, when designing the rainfall distribution for micro-catchment RWMSs, it is recommended to select the curve of the heaviest cumulative percentage for the time increment just before the peak rainfall among different curves with probability of dominant types.

Table 2.2 Procedure for the design rainfall hyetograph following Huff method.

\begin{tabular}{lll}
\hline $\begin{array}{l}\text { Step } \\
\text { No. }\end{array}$ & $\begin{array}{l}\text { Parameter to be } \\
\text { Determined }\end{array}$ & Notes \\
\hline 1 & $\begin{array}{l}\text { Find dominant rainfall type from } \\
\text { the Huff method in the region of } \\
\text { interest }\end{array}$ & $\begin{array}{l}50 \% \text { in second quartile } \\
\text { is recommended for } \\
\text { conventional hydrology }\end{array}$ \\
2 & $\begin{array}{l}\text { Select a time distribution curve } \\
\text { as the frequency in duration time } \\
\text { Total rainfall depth }\end{array}$ & $\begin{array}{l}\text { From Intensity-Duration- } \\
\text { Frequency (IDF) curves for } \\
\text { the construction region } \\
\text { By using the dimensionless } \\
\text { hyetograph and the total } \\
\text { rainfall depth }\end{array}$ \\
\hline 4 & $\begin{array}{l}\text { Construction of design rainfall } \\
\text { hyetographs }\end{array}$ & \\
\hline
\end{tabular}




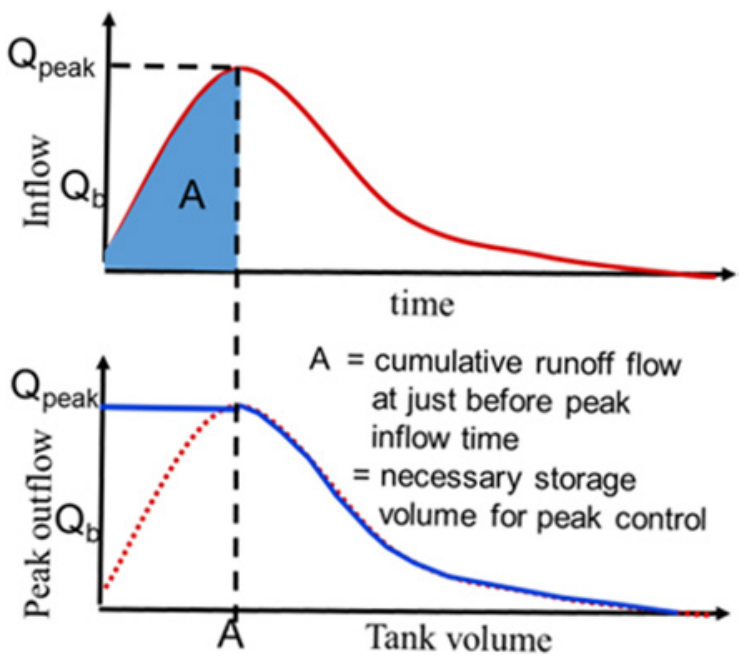

Figure 2.10 Design inflow and rainwater storage tank.

The third step of the process depends on site-specific conditions. The fourth step is simply related to the calculation following the general guideline.

\subsubsection{Runoff modeling (Q)}

The estimation of runoff for micro-catchment RWMS should consider the characteristics and shape of building rooftops. Figure 2.11 shows the relevant factors for rooftop runoff modeling. Most general urban building rooftops have a reinforced concrete structure and are designed to drain storm water rapidly and completely. The effects of infiltration can be omitted since most of the roofs have an impermeable coating or concrete roof. The loss of precipitated water for evaporation and transpiration is inconsiderable for heavy rainfall during individual storm events (Akan et al. 2003; Haestad et al. 2003). Here, it is assumed that there is no loss of rainwater and no delay 
32 Hydrological Design of Multipurpose Micro-catchment RWM

time of concentration from the building rooftop to the rainwater tank system. These are the same conditions as those for an ideal runoff surface in Mulvaney's equation. In short, the runoff flow $\left(Q_{t}\right)$ follows the rainfall intensity pattern with time $\left(i_{t}\right)$ (Huggins $\&$ Burney, 1982). The runoff curves have the same shape as the original rainfall event. A simple conceptual equation for constructing flow rate in micro-catchment RWMS is proposed in Eq. (2.7)

$$
Q_{t}=C \times i_{t} \times A \times 0.001
$$

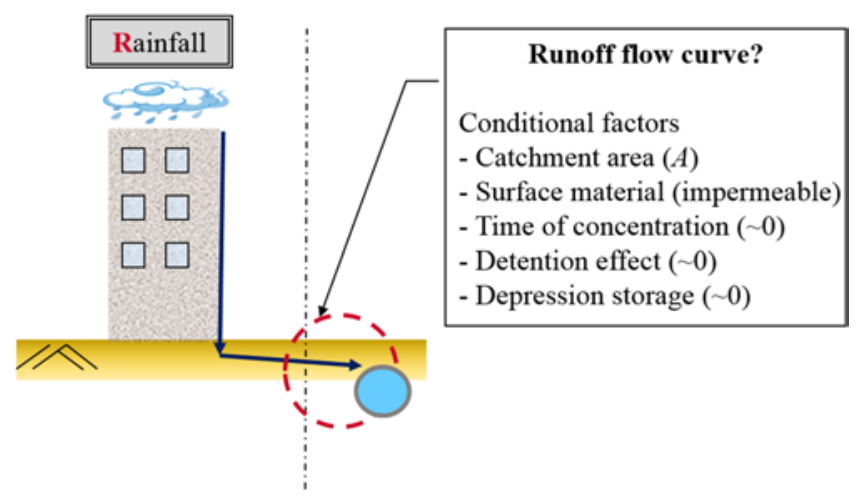

Figure 2.11 Schematic diagram of runoff conditions for rooftops.

$Q_{t}$ is the runoff from catchment area $\left(\mathrm{m}^{3} / \mathrm{h}\right)$ at time $t . A$ is the catchment area $\left(\mathrm{m}^{2}\right) . C$ is the runoff coefficient (cumulative flow volume/cumulative rainfall volume). $i_{t}$ is the rainfall intensity $(\mathrm{mm} / \mathrm{h})$ at time $t$ in design rainfall hyetograph. $t$ is elapsed time after start of rainfall.

The proposed equation is similar to the Rational formula except some differences. The Rational method is designed to estimate peak runoff for the inlet of a storm drainage hydrologic structure. Meanwhile, the proposed equation is designed to 
construct design inflow hydro curves, not peak runoff from design rainfall hyetograph and roof catchment areas for microcatchment RWMS. The Rational formula is expressed using $C$, the runoff coefficient, representing the ratio of peak runoff to rainfall, which usually does not produce accurate hydrologic estimates such as runoff hydro curves. Meanwhile, in the proposed equation, the runoff coefficient $(C)$ represents the ratio of the cumulative flow volume and the cumulative rainfall volume. In addition, the application of the Rational method requires that the duration of the design rainfall event be equal to the time of concentration in the basin. The concentration time for micro-catchment RWHS is inconsiderable.

\subsubsection{Discharge modeling (D)}

Although conventional hydrology that involves a large catchment area and large amount of flow rate is unable to verify experimentally, it is possible for micro-catchment hydrology to verify. Only a handful of studies focus on the estimation of discharge after a rainwater storage system is designed for flood mitigation.

Hermann and Schmida (2000) simulated the case of microcatchment with real rainfall conditions from 1981 to 1990 in Germany. As the tank volume and rainwater consumption increased, the number of overflow events and the overflow volume reduced. As a result, a $20 \mathrm{~m}^{3}$ tank of $100 \mathrm{~m}^{2}$ catchment area to supply rainwater of $240 \mathrm{~L} / \mathrm{day}$, was able to control rainfall from the year 1981 to 1990 in Germany, which led to zero discharge from the building.

Vaes and Berlamont (2001) reported a study on rainfall-runoff reduction response based on triangular distribution rainfall intensity. They showed that rainwater tank retention and the usage of facilities upstream can significantly reduce the peak flow in the sewer system especially if installed on a sufficiently large 
34 Hydrological Design of Multipurpose Micro-catchment RWM

scale. Figure 2.12 is an example for a design rainfall of 5-year return period. Here, the peak of the composite storm for 5 years is reduced to the value of the composite storm for 1 year.

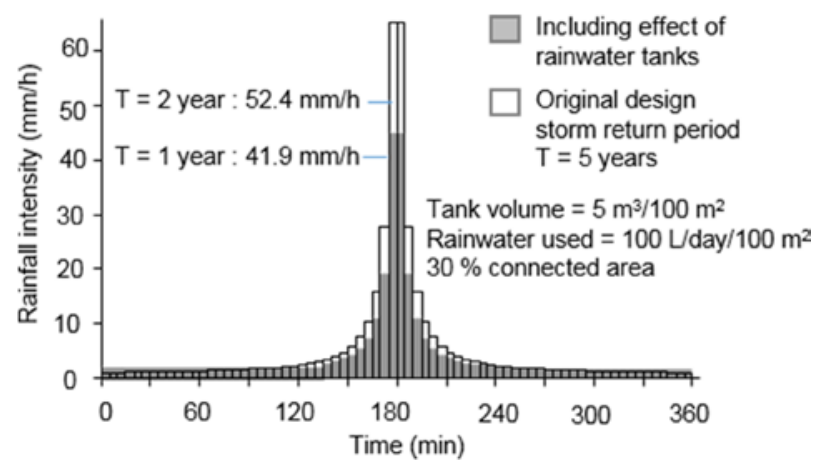

Figure 2.12 The effect of rainwater tank on the design storm of 5 years (Vaes \& Berlamont, 2001).

The above studies show that urban storm runoff can be controlled by rainwater tanks, but they fail in providing a reasonable design rainfall analysis to control the runoff for a micro-catchment RWMSs.

Mun et al. (2005) used a Storm Water Management Model (SWMM) modeling analysis to show that relatively small and decentralized rainwater tanks could be more effective in flood control than one large tank of same total volume.

Environmental Protection Agency (EPA) SWMM (Metcalf \& Eddy, 1971) was developed by the US EPA to analyze the storm water quantity problems associated with runoff from urban areas. The model provides many options such as bottom orifice outlet, constant rate pump and a spillway as demonstrated in Figure 2.13. However, the model is complicated and imposes many requirements on the user. In addition, it is difficult to identify when the model should be applied, or to determine what requirements of detention should be needed for a single site. 


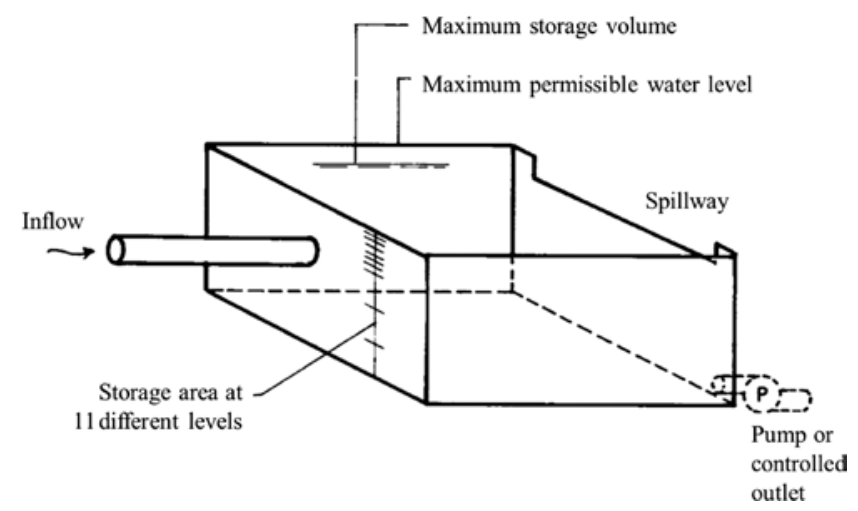

Figure 2.13 Detention facility as defined in EPA SWMM.

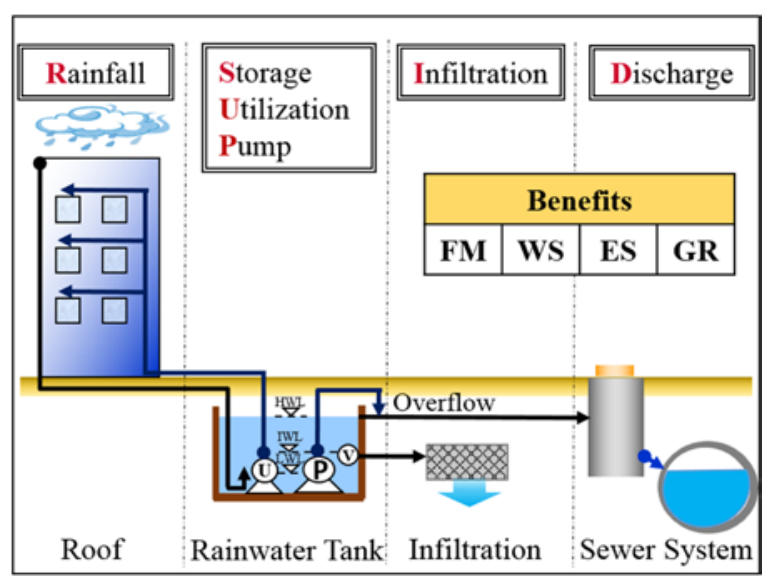

Figure 2.14 Controllable R-S-U-P-I-D (Rainfall-Storage-UtilizationPump-Infiltration-Discharge) system.

In practice, micro-catchment RWMS may require specific design that has controlled hydraulic measures (i.e., storage, utilization, pump to discharge, and infiltration) as shown in Figure 2.14. Moreover, the multipurpose benefits such as flood 
36 Hydrological Design of Multipurpose Micro-catchment RWM mitigation, water saving, emergency storage and groundwater recharge can be also quantified. The design and prediction of the cases where a combination of controlled measures are installed will be described in detail in Chapter 3.

\subsection{CASE STUDY OF MICRO-CATCHMENT HYDROLOGY MODELING}

Following the procedures shown in the flow chart for microcatchment hydrology (Figure 2.2), a detailed method to design a rainwater management system in Seoul, South Korea is presented as a case study.

First, the design rainfall hyetograph $(i)$ is calculated using the Huff method, which is one of the existing theories based on conventional hydrology. The design rainfall hyetograph for a certain duration of a certain year of return period can be calculated. This can make it compatible with the design of other hydraulic structures based on conventional hydrology.

Second, the runoff flow rate $(Q)$ can be estimated by using the Rational formula. In this section, the modeling result is compared with field measurements of runoff flow rate, which was measured prior to its entrance to the rainwater system.

Third, the discharge $(D)$ can be predicted as an outflow from a particular rainwater management measure such as storage, utilization, pump to discharge, and infiltration. All of these measures are explained in detail throughout Chapter 3.

\subsubsection{Design rainfall hyetograph for micro-catchment RWMS}

The design rainfall hyetograph is calculated following the Huff method using the step by step procedure in Table 2.2. The detailed methods are available in any hydrology textbooks, including American Society of Civil Engineers (1993). 


\section{Step 1: Find dominant rainfall type}

In order to decide the dominant type for a hydrologic structure, the design rainfall duration time must be determined. A 24-hour rainfall duration is recommended as the operation time. The most frequently occurring quartile type for the design duration under consideration should be used. Table 2.3 shows the rainfall frequency distribution based on the rainfall Huff types in Seoul. From the table, the fourth quartile type of rainfall has low frequency for all duration times except for the 7-12 hour range. For example, if the time of concentration of the system is 19-25 hours, then the fourth quartile should not be used.

Table 2.3 Frequency distribution of Huff types of Seoul.

\begin{tabular}{lllll}
\hline & 1st Quartile & 2nd Quartile & 3rd Quartile & 4th Quartile \\
\hline$<6$ & 35.8 & 23.1 & 23.7 & 17.4 \\
$7-12$ & 33.9 & 25.3 & 18.5 & 22.3 \\
$13-18$ & 24.9 & 28.3 & 32.2 & 14.6 \\
$19-24$ & 21.6 & 26.8 & 35.1 & 16.5 \\
$>25$ & 25.7 & 31.7 & 24.6 & 18.0 \\
\hline
\end{tabular}

Source: MOCT (2000).

\section{Step 2: Select heaviest cumulative rainfall percent curve}

In order to find the most useful curve, it is necessary to calculate the cumulative rainfall depth percentage at the time of peak rainfall intensity for each probability among the dominant quartile types of rainfall. The probability curve with the deepest cumulative depth at the time of peak rainfall should be taken into account for safety design of a retention system. Figure 2.15 shows the time variation of probabilities for rainfall from the first, the second and the third quartiles. Based on these time variation of probabilities, the cumulative rainfall percentage at the time of peak rainfall intensity for storm probabilities from the first, the 
38 Hydrological Design of Multipurpose Micro-catchment RWM
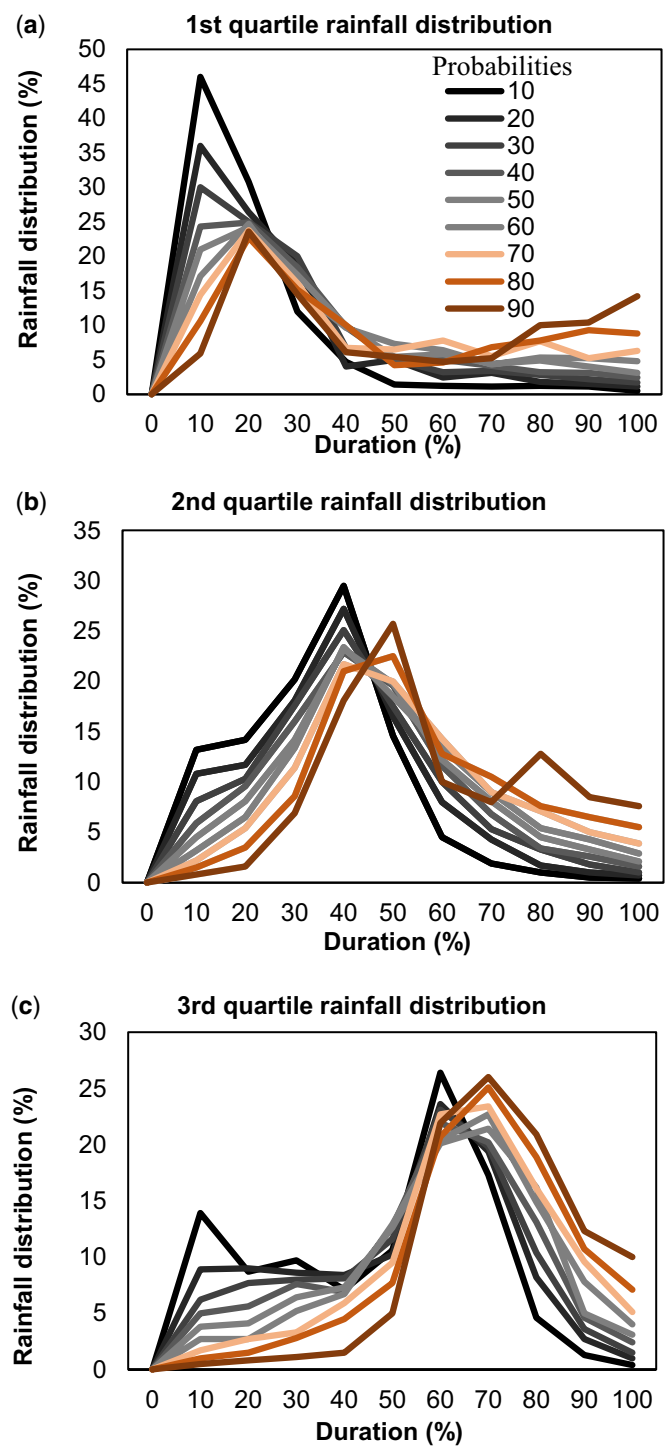

Figure 2.15 Time variation of probabilities for (a) the first, (b) the second, and (c) the third quartile type of rainfall in Seoul. 
second and the third quartiles in Seoul are calculated and shown in Table 2.4.

As shown in Table 2.4, cumulative rainfall of $10 \%$ in the second quartile in Seoul has the heaviest cumulative rainfall depth at the time of peak rainfall intensity. This time distribution will be selected for the determination of runoff flow for a retention basin. Figure 2.16 illustrates the cumulative rainfall of $10 \%$ in the second quartile in Seoul.

Table 2.4 Cumulative rainfall percentage depth at the peak intensity time for different quartile Huff types in Seoul.

\begin{tabular}{llllllllll}
\hline \multicolumn{10}{c}{ 1st Quartile } \\
\hline Probability (\%) & 10 & 20 & 30 & 40 & 50 & 60 & 70 & 80 & 90 \\
Depth (\%) & 46 & 36 & 30 & 49.2 & 45.2 & 41.8 & 38.2 & 33.3 & 29.5 \\
\hline \multicolumn{10}{c}{ 2nd Quartile } \\
\hline Probability (\%) & 10 & 20 & 30 & 40 & 50 & 60 & 70 & 80 & 90 \\
Depth (\%) & 77.1 & 68.7 & 61.1 & 54.4 & 50 & 45.5 & 40.7 & 57.1 & 53.1 \\
\hline \multicolumn{8}{c}{ 3rd Quartile } \\
\hline Probability (\%) & 10 & 20 & 30 & 40 & 50 & 60 & 70 & 80 & 90 \\
Depth (\%) & 76.4 & 68.7 & 64.7 & 59.7 & 75.7 & 77.3 & 69.2 & 63.3 & 56.8 \\
\hline
\end{tabular}

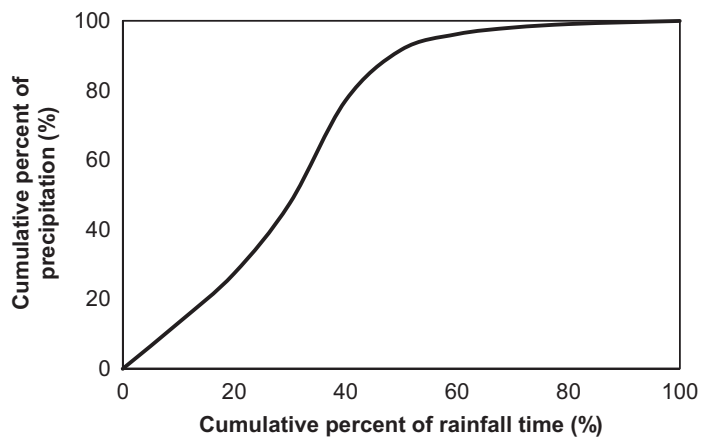

Figure 2.16 Cumulative rainfall of $10 \%$ in second quartile in Seoul. 
40 Hydrological Design of Multipurpose Micro-catchment RWM

\section{Step 3: Total rainfall depth}

The third step of the process depends on site-specific conditions, for a specific region of the design conditions. Figure 2.17 shows the IDF curve for Seoul area. The selection of the total rainfall depth from IDF curves is based on the duration time of rainfall. For conventional hydrology, the duration time of rainfall is determined as the time of concentration. For example, from the IDF curves for Seoul area as shown in Figure 2.17, the rainfall intensity for a return period of 100 years were found to be $110.023 \mathrm{~mm} / \mathrm{h}$ and $81.5 \mathrm{~mm} / \mathrm{h}$ for 1 and $2 \mathrm{~h}$ rainfall duration time, respectively.

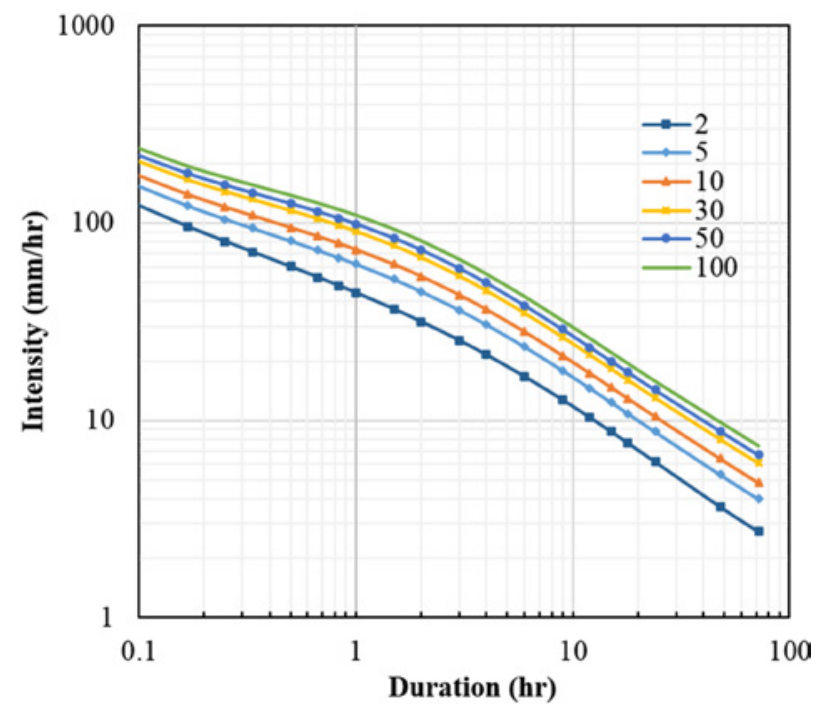

Figure 2.17 IDF curves for Seoul, Korea.

Step 4: Construction of design rainfall hyetograph

Finally, to find the cumulative percentage of rainfall depth for the rainfall time of a time increment below $10 \%$, Weibull's sixth order 
polynomial regression formula (Eq. 2.8) with a time increment of $10 \%$ is used:

$$
Y=\mathrm{a}+\mathrm{b} x+\mathrm{c} x^{2}+\mathrm{d} x^{3}+\mathrm{e} x^{4}+\mathrm{f} x^{5}+\mathrm{g}^{6}
$$

$Y=$ cumulative percent of rainfall depth (\%)

$x=$ cumulative percent of rainfall time $(\%)$

$\mathrm{a}, \mathrm{b}, \mathrm{c}, \ldots \mathrm{g}=\mathrm{constants}$

The constants are calculated by regression using a spreadsheet program as shown in Table 2.5.

Table 2.5 Constants from the regression for cumulative distribution curves.

\begin{tabular}{cccccccc}
\hline $\mathbf{a}$ & $\mathbf{b}$ & $\mathbf{c}$ & $\mathbf{d}$ & $\mathbf{e}$ & $\mathbf{f}$ & $\mathbf{g}$ & $\mathbf{R}^{2}$ \\
\hline$-6.113 e-09$ & $1.815 e-06$ & $-1.939 e-4$ & $8.6334 \mathrm{e}-3$ & -0.13804 & 1.9446 & 0.15956 & 0.99 \\
\hline
\end{tabular}

By using this dimensionless equation and the total rainfall depth in Step 3, a design rainfall hyetograph can be constructed for any duration time and return period. Figure 2.18 is the hyetograph for a duration time of $90 \mathrm{~min}$ and a 100-year return period for Seoul, as an example.

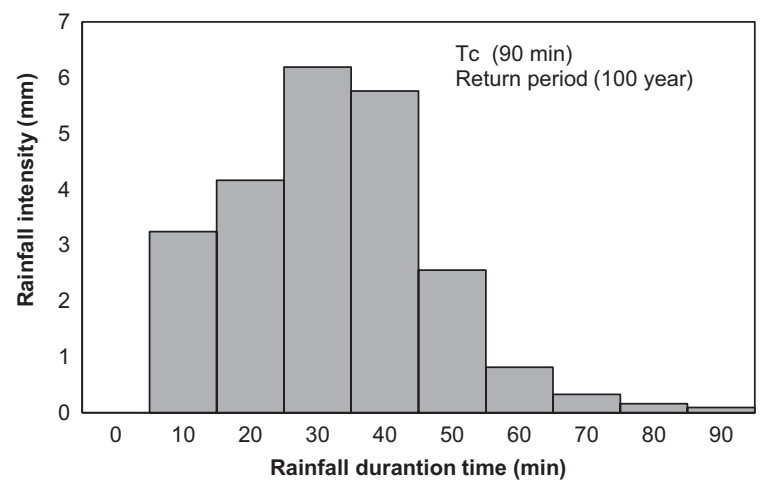

Figure 2.18 A design rainfall hyetograph for 90 min duration time and a 100-year return period for Seoul (using Seoul rainfall data and Huff method). 
42 Hydrological Design of Multipurpose Micro-catchment RWM

\subsubsection{Verification of the runoff equation}

The runoff from a rooftop $(Q)$ can be calculated from a simple rational equation using the runoff coefficient $C$. Kim et al. (2009) examined the applicability of the runoff equation by field measurement at two building rooftops in Seoul National University (SNU), South Korea. The runoff coefficient is calculated by comparing the predicted and measured cumulative rainfall volume (Figure 2.19).

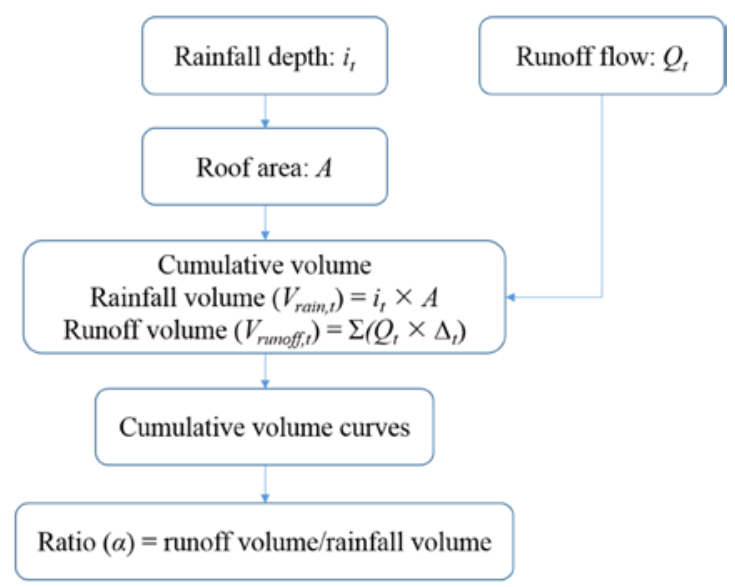

Figure 2.19 Field monitoring and calibration of runoff coefficient.

The rainfall data is used from Automatic Weathering Station (AWS) (KMA, 2004) located at SNU. This station continuously measures the depth of daily rainfall. Runoff flows are monitored from rooftops of two buildings in SNU, namely dormitory building and buildin \#39, as shown in Figure 2.20. The total roof area from the three blocks making up the SNU dormitory is $2098 \mathrm{~m}^{2}$ and the rainwater storage tank volume is $200 \mathrm{~m}^{3}$. Only a part $\left(960 \mathrm{~m}^{2}\right)$ of building \#39 was used during field measurement and the volume of the storage tank is $250 \mathrm{~m}^{3}$. 

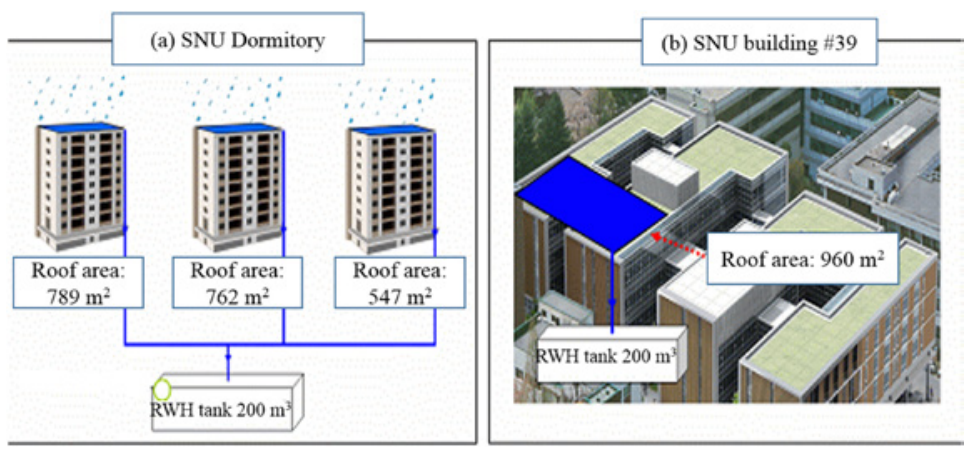

Figure 2.20 Rainwater harvesting (RWH) system in Seoul National University. a) Dormitory, b) Building \# 39.

A total of six rainfall events were recorded (from E1 to E6) for two years from April 2005 to April 2007 as shown in Table 2.6.

Table 2.6 Monitored rainfall events.

\begin{tabular}{lllrrr}
\hline Event & Date & Position & $\begin{array}{l}\text { Rainfall } \\
\text { Depth } \\
\text { (mm) }\end{array}$ & $\begin{array}{l}\text { Duration } \\
\text { Time } \\
\text { (min) }\end{array}$ & $\begin{array}{l}\text { Peak Intensity } \\
\text { (mm/10 min) }\end{array}$ \\
\hline E1 & 2005.4 .9 & Dormitory & 45.97 & 400 & 2.03 \\
E2 & 2005.4 .19 & Dormitory & 16.51 & 380 & 1.78 \\
E3 & 2005.5 .5 & Dormitory & 29.21 & 1440 & 1.02 \\
E4 & 2006.6 .29 & Building \#39 & 8.89 & 280 & 3.56 \\
E5 & 2006.7 .10 & Building \#39 & 8.13 & 240 & 1.52 \\
E6 & 2007.4 .10 & Building \#39 & 2.03 & 80 & 2.03 \\
\hline
\end{tabular}

\subsubsection{Results and discussion}

Figure 2.21 shows the cumulative runoff volume curves of the measured and estimated volumes using Mulvaney's equation. The estimated runoff flow was calculated from the measured rainfall data, which were actual runoff data collected by the rainwater system at the site. Table 2.7 summarizes the results from the data 
44 Hydrological Design of Multipurpose Micro-catchment RWM analysis of the rainfall depth, the cumulative volume at peak time and the total volume.

(a)

E1

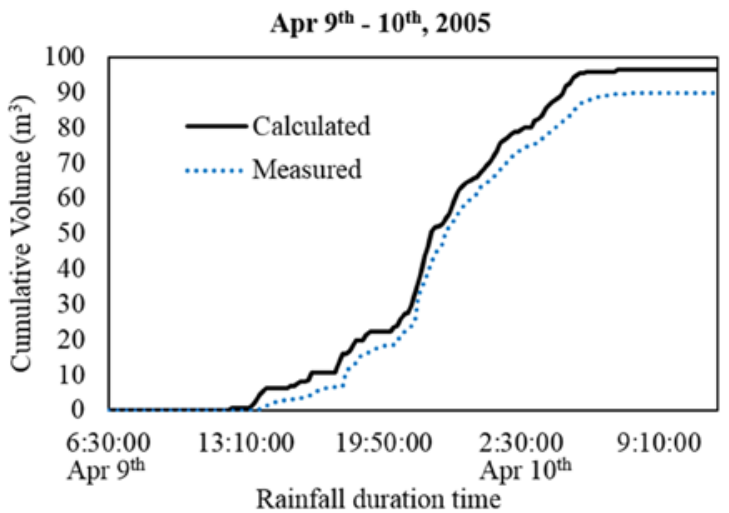

(b)

E3

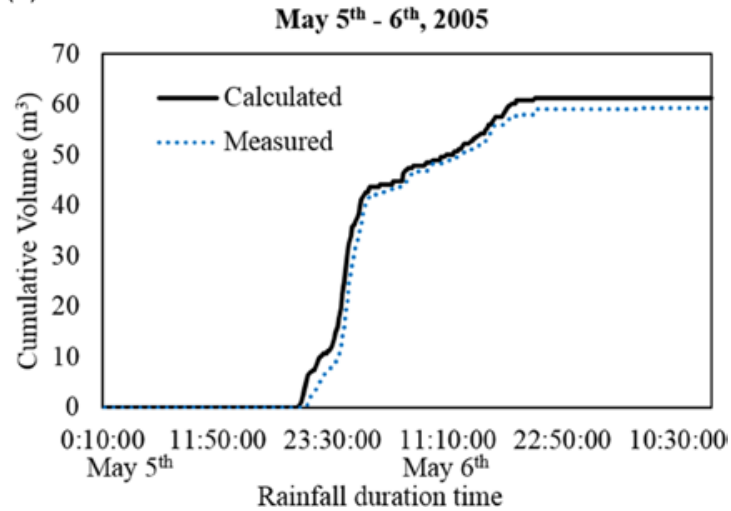

Figure 2.21 Cumulative runoff volume curves for (a) E1 and (b) E3 events.

The runoff coefficient from observation of total volume of rainfall and runoff was stable from 0.92 to 0.97 . This is 
similar to the value of the runoff coefficient for roofs in a residential area, 0.90 to 0.99 proposed by Ragab et al. (2003). The cumulative runoff volume curves of E1 and E3 rainfall events are relatively well correlated for the measured and the estimated cases.

Table 2.7 Analysis of runoff coefficient from field measurement.

\begin{tabular}{|c|c|c|c|c|c|c|c|}
\hline \multirow[t]{2}{*}{ Event } & \multirow[t]{2}{*}{$\begin{array}{l}\text { Depth } \\
(\mathrm{mm})\end{array}$} & \multicolumn{3}{|c|}{$\begin{array}{l}\text { Cumulative volume at } \\
\text { peak time }\left(\mathrm{m}^{3}\right)\end{array}$} & \multicolumn{3}{|c|}{ Total volume $\left(\mathrm{m}^{3}\right)$} \\
\hline & & Rainfall & Runoff & Ratio $(\alpha)$ & Rainfall & Runoff & Ratio $(\alpha)$ \\
\hline $\mathrm{E} 1$ & 45.97 & 4.26 & 3.16 & 0.74 & 96.45 & 89.28 & 0.93 \\
\hline E2 & 16.51 & 2.13 & 2.13 & 1.00 & 34.64 & 32.33 & 0.93 \\
\hline E3 & 29.21 & 3.73 & 3.15 & 0.84 & 61.28 & 59.56 & 0.97 \\
\hline E4 & 8.89 & 3.32 & 2.04 & 0.61 & 8.31 & 8.01 & 0.96 \\
\hline E5 & 8.13 & 1.42 & 1.23 & 0.86 & 7.60 & 7.16 & 0.94 \\
\hline E6 & 2.03 & 0.48 & 0.89 & 1.87 & 1.90 & 1.75 & 0.92 \\
\hline
\end{tabular}

Based on the above results, Eq. (2.9) is proposed as an experimental formula for cumulative runoff analysis for the building roof in on-site rainwater management. This experimental runoff formula can be the basis of estimating cumulative runoff volume by multiplying roof area $(A)$ and rainfall depth $(i)$. The results can be used as a reasonable inflow condition for the design of a rainwater management system.

$$
Q_{t}=i_{t} \times(0.90 \sim 0.95) \times A \times 0.001
$$

Where, $Q_{t}$ is the runoff from catchment area $\left(\mathrm{m}^{3} / \mathrm{h}\right)$ at time $t$. $A$ is the catchment area $\left(\mathrm{m}^{2}\right) .0 .90-0.95$ is the runoff coefficient. $i_{t}$ is the rainfall intensity $(\mathrm{mm} / \mathrm{h})$ at time $t$. 
46 Hydrological Design of Multipurpose Micro-catchment RWM

\subsection{SUMMARY}

To sum up, for the proper design of a RWMS that has a small area, hydrological analysis is inevitable. Although the established hydrology theories can be applied, some of the basic assumptions and conditions are different when designing RWMSs. The catchment area of a RWMS is usually less than $2000 \mathrm{~m}^{2}$, and the system is made controllable by adding various multi-functional features.

In this chapter, after reviewing existing hydrology theories, a model for micro-catchment hydrology to design RWMS has been proposed: The rainfall $(i)$ is calculated by the Huff method. The runoff $(Q)$ is calculated by the experimental (or Mulvaney's) equation, and verified from field measurement data. The detailed hydrological process for the case of Seoul city has been presented step by step.

The interesting hydrological behavior of RWMSs using different controllable measures will be presented in Chapter 3.

\section{REFERENCES}

Akan A. O. and Houghtalen R. J. (2003). Urban Hydrology, Hydraulics, and Stormwater Quality: Engineering Applications and Computer Modeling. John Wiley \& Sons INC, New York.

American Society of Civil Engineers (1993). Design and Construction of Urban Stormwater Management Systems. ASCE, New York.

Bonta J. V. and Rao A. R. (1988). Comparison of four design-storm hyetographs.

Transactions of the American Society of Agricultural Engineers, 31(1), 102-106.

Clark C. O. (1945). Storage and the unit hydrograph. Transaction of the American Society of Civil Engineers, 110, 1419-1446.

Dingman S. L. (2015). Physical Hydrology (3rd ed.), Waveland Press, Illinois. Haestad M. and Durrans S. R. (2003). Stormwater Conveyance Modeling and Design 1st edition. Haestad Press.

Hermann T. and Schmida U. (2000). Rainwater utilization in Germany: efficiency, dimensioning, hydraulic and environmental aspects. Urban Water, 1(4), 307-316.

Huff F. A. (1967). Time distribution of rainfall in heavy storms. Water Resources Research, 3(44). 
Huggins L. F. and Burney J. R. (1982). Surface runoff, storage and routing. In: Hydrologic Modeling of Small Watersheds, C. T. Haan, H. P. Johnson and D. L. Brakensiek (eds), ASAE, Michigan, USA, pp. 169-225.

Keifer C. J. and Chu H. H. (1957). Synthetic storm pattern for drainage design. Journal of the Hydraulics, 83(HY4), 1-25.

Kim Y. J., Han M. Y., Kim Y. H. and Mun J. S. (2009). An experimental runoff formula in building roof area for on-site rainwater management. Journal of Korea Water Resources Association, 42(2), 171-176.

KMA, Korean Meteorological Administration. web.kma.go.kr.

Linsely R. K., Paulhus J. L. H., Kohler M. A. (1975). Hydrology for engineers: 2nd Edition, McGraw-Hill.

Lloyd-Davies D. E., Jones A. S. and Travis W. O. (1906). The elimination of stormwater from sewerage systems. Institution of Civil Engineering, 164, $41-67$.

Mays L. (2001). Stormwater Collection Systems Design Handbook. Mcgrawhill, New York.

Metcalf and Eddy (1971). Water Resources Engineers. University of Florida.

Ministry of Construction and Transportation (2000). Report of Research and Survey on Water Resources Management and Development Method. Republic of Korea.

Mun J. S., Han M. S., Ki D. W. and Han M. Y. (2005). Design of Rainwater Tank Capacity for preventing sewer pipe Flood, 2005 KSWQ-KSWW Joint Spring Academic Conference proceeding book, Korean Society of Water Quality, Korean Society of Water and Wastewater.

Ponce V. M. (1989). Engineering Hydrology-principles and Practices. PrenticeHall, New Jersey.

Ragab R., Bromley J., Rosier P., Cooper J. D. and Gash J. H. C. (2003). Experimental study of water fluxes in a residential area: 1. Rainfall, roof runoff and evaporation: the effect of slope and aspect. Hydrological Processes, 17(12), 2409-2422.

Sherman L. K. (1932). Stream flow from rainfall by the unit hydrograph method. Engineering News-Record, 108, 501-505.

Snyder F. F. (1938). Synthetic unit graphs. Transactions of the American Geophysics Union, 19(1), 447-454.

Storm Water Management Model, US EPA, Washington, D.C. Vol. I - Final Report, 11024DOC 7/71. Vol. II - Verification and Testing, 11024DOC 8/71. Vol. III - User's Manual, 11024DOC 9/71. Vol. IV - Program Listing, 11024DOC 10/71.

Vaes G. and Berlamont J. (2001). The effect of rainwater storage tanks on design storms. Urban Water, 3(4), 303-307. 


\section{Hydrological Design of Multipurpose Micro-catchment RWM}

Wilson J. P. (1992). Regional Applicability of Synthetic Rainfall Distributions for Hydrologic Modeling. Masters theses, 1096. http://scholarsmine.mst.edu/ masters_theses/1096 (accessed 30 November 2017).

Yen B. C. and Chow V. T. (1980). Design hyetographs for small drainage structures. Journal of the Hydraulics Division, American Society of Civil Engineers, 106(HY6), 1055-1076. 


\section{Chapter 3}

\section{Hydrological design of multipurpose micro-catchment rainwater management}

\subsection{INTRODUCTION}

The existing sewer systems built in most of the cities in the world are designed to drain rainwater as quickly as possible for the single purpose of flood mitigation at the site (Rainfall-Discharge Model). In this system, the sewer capacity is designed to transport the amount of rainwater calculated for a certain design return period, which is determined according to the importance of the area and available budget to construct it.

One of the major urban water problems in the world is urban flooding, which occurs when the discharged rainwater is larger than the flowing capacity of connected sewer. This may occur due to (1) change of surface characteristic that results in an increase of runoff coefficient (an increase of $C$ ); (2) heavier rainfall than the design rainfall due to climate change (an increase of $i$ ); or (3) both. This can be conceptually explained by the traditionally accepted Rational formula $(Q=C i A)$. Expanding sewer capacity in existing congested cities is not easy because it is too expensive

C) IWA Publishing 2018. Hydrological Design of Multipurpose Micro-catchment Rainwater Management

Mooyoung Han, Duc Canh Nguyen

doi: 10.2166/9781780408712_049 
and time consuming. Under the traditional hydrology concept, the control of discharge from the source has rarely been considered or practiced.

Also, our urban water environment is suffering from water shortage, the lack of water supply options during emergencies and groundwater depletion. Understanding that rainwater collected from a roof catchment is clean enough, it can be used for multiple purposes including non-drinking or drinking purposes with minor treatment or no treatment at all. It can also be used to supply water during emergency and to recharge groundwater by rainwater infiltration.

\subsubsection{Development of rainwater management (RWM) models}

By adding controllable measures between the roof and the sewer system, such as storage, utilization pump, discharge pump and infiltration, or a combination of these, the sewer system can be made more efficient and resilient. The progressive development of RWM models is shown schematically in Figure 3.1. The multiple benefits for each model are shown in a diagram for flood mitigation, water saving, emergency storage and groundwater recharge.

$R-D$ (Rainfall-Discharge) Model: This model is exactly the same as the traditional way of discharging rainwater to the sewer. The only purpose is to drain rainwater to the sewer in order to prevent flooding at the site, not necessarily considering the flooding at downstream sewer.

$R-S-D$ (Rainfall-Storage-Discharge) Model: This model includes a rainwater tank at between the roof and sewer system. By providing a rainwater tank, flooding can be mitigated. And some portion of rainwater can be stored depending on the level of drain valve to be used for emergency. 
Hydrological design of multipurpose micro-catchment RWM 51

\section{R-D Model}

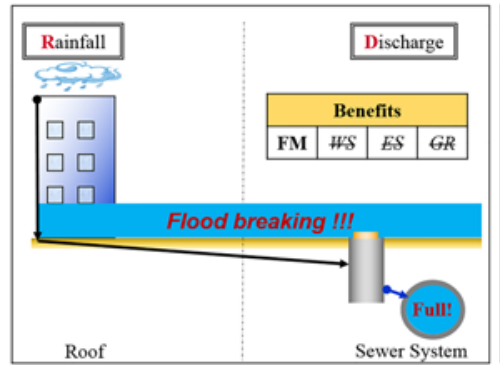

R-S-P-D Model

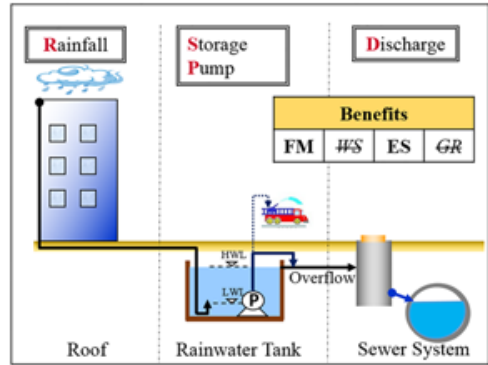

\section{R-S-I-D Model}

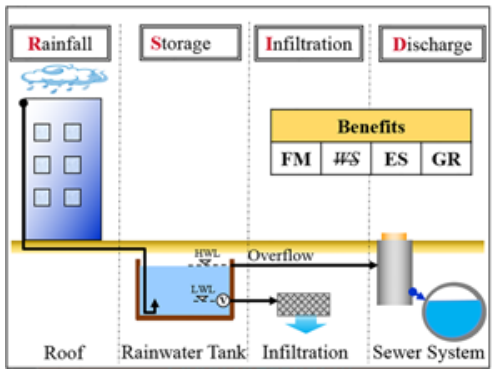

\section{R-S-D Model}

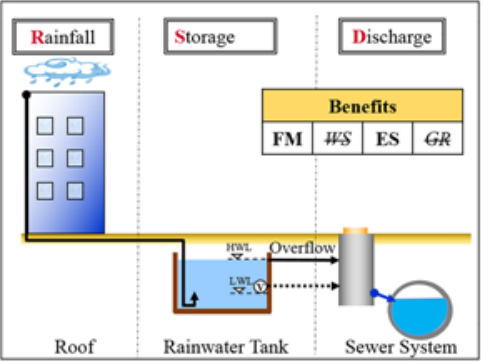

\section{R-S-U-D Model}

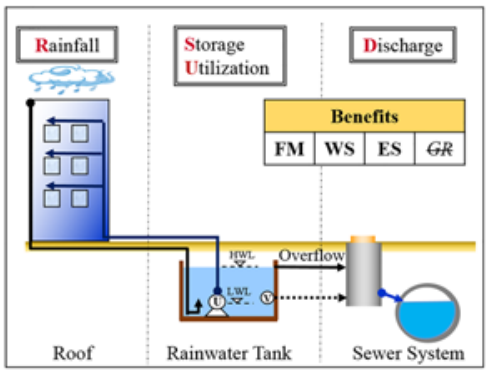

\section{R-S-U-I-D Model}

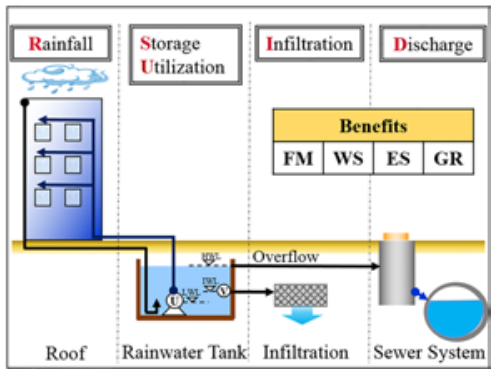

Figure 3.1 Schematic diagram of different rainwater management models. R (Rainfall), D (Discharge), S (Storage), P (Discharge pump), U (Utilization pump), I (Infiltration). FM (Flood mitigation), WS (Water saving), ES (Emergency storage), and GR (Groundwater recharge). v (Valve), H.W.L (High water level), L.W.L (Low water level), and I.W.L (Infiltration water level). 
$R-S-P-D$ (Rainfall-Storage-Pumping-Discharge) Model: This model includes a discharge pump to RSD Model. In case the tank is full with previous rainfalls, and later, when a heavy rainfall is expected, the system can be made more resilient by emptying the tank in advance using a pump large enough to empty the tank in a couple of hours. And also the tank can be emptied to be ready for flood mitigation by supplying water for fire-fighting or road cleaning.

$R-S-U-D$ (Rainfall-Storage-Utilization-Discharge) Model: This model includes a utilization pump to RSD Model. By utilizing the water in the tank for domestic water supply, the tank can be slowly emptied and become ready for flood mitigation. Some portion of rainwater can be stored for emergency by setting the low water level of the pump operation.

$R-S-I-D \quad$ (Rainfall-Storage-Infiltration-Discharge) Model: This model includes an infiltration facility to RSD Model. The upper volume of rainwater tank can be emptied slowly by infiltrating rainwater into nearby ground. It can be used for both flood mitigation and groundwater recharge. The water below the infiltration water level can be used for emergency water.

$R-S-U-I-D$ (Rainfall-Storage-Utilization-Infiltration-Discharge) Model: This model includes both utilization pump and infiltration facility to RSD Model. It can be used for the multipurpose of flood mitigation, water supply, emergency storage and groundwater recharge.

\subsubsection{Procedure of hydrological modeling}

The main goal of hydrological modeling is to design the system and predict the performance of the system in a logical and reasonable way that is acceptable for capable design engineers and practitioners. Table 3.1 summarizes an example of input data, design options and resultant performance for different RWM models. 
Table 3.1 An example of input, design data and results for different rainwater management models.

\begin{tabular}{|c|c|c|c|c|c|c|c|}
\hline & & \multicolumn{6}{|c|}{ Rainwater Management Model } \\
\hline & & RD & RSD & RSPD & RSUD & RSID & RSUID \\
\hline $\begin{array}{l}\text { Input } \\
\text { Data }\end{array}$ & $\begin{array}{l}\text { Design Site } \\
\text { Rainfall } \\
\text { equation }(i) \\
\text { Design method } \\
\text { Design return } \\
\text { period of } \\
\text { connected sewer }\end{array}$ & & & & Same & & \\
\hline \multirow{3}{*}{$\begin{array}{l}\text { Design } \\
\text { Data }\end{array}$} & Tank size & $\mathrm{X}$ & $\mathrm{O}$ & $\mathrm{O}$ & $\mathrm{O}$ & $\mathrm{O}$ & $\mathrm{O}$ \\
\hline & Utilization pump & $\mathrm{X}$ & $X$ & $X$ & $\mathrm{O}$ & $X$ & $\mathrm{O}$ \\
\hline & Infiltration facility & $x$ & $X$ & $\mathrm{X}$ & $X$ & $\mathrm{O}$ & $\mathrm{O}$ \\
\hline \multirow[t]{8}{*}{ Result } & Performance & & & & & & \\
\hline & TP Curve & $x$ & $\mathrm{O}$ & $\mathrm{O}$ & $\mathrm{O}$ & $\mathrm{O}$ & $\mathrm{O}$ \\
\hline & TD Curve & $\mathrm{X}$ & $\mathrm{O}$ & $\mathrm{O}$ & $\mathrm{O}$ & $\mathrm{O}$ & $\mathrm{O}$ \\
\hline & Multiple Benefit & & & & & & \\
\hline & FM & $X$ & 0 & O & O & O & O \\
\hline & WS & $x$ & $X$ & $X$ & O & $x$ & 0 \\
\hline & ES & $X$ & 0 & 0 & O & O & 0 \\
\hline & GR & $X$ & $x$ & $X$ & $x$ & $\mathrm{O}$ & 0 \\
\hline
\end{tabular}

Note: TP (Tank volume - Peak runoff), TD (Tank volume - Design return period).

\section{Input data}

Because the rainfall and design method are site specific, the rainfall data should be gathered for the design site. The capacity of nearby sewer systems should be analyzed.

\section{Design data}

The tank size should be designed, according to the choice of controllable measures. The pumping rate and operation rules 
54 Hydrological Design of Multipurpose Micro-catchment RWM should be specified. The infiltration capacity should also be determined based on the site condition and soil characteristic.

\section{Results}

The results will show how much the sewer capacity would be increased without physically increasing the sewer, i.e. with the increase of rainwater tank volume, how much the peak runoff rate will decrease or how much the design return period will increase. Multiple benefits such as flood mitigation, water supply, emergency water supply and groundwater recharge will be quantified as a result of the model.

Although the methods and results in this chapter are based on the case of Seoul city, these methods can be easily developed for any other city using the local rainfall data. The results can be used in the design and operation of sewer systems for flood mitigation plans and climate change adaptation strategies by city planners, designers, and even politicians.

\subsubsection{Other considerations in micro-catchment hydrology}

The motivation of multipurpose rainwater management is based on the research findings that the quality of roof-harvested rainwater is relatively clean. It can be used for non-drinking purposes such as toilet flushing and irrigation after simple screening and sedimentation. After a minor treatment, it can be used for drinking purposes, meeting the local or WHO drinking water standards. It can also be used for, emergency use, and groundwater recharge by small effort to clean the water to a designated level. However, rainwater collected from the roads and ground needs more treatment than roof-harvested rainwater. 
The size of one rainwater catchment system is assumed to be smaller than $2000 \mathrm{~m}^{2}$. However, for the case of a building with a larger roof area than $2000 \mathrm{~m}^{2}$, the catchment can be divided into several systems smaller than $2000 \mathrm{~m}^{2}$. Therefore, there is no limit of roof area to apply this model.

For a certain design area, the rainfall characteristic is analyzed rigorously considering all the design return period and rainfall duration. In order to apply to any catchment area, the design data and result are normalized to a unit catchment area $\left(100 \mathrm{~m}^{2}\right)$. For other catchment area, the results can be multiplied by the ratio of the actual catchment area to the unit catchment area. For example, if the roof area is $300 \mathrm{~m}^{2}$, then the result can be obtained by multiplying $3(=300 / 100)$ to the result developed for a unit catchment area $\left(100 \mathrm{~m}^{2}\right)$.

Another advantage of roof-harvested rainwater is that it has inherent potential energy. Roof-harvested rainwater can be transferred to any place in or below the building by gravity obviating the need for any mechanical energy. However, the overflow pipe level of rainwater tank should be high enough to transfer the water to the nearby sewer system.

\subsection{RAINFALL-DISCHARGE (R-D) MODEL}

Figure 3.2 shows the scheme of an R-D system for a building. The R-D system is designed based on the concept of traditional storm-water management, which is to drain rainwater as quickly as possible from the building rooftop to the sewer system. Due to urbanization and climate change, runoff may increase and exceed the capacity of connected sewer system, which is believed to be one of the main causes of urban flooding. The R-D model has been used in estimating the rainfall-runoff for a micro-catchment from the building rooftop to the sewer system. 
56 Hydrological Design of Multipurpose Micro-catchment RWM

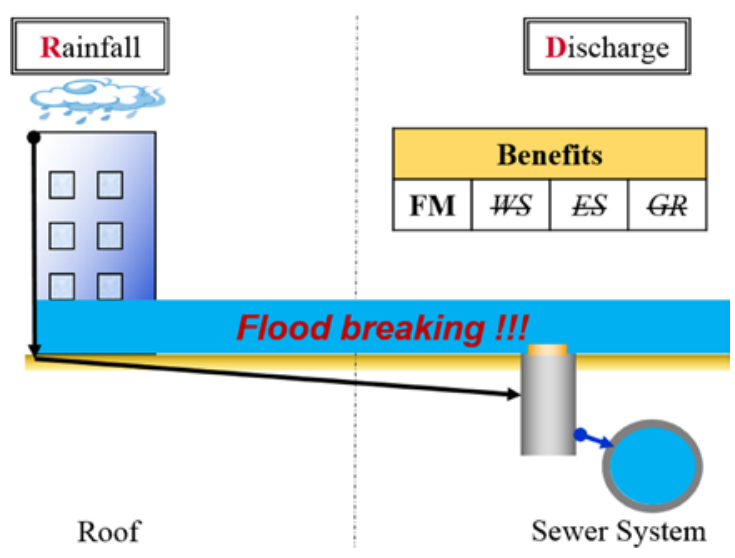

Figure 3.2 Rainfall-Discharge (R-D) system.

\subsubsection{Modeling of R-D system}

\subsubsection{Diagram}

Figure 3.3 shows the flow diagram of an R-D system for a building, which generally consists of a building rooftop, downpipe, and a connection pipe to the nearby sewer system.

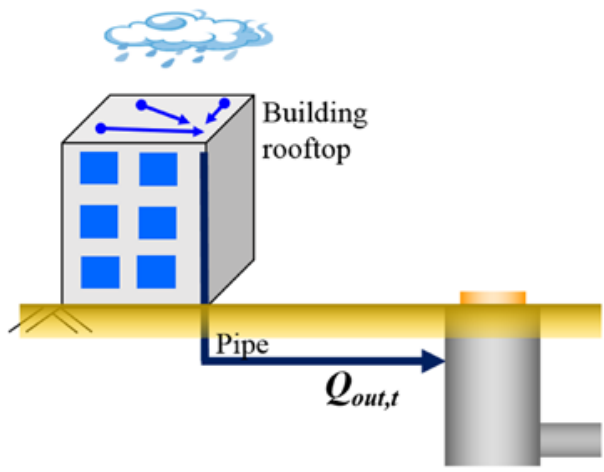

Sewer system

Figure 3.3 Notation and water flow of an R-D system. 
Hydrological design of multipurpose micro-catchment RWM 57

\subsubsection{Equations \\ Design rainfall}

The procedure to develop a rainfall hyetograph for an R-D system, is described in Table 3.2 for the case of Seoul city as an example

Table 3.2 Procedure to develop a design rainfall hyetograph for R-D system.

\begin{tabular}{lll}
\hline $\begin{array}{l}\text { Step } \\
\text { No. }\end{array}$ & $\begin{array}{l}\text { Parameter to be } \\
\text { Determined }\end{array}$ & Notes \\
\hline 1 & $\begin{array}{l}\text { Find dominant rainfall type } \\
\text { from the Huff method in the } \\
\text { region of interest } \\
\text { Select the heaviest } \\
\text { cumulative rainfall percent } \\
\text { curve }\end{array}$ & $\begin{array}{l}\text { Find the most frequently } \\
\text { occurring quartile types }\end{array}$ \\
& $\begin{array}{l}\text { Among curves with } \\
\text { probability in the dominant } \\
\text { types, the curve of heaviest } \\
\text { cumulative percent for the } \\
\text { time increment just before } \\
\text { peak rainfall }\end{array}$ \\
3 & Total rainfall depth & $\begin{array}{l}\text { From Intensity-Duration- } \\
\text { Frequency (IDF) curves for } \\
\text { the region of interest } \\
\text { By using the dimensionless } \\
\text { hyetograph and the total } \\
\text { rainfall depth }\end{array}$ \\
\hline & $\begin{array}{l}\text { Construction of a design } \\
\text { rainfall hyetograph }\end{array}$ &
\end{tabular}

Detailed example is explained in Chapter 2.

\section{Runoff analysis}

The runoff from R-D system can be estimated using the experimental formula for cumulative runoff analysis in the building roof for on-site rainwater management (Kim et al. 2009):

$$
Q_{\text {out }, t}=i_{t} \times(0.90 \sim 0.95) \times \mathrm{A} \times 0.001
$$


58 Hydrological Design of Multipurpose Micro-catchment RWM

$Q_{\text {out }, t}$ is the runoff from building rooftop catchment area $\left(\mathrm{m}^{3} / \mathrm{h}\right)$ at time $t . A$ is the catchment area $\left(\mathrm{m}^{2}\right) .0 .90-0.95$ is the runoff coefficient. $i_{t}$ is the rainfall intensity $(\mathrm{mm} / \mathrm{h})$ at time $t$.

\section{Methods}

The design rainfall hyetograph can be developed following the Huff method with the steps mentioned in Table 3.2. The design rainfall hyetograph is presented by a specific design return period $(2,5,10,30,50$, and 100 years) and a rainfall duration $(30,60$, 90 min and other).

Finally, runoff flow can be calculated based on the experimental formula (Eq. 3.1). The peak of runoff flow $\left(Q_{\text {peak }}\right)$ which represents the highest value of runoff flow will be the basis of the system design.

\subsubsection{Results and discussion}

Figure 3.4 is an example of a design rainfall hyetograph for various design periods for 90 min design rainfall duration for Seoul city using the Huff method. The longer the design return period, the higher rainfall intensity becomes.

Peak runoff flow rates for the R-D model are calculated by using Equation 3.1 using unit catchment area (of $100 \mathrm{~m}^{2}$ ) and rainfall duration time of 90 min under different design rainfall periods of 2, 5, 10, 30, 50, and 100 years as inputs, as shown in Figure 3.5. The pattern of peak runoff flow rates is similar to that of the design rainfall hyetographs. The highest value of runoff flow rate is $Q_{\text {peak }}$ which is generally used to design the sewer system. As demonstrated in Figure 3.5, with heavier rainfall, the peak runoff flow rates becomes higher. $Q_{\text {peak }}$ values are $8.3,11.8,14.0,17.5,19.1$, and $21.2 \mathrm{~m}^{3} / \mathrm{h}$ for design periods of $2,5,10,30,50$, and 100 years for a rainfall with duration of $90 \mathrm{~min}$, respectively. 
Hydrological design of multipurpose micro-catchment RWM $\mathbf{5 9}$

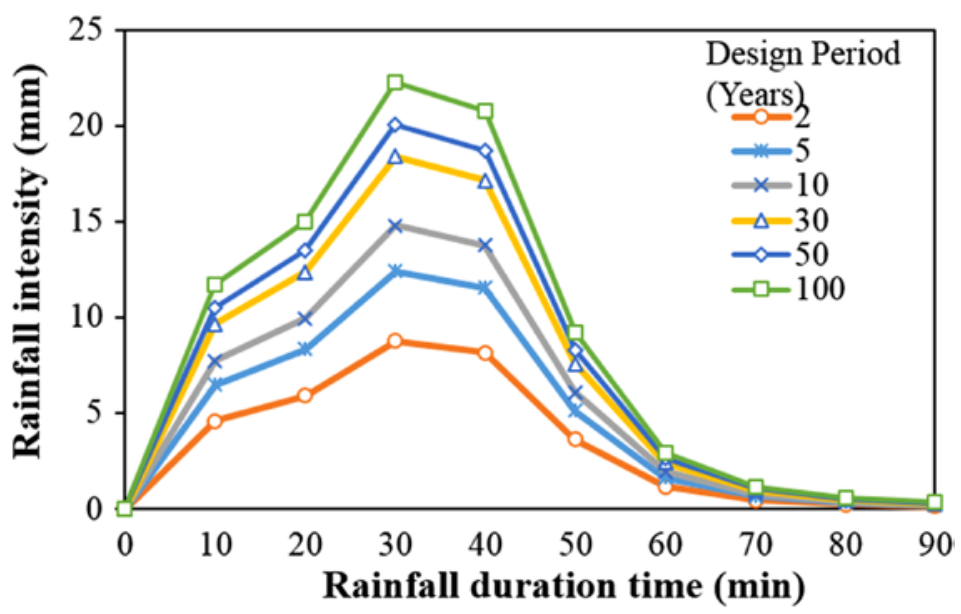

Figure 3.4 Design rainfall hyetographs for various design return periods of 90 min (using Seoul rainfall data and Huff method).

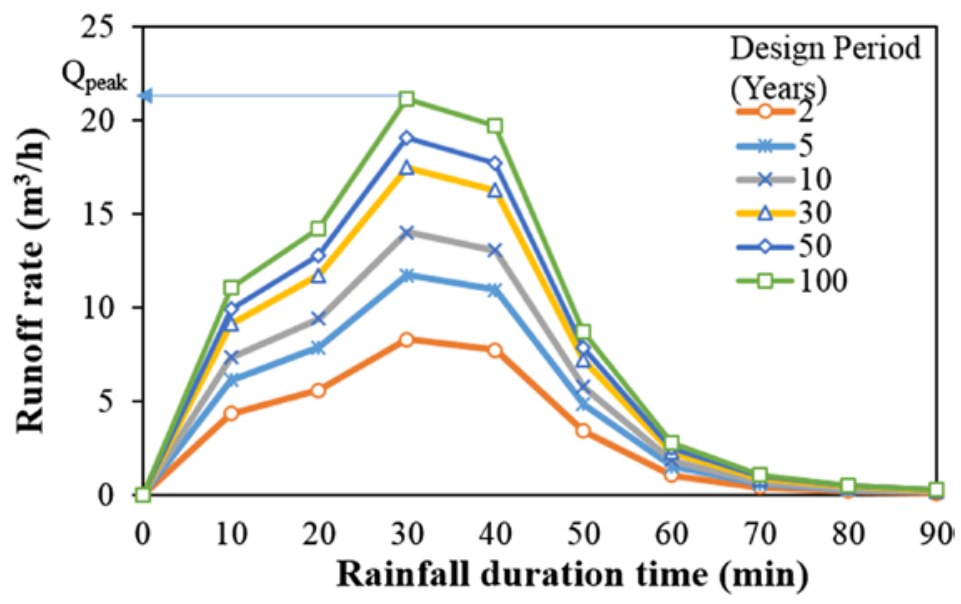

Figure 3.5 Peak runoff curves for R-D system at different design return periods with 90 minute rainfall duration time for $100 \mathrm{~m}^{2}$ catchment area (using Seoul rainfall data and Huff method). 
60 Hydrological Design of Multipurpose Micro-catchment RWM

The design example shown here are the result for a rainfall duration time of $90 \mathrm{~min}$. For other rainfall duration times, similar graphs can be made.

\subsection{RAINFALL-STORAGE-DISCHARGE (R-S-D) MODEL}

By storing some of the rain that falls on a building rooftop, the outflow volume can be reduced, thus the risk of flooding can be mitigated. And some storage can be secured for emergency as well. The Rainfall-Storage-Discharge (R-S-D) model has been proposed and developed by Kim et al. (2006) to estimate the effect of a rainwater retention tank. Figure 3.6 shows the scheme of an R-S-D system, where a rainwater tank is added at between the roof and sewer system. Depending on the available volume below overflow level, flooding can be mitigated.

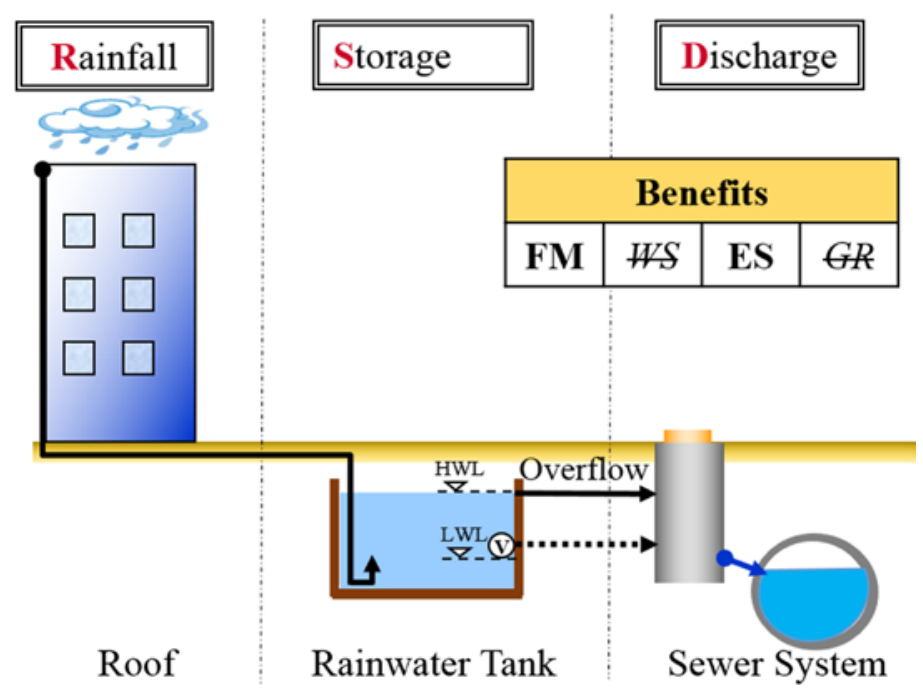

Figure 3.6 R-S-D rainwater management system. 
The water volume stored below the Low Water Level (L.W.L) can be used for emergencies. When conditions permit, the L.W.L outlet can be controlled by a valve, which is always closed and only opened to empty the tank in advance before a heavy rainfall is expected. Once the level reaches the High Water Level (H.W.L), which means that tank is full, this system does not function any more as a flood mitigation measure, and responds as if there is no storage. The high and low water levels can be set by the designer or operators according to the need of emergency storage or flood mitigation.

\subsubsection{Modeling of R-S-D system}

\subsubsection{Diagram}

Figure 3.7 shows the flow diagram of an R-S-D system for a building, which generally consists of a building rooftop, downpipe, storage tank, low and high water levels, with one or two connection pipes to the nearby sewer system.

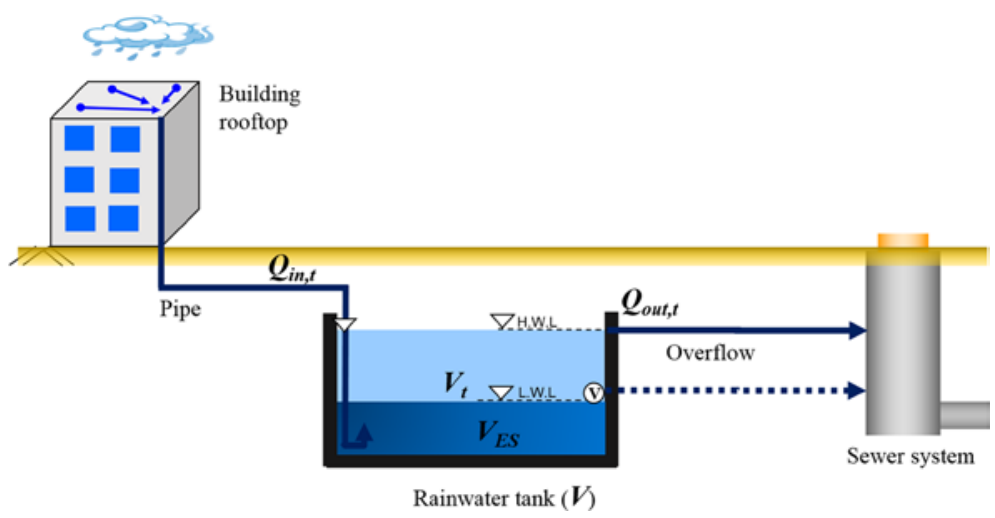

Figure 3.7 Notation and water flow of an R-S-D system. 


\subsubsection{Equations}

To simulate water flow through a rainwater tank in the R-S-D system (Figure 3.7), the water balance can be set up as follows:

$$
V_{t}=V_{t-1}+Q_{\text {in }, t} \Delta_{t}-Q_{\text {out }, t} \Delta_{t}
$$

$V_{t}$ is the cumulative water stored in the tank $\left(\mathrm{m}^{3}\right)$ at time $t . V_{t-1}$ is the cumulative water stored in the tank $\left(\mathrm{m}^{3}\right)$ at time $t-1 . \Delta_{t}$ is the time increment (h). In determining retention volumes, small time increments are more useful than large time increments to avoid the underestimation of the cumulative rainfall depth from hyetographs. In this section, a time increment of 5 minutes, which is generally the smallest value, is used. $Q_{\mathrm{in}, t}$ is the inflow rate of the rainwater tank $\left(\mathrm{m}^{3} / \mathrm{h}\right)$ at time $t$, which is the same as the runoff flow rate from the roof in Eq. (3.1). $Q_{\text {out }, t}$ is the overflow rate from the tank to the sewer system $\left(\mathrm{m}^{3} / \mathrm{h}\right)$ at time $t$. $Q_{\text {out }, t}$ can be mathematically described as follows:

$$
\text { If } V_{t} \leq V, \quad Q_{\text {out }, t}=0
$$

If $V_{t}>V$, the tank is full,

$$
Q_{\text {out }, t} \Delta_{t}=V_{t-1}-V+Q_{\text {in }, t} \Delta_{t}
$$

$V$ is the volume of the rainwater tank $\left(\mathrm{m}^{3}\right)$.

\subsubsection{Flow chart}

The outflows from an R-S-D system under various design parameters can be calculated through the flow chart based on the above equations (Figure 3.8). The R-S-D model requires inputs of design parameters including runoff coefficient $(C)$, catchment area $(A)\left(\mathrm{m}^{2}\right)$, tank volume $(V)\left(\mathrm{m}^{3}\right)$, emergency storage $\left(\mathrm{V}_{\mathrm{ES}}\right)\left(\mathrm{m}^{3}\right)$ and design rainfall $\left(i_{p, d, t}\right)(\mathrm{mm} / \mathrm{h})$; outputs are the outflows presented by TP (Tank volume - Peak runoff) curves and TD (Tank volume - Design period) curves, and Emergency Storage (ES). 


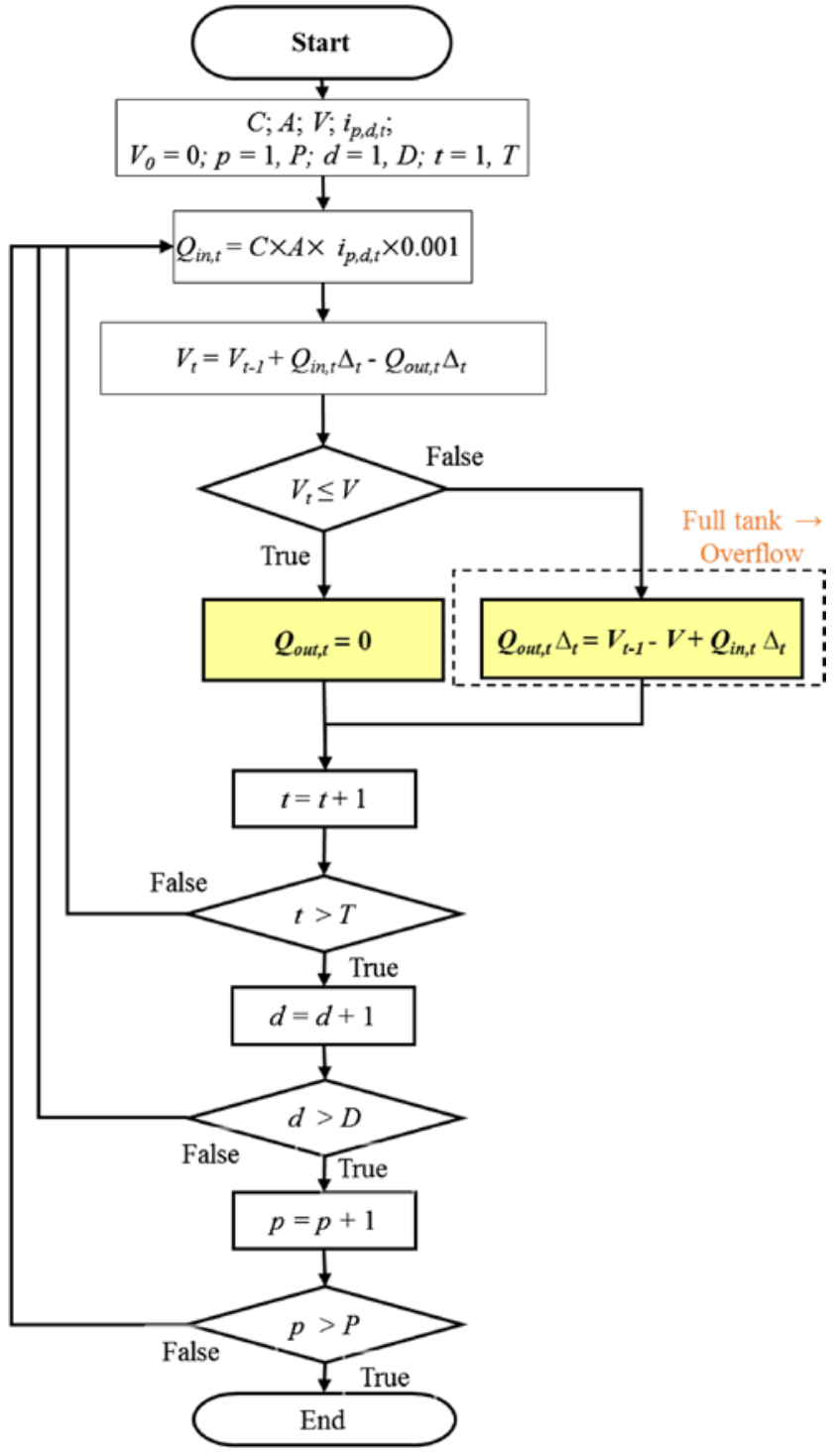

Figure 3.8 Flow chart for R-S-D Model, $P$ (Design period), $D$ (Rainfall duration), $T$ (Simulation period). 
64 Hydrological Design of Multipurpose Micro-catchment RWM

\subsubsection{Results and discussion}

\subsubsection{TP (Tank volume - Peak runoff) curve}

The effect of rainwater tank volume of an R-S-D system on peak runoff reduction can be calculated following the flowchart described in Figure 3.8. Figure 3.9 presents TP (Tank volume Peak runoff) curves for an R-S-D system which shows how peak runoff rates can be reduced by increasing the tank volume $\left(\mathrm{m}^{3} / 100 \mathrm{~m}^{2}\right.$ roof catchment area) for the case of a 100-year return period in Seoul for different rainfall duration times. Volume and peak flowrate are normalized to $100 \mathrm{~m}^{2}$ catchment area. For larger roof area, the real $Q_{\text {peak }}$ and tank volumes can be multiplied by the ratio of roof area to $100 \mathrm{~m}^{2}$.

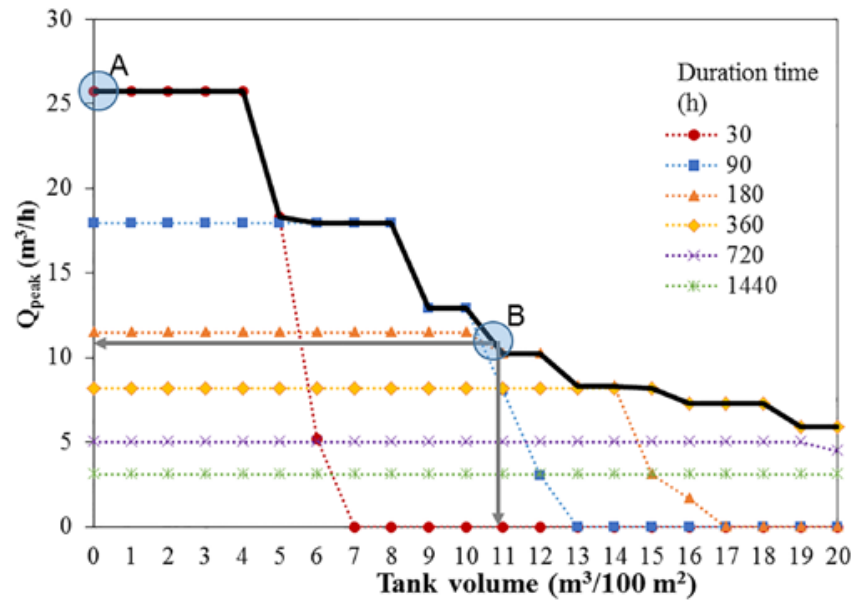

Figure 3.9 TP (Tank volume - Peak runoff) curves for R-S-D system using 100-year design return period rainfall (using Seoul rainfall data and Huff method, normalized for $100 \mathrm{~m}^{2}$ catchment area).

A dotted line connecting dark circles represents the runoff flow for different tank sizes for the case of $0.5 \mathrm{~h}$ duration time. When the tank size is less than $4 \mathrm{~m}^{3}$, the runoff rate is $26 \mathrm{~m}^{3} / \mathrm{h}$, 
and gradually decrease until $7 \mathrm{~m}^{3}$, after which there will be no runoff at all. Similar dotted lines can be drawn for other duration times of $0.5,1.5,3,6,12$, and $24 \mathrm{~h}$. Among these dotted lines, by connecting the peak points at each tank volume, a peak runoff line can be drawn as shown by a thick line in Figure 3.9. When the tank volume is $0 \mathrm{~m}^{3}$ (R-D system) (Point A), the peak outflow is $26 \mathrm{~m}^{3} / \mathrm{h}$, but in the R-S-D model, when the tank volume is $11 \mathrm{~m}^{3} / 100 \mathrm{~m}^{2}$ (Point B), the peak outflow is reduced to $11 \mathrm{~m}^{3} / \mathrm{h}$. This proves the flooding mitigation potential of R-S-D model.

Following the procedure to develop TP curves as in Figure 3.9, which is made for 100 year return period rainfall, similar graphs can be generated for other design return periods such as 2, 5, 10, 30, and 50 year. The peak curves from each design return periods are combined and shown in Figure 3.10. It shows an obvious result quantitatively that when the design return period is longer (heavier rainfall), the peak runoff increases. For example, the peak runoff for a 100-year design without a tank is $26 \mathrm{~m}^{3} / \mathrm{h}$ (Point A). However, when the tank size is $11 \mathrm{~m}^{3} / 100 \mathrm{~m}^{2}$ (Point B), the peak runoff for the same 100-year design period will become $11 \mathrm{~m}^{3} / \mathrm{h}$ (Point $\mathrm{C}$ ), which is equivalent to the peak runoff at a rainfall of a 2-year return period (Point D). Kim et al. $(2006,2014)$ reported similar results.

From Figure 3.10, it is easy to compare the flood mitigation effect of rainwater tank volume for different design return periods. Table 3.3 compares the peak runoffs of R-D and R-S-D systems, and peak runoff reduction ratio. If the peak runoff of a system $\left(Q_{\text {peak }}\right)$ is larger than the sewer flow capacity $\left(Q_{\text {sewer }}\right)$ $\left(Q_{\text {peak }} / Q_{\text {sewer }}>1\right)$, flooding will occur.

If existing sewer system is designed for a rainfall of 2-year return period, then the flow capacity is $11 \mathrm{~m}^{3} / \mathrm{h}$. If there is no rainwater tank (R-D system), the sewer will overflow when there is heavier rainfall than 2 year return period. However, by installing a rainwater tank of $10 \mathrm{~m}^{3} / 100 \mathrm{~m}^{2}$, the sewer system can still be safe until a heavier rainfall of around 50-year return 
66 Hydrological Design of Multipurpose Micro-catchment RWM period. Also by installing a rainwater tank $\left(10 \mathrm{~m}^{3} / 100 \mathrm{~m}^{2}\right)$, the peak runoff can be reduced by $50-91.8 \%$. The smaller the rainfall return period, the more the peak is reduced. Similar analysis can easily be made for other size of rainwater tanks.

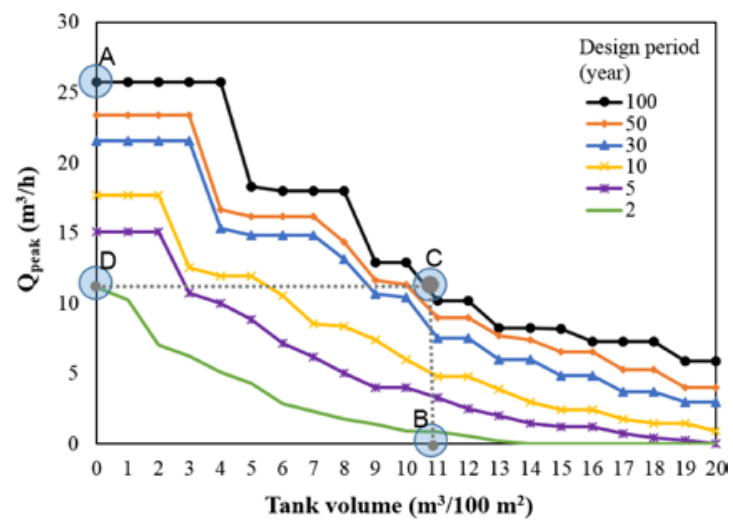

Figure 3.10 TP (Tank volume - Peak runoff) curves for R-S-D system using different design return periods (using Seoul rainfall data and Huff method, normalized for $100 \mathrm{~m}^{2}$ catchment area).

Table 3.3 Peak reduction of R-S-D system (when rainwater tank $10 \mathrm{~m}^{3} / 100 \mathrm{~m}^{2}$ is installed).

\begin{tabular}{|c|c|c|c|c|c|}
\hline \multirow{2}{*}{$\begin{array}{l}\text { Return } \\
\text { Period } \\
\text { (Year) }\end{array}$} & \multicolumn{2}{|c|}{ R-D System } & \multicolumn{2}{|c|}{$\begin{array}{l}\text { R-S-D System } \\
\left(10 \mathrm{~m}^{3} / 100 \mathrm{~m}^{2}\right)\end{array}$} & \multirow{2}{*}{$\begin{array}{l}\text { Peak Runoff } \\
\text { Reduction } \\
\text { Ratio (\%) }\end{array}$} \\
\hline & $\begin{array}{l}Q_{\text {peak }} \\
\left(\mathrm{m}^{3} / \mathrm{h}\right)\end{array}$ & $Q_{\text {peak }} / Q_{\text {sewer }}$ & $\begin{array}{l}Q_{\text {peak }} \\
\left(\mathrm{m}^{3} / \mathrm{h}\right)\end{array}$ & $Q_{\text {peak }} / Q_{\text {sewer }}$ & \\
\hline 100 & 26.0 & 2.36 & 13.0 & 1.18 & 50 \\
\hline 50 & 23.4 & 2.13 & 11.4 & 1.04 & 51.3 \\
\hline 30 & 21.6 & 1.96 & 10.4 & 0.95 & 51.9 \\
\hline 10 & 17.7 & 1.61 & 6.0 & 0.55 & 66.1 \\
\hline 5 & 15.0 & 1.36 & 4.0 & 0.36 & 73.7 \\
\hline 2 & 11.0 & 1 & 0.9 & 0.08 & 91.8 \\
\hline
\end{tabular}


The result clearly shows that, by installing rainwater tanks, the nearby sewer system can mitigate flooding risks without physically increasing the capacity of the existing sewer system; thus, it can save time and reduce implementation costs.

\subsubsection{TD (Tank volume - Design period) curve}

For a more simple and practical design of RWMS, the necessary tank volumes required to control heavy rainfall of various design periods that help secure the system are summarized in Figure 3.11. As shown, TD (Tank volume - Design period) curve for the R-S-D system describes how tank volume can help reduce the peak runoff so that the sewer system can be maintained even for longer design periods without increasing the capacity of the sewer system. For example, let us consider a sewer system designed for a 2-year return period of rainfall with no rainwater tank (R-D system). When a rainwater tank of $11 \mathrm{~m}^{3} / 100 \mathrm{~m}^{2}$ (Point A) is installed, then the sewer system can be secured even at the much stronger rainfall of a 100 -year return period. If we wish to improve the existing sewer system to be safe for a rainfall of a 30 -year return period, a rainwater tank of $9 \mathrm{~m}^{3} / 100 \mathrm{~m}^{2}$ (Point B) can perform the same effect as increasing the capacity of sewer system which costs a lot of money and time.

\subsubsection{ES (Emergency Storage)}

In an emergency, such as disaster or war, the water supply may be interrupted or broken for a short period of time. This means we may need to use stored water for drinking and other non-drinking purposes for several days or more. An R-S-D system can provide ES by storing rainwater for such emergency cases. The water volume stored below the L.W.L can be used during emergency. The L.W.L. can be set by the designer according to the need for emergency storage or flood mitigation. For example, if the L.W.L is set at $25 \%$ of the depth of rainwater tank, the ES will be $2 \mathrm{~m}^{3} / 100 \mathrm{~m}^{2}$ for a rainwater tank of $8 \mathrm{~m}^{3} / 100 \mathrm{~m}^{2}$. 
68 Hydrological Design of Multipurpose Micro-catchment RWM

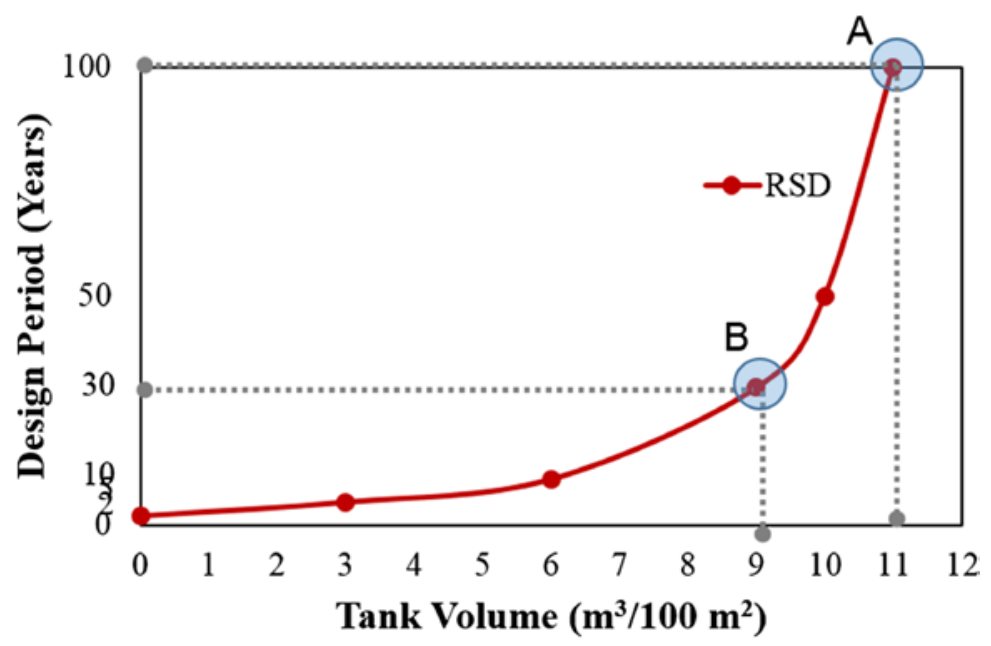

Figure 3.11 TD (Tank volume - Design period) curve for R-S-D system (using Seoul rainfall data and Huff method, normalized for $100 \mathrm{~m}^{2}$ catchment area).

\subsection{RAINFALL-STORAGE-PUMP-DISCHARGE (R-S-P-D) MODEL}

The R-S-P-D system consists of a rainwater tank, discharge pump, and connection pipe to the nearby sewer system (Figure 3.12). During the operation of rainwater tank, there may be a case when the tank is full with previous rainfalls and a heavy storm is expected in a day or two. In this case, the rainwater tank does not function for flood mitigation any more, until some part of the tank is emptied to store rainwater. If conditions permit, a valve can be installed to slowly empty the tank as in R-S-D system when is required. It is possible to install a pump large enough to empty the tank within a couple of hours and transfer to the sewer system. Because before the heavy storm comes, the connected sewer system may still have enough capacity to drain the pumped rainwater. 


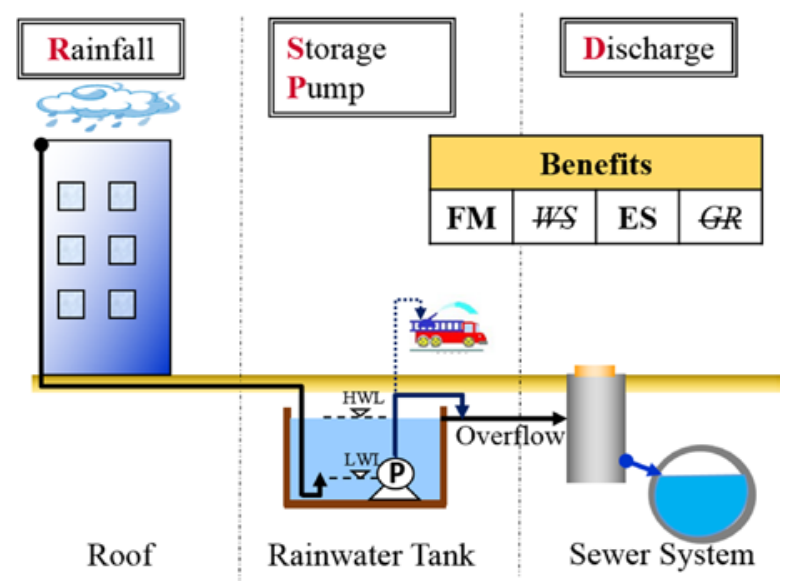

Figure 3.12 Rainfall-Storage-Pump-Discharge (R-S-P-D) system.

This system is especially useful when and where heavy rainfall caused by typhoon or hurricane occurs frequently. By emptying the rainwater tank in advance down to the L.W.L. before a heavy rainfall comes, flooding risks at a local level can be mitigated. Once it is emptied, the system behaves like the R-S-D model. The water level change before and after the pumping is shown as Figure 3.13 (a). However, the pump should be carefully operated to avoid operation during heavy rainfall, because it might result in the overload to the sewer system. The water volume stored below the L.W.L can be used for emergencies (ES).

Although one small rainwater tank may not be big enough to prevent flooding for a whole street or a city, installation of many small R-S-P-D systems in a flood prone street or a city can be the cheapest and surest measure among all currently considerable options. Especially, the maximum benefit can be obtained by IT (information technology) assisted monitoring and control coupled with encouragement of public participation by providing economic incentives. 
(a) Water level

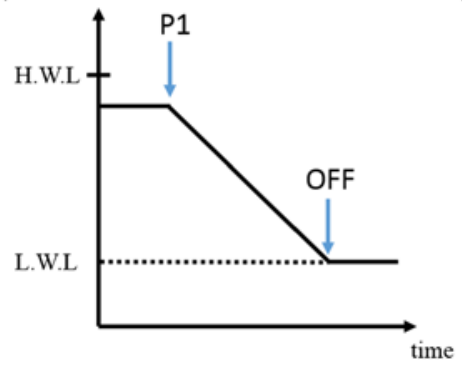

(b) Water level

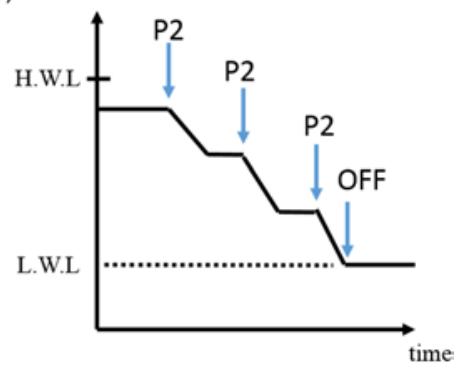

Figure 3.13 Operation of discharge pump (a) to empty rainwater tank in advance before a heavy rain is expected and (b) to provide outdoor water consumptions such as water for fire-fighting and road cooling and cleaning.

Additional benefits can be made if the pump is used for the supply of non-drinking outdoor water consumption such as water supply for road management or fire-fighting. The water level in the tank may change as in Figure 3.13 (b). In monsoon areas like Korea, heavy rainfall is expected in hot summer. If a city makes a rule to purchase the stored rainwater from the building owner at a cheaper price than usual and use the water for cooling or cleaning the road, it can create a win-win situation for both city government and citizens: The tank is emptied for flood mitigation, city saves money and building owners earn money, while keeping the city cooler.

Also, in case when and where it is difficult or takes some time for fire engines approach to the fire site, the R-S-P-D system can provide water as a decentralized fire prevention system. It is very important to extinguish fire at its early stage before it becomes bigger. By monitoring the rainwater inventory of the rainwater tanks in several buildings using IT, the fire risks will be reduced by providing water from a short distance. Therefore, it is possible to reduce fees for fire insurance to the building owners who maintains the R-S-P-D system. This also can create 
another win-win case between insurance companies and the building owners.

In R-S-P-D model, after the pump is operated to empty the tank down to the L.W.L, and later rain falls, it behaves as if there is no pump, therefore, it will function exactly the same as R-S-D model. So the flowchart, equations, and results of TD and TP curves developed for R-S-D model can be used for the simulation of R-S-P-D model.

\subsection{RAINFALL-STORAGE-UTILIZATION- DISCHARGE (R-S-U-D) MODEL}

The stored rainwater can be maintained to keep good quality and can be used in or near the building for non-drinking or drinking purposes after appropriate treatment, thus reducing the demand from municipal water supply. Timely utilization of stored rainwater in tanks can also help reduce peak runoff flows by increasing available storage volume. The Rainfall-StorageUtilization-Discharge (R-S-U-D) model can be used for the analysis and design of RWMS for flooding mitigation and water saving (Nguyen \& Han, 2017). Figure 3.14 shows the scheme of an R-S-U-D system which consists of rainwater tank, utilization pump and 2 discharge lines to sewer connection, one is by overflow and the other is by valve control if conditions permit. The volume of rainwater discharged to the sewer system can be controlled by rainwater tank volume and water supply for domestic use.

The water volume stored below the L.W.L can be used for emergency. Once the water level reaches the L.W.L, the utilization pump stops, and responds as if there is no utilization. When the tank is full and water level reaches the H.W.L, the outflow will be the same as inflow and there is no flooding mitigation effect. The high and low water levels can be set by the designer or operator according to the need for emergency storage, flood mitigation or water utilization. 
72 Hydrological Design of Multipurpose Micro-catchment RWM

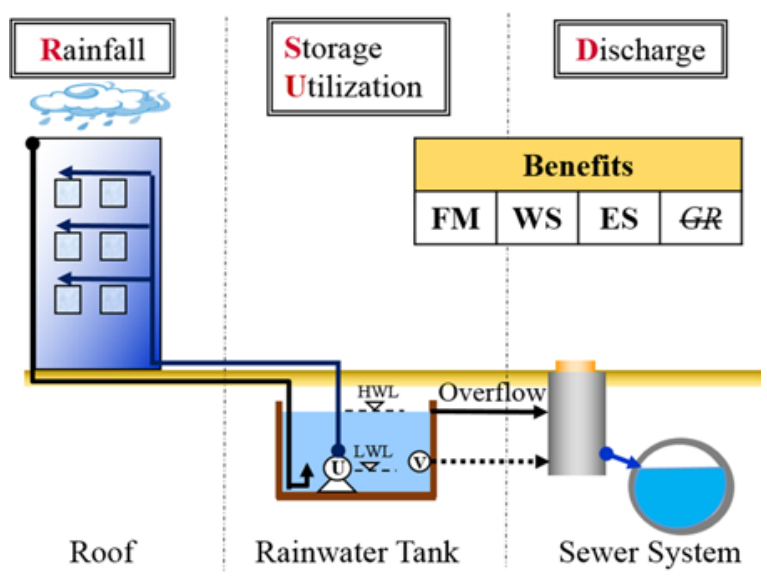

Figure 3.14 R-S-U-D rainwater management system.

\subsubsection{Modeling of R-S-U-D system}

\subsubsection{Diagram}

Figure 3.15 shows the water flow of an R-S-U-D system, which consists of rooftop, downpipe, storage tank, small utilization pump, water supply facility, low and high water levels, and a connection pipe to sewer system.

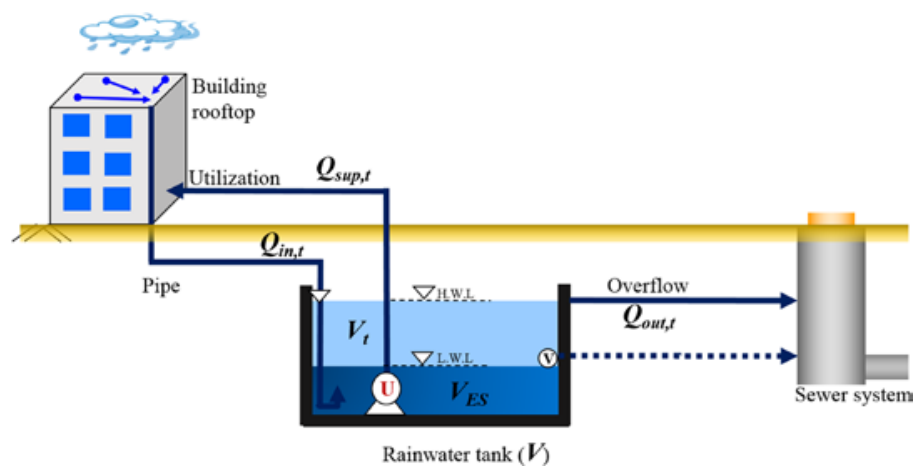

Figure 3.15 Notations and water flow of an R-S-U-D system. 
Hydrological design of multipurpose micro-catchment RWM 73

\subsubsection{Equations}

To simulate water flow in a rainwater tank in R-S-U-D system, the water balance can be set up around the rainwater tank (Figure 3.13) as follows:

$$
V_{t}=V_{t-1}+Q_{\mathrm{in}, t} \Delta_{t}-Q_{\text {sup }, t} \Delta_{t}-Q_{\text {out }, t} \Delta_{t}
$$

$Q_{\text {sup }, t}$ is the water supply rate to the building from the rainwater tank $\left(\mathrm{m}^{3} / \mathrm{h}\right)$ at time $t$. $Q_{\text {sup }, t}$ can be mathematically described as follows:

$$
\text { If } V_{t} \leq V_{\mathrm{ES}}, \quad Q_{\text {sup }, t}=0,
$$

$V_{\mathrm{ES}}$ is the water volume stored below the L.W.L $\left(\mathrm{m}^{3}\right)$. If $V_{t}>V_{\mathrm{ES}}$, the water supply is determined by the available water stored in the tank and the utilization rate $Q_{\text {utilization }}$ (pump capacity) $\left(\mathrm{m}^{3} / \mathrm{h}\right)$.

$$
\begin{aligned}
& V_{t-1}-V_{\mathrm{ES}}+Q_{\mathrm{in}, t} \Delta t<Q_{\mathrm{utilization}} \Delta t \rightarrow Q_{\mathrm{sup}, t} \Delta t \\
& \quad=V_{t-1}-V_{\mathrm{ES}}+Q_{\mathrm{in}, t} \Delta t-Q_{I, t} \Delta t \\
& V_{t-1}-V_{\mathrm{ES}}+Q_{\mathrm{in}, t} \Delta t \geq Q_{\text {utilization }} \Delta t \rightarrow Q_{\mathrm{sup}, t}=Q_{\text {utilization }}
\end{aligned}
$$

Outflow occurs only when the tank is full.

$$
\text { If } V_{t} \leq V, \quad Q_{\text {out }, t}=0
$$

If $V_{t}>V$, the tank is full,

$$
Q_{\text {out }, t} \Delta t=V_{t-1}-V+Q_{\text {in }, t} \Delta t-Q_{\text {sup }, t} \Delta t
$$

$V$ is the volume of the rainwater tank $\left(\mathrm{m}^{3}\right)$.

\subsubsection{Flow chart}

The outflows from an R-S-U-D system under various design parameters are calculated by the simulations based on the flow chart (Figure 3.16). The R-S-U-D model requires input of 
74 Hydrological Design of Multipurpose Micro-catchment RWM

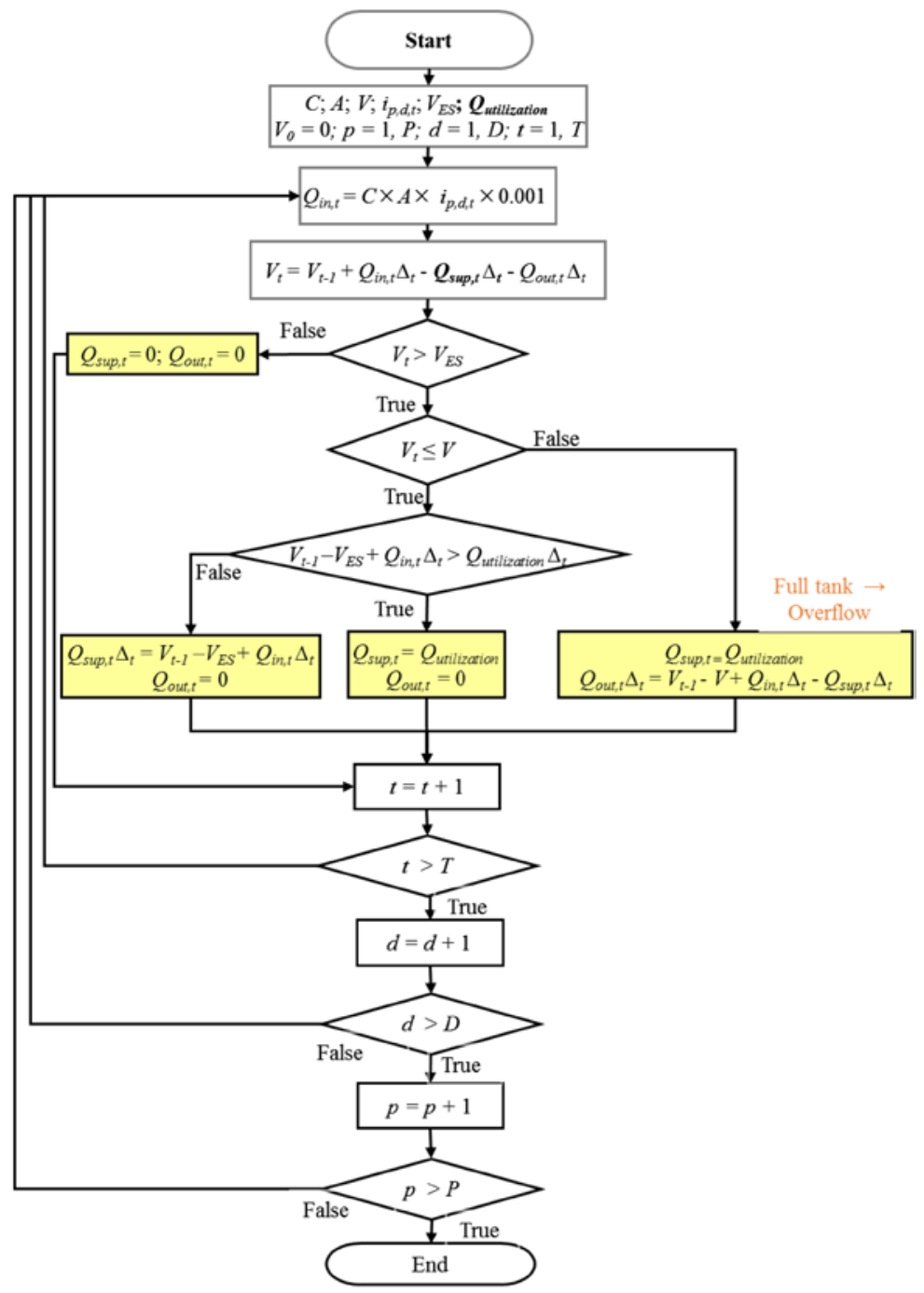

Figure 3.16 Flow chart figure for R-S-U-D, $P$ (Design period), $D$ (Rainfall duration), $T$ (Simulation period). 
design parameters including runoff coefficient $(C)$, catchment area $(A)\left(\mathrm{m}^{2} / 100 \mathrm{~m}^{2}\right)$, tank volume $(V)\left(\mathrm{m}^{3}\right)$, emergency storage $\left(V_{\mathrm{ES}}\right)$, utilization rate $\left(Q_{\text {utilization }}\right)\left(\mathrm{m}^{3} / \mathrm{h}\right)$ and design rainfall $\left(i_{p, d, t}\right)$ $(\mathrm{mm} / \mathrm{h})$; Outputs are the outflows presented by TP (Tank volume Peak runoff) curves and TD (Tank volume - Design period) curves, Rainwater Utilization Ratio (RUR) and Emergency Storage (ES).

\subsubsection{Results and discussion}

\subsubsection{TP (Tank volume - Peak runoff) curve}

If the tank is slowly emptied by utilizing stored rainwater for domestic non-drinking or drinking purposes, the outflow can be reduced and flooding is further mitigated. In order to understand the effect of utilization rate on peak outflow reduction, Figure 3.17 is made to show TP (Tank volume versus Peak runoff) curves under different utilization rates for a 100 -year design period in Seoul. $0 \sim 20 \mathrm{~L} / \mathrm{min} / 100 \mathrm{~m}^{2}$ (equal to $0 \sim 28.8 \mathrm{~m}^{3} /$ day $/ 100 \mathrm{~m}^{2}$ ) of water consumption is a reasonable range for multi-story buildings. Because the utilization is normalized for $100 \mathrm{~m}^{2}$ in this graph, the actual utilization ratio should be multiplied by the area ratio.

The solid circle symbols represents R-S-D model with no utilization which is the same solid line in Figure 3.9. The other four lines in the figure represents the result when there is utilization. With a larger tank volume or a higher utilization rate, outflow is reduced. The solid horizontal line represents the peak runoff flow $\left(11 \mathrm{~m}^{3} / \mathrm{h}\right)$ which is calculated for the 2-year design rainfall. When there is no utilization, the required minimum tank volume to reduce a 100 year peak runoff to 2 year peak runoff is $11 \mathrm{~m}^{3} / 100 \mathrm{~m}^{2}$ (Point A). The tank volume can be reduced to 10 (Point B) and 9 (Point C) $\mathrm{m}^{3} / 100 \mathrm{~m}^{2}$ with the utilization rates of 10 and $20 \mathrm{~L} / \mathrm{min} / 100 \mathrm{~m}^{2}$, respectively. Utilization rates of as low as $5 \mathrm{~L} / \mathrm{min} / 100 \mathrm{~m}^{2}$ have a small effect on the outflow for a high rainfall events of 100-year frequency. 


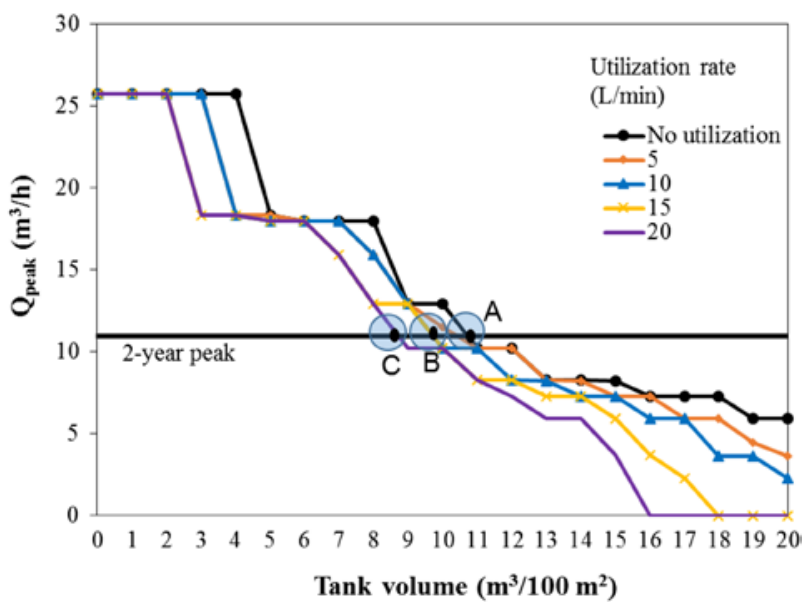

Figure 3.17 TP (Tank volume - Peak runoff) curves for R-S-U-D system (using 100-year design return period rainfall in Seoul, normalized for $100 \mathrm{~m}^{2}$ catchment area)

For other return period such as 50, 30, 10, 5, 2 year, the TP curves similar to Figure 3.17 can be generated. Based on the result, Table 3.4 compares the peak runoff of R-D and R-S-U-D systems, and peak reduction ratio. By installing a rainwater tank of $10 \mathrm{~m}^{3} / 100 \mathrm{~m}^{2}$ with a utilization rate of $10 \mathrm{~L} / \mathrm{min} / 100 \mathrm{~m}^{2}$, the sewer system can even be safer for a heavier rainfall of 100year return period. It is also found that the peak runoff can be reduced by $60.8-100 \%$ for a $10 \mathrm{~m}^{3} / 100 \mathrm{~m}^{2}$ rainwater tank and $10 \mathrm{~L} / \mathrm{min} / 100 \mathrm{~m}^{2}$ of utilization.

\subsubsection{TD (Tank volume - Design return period) curve}

Using similar procedures to make Figure 3.11 for R-S-D Model, TD curves for the R-S-U-D system can be generated as in Figure 3.18. In a sewer system designed for a 2-year return period of rainfall, if a rainwater tank of $9 \mathrm{~m}^{3} / 100 \mathrm{~m}^{2}$ (Point A) is installed, then the sewer system can stay safe even at the stronger rainfall of a 30-year return 
Hydrological design of multipurpose micro-catchment RWM 77

period with an R-S-D model (Point B). If the stored rainwater is utilized at the rates of 10 and $20 \mathrm{~L} / \mathrm{min} / 100 \mathrm{~m}^{2}$, the sewer system can maintain safety even with a higher return rainfall of 50-year and 100-year periods (Point C and Point D), respectively.

Table 3.4 Peak reduction effect of R-S-U-D system $\left(10 \mathrm{~m}^{3} / 100 \mathrm{~m}^{2}\right.$ of rainwater tank and $10 \mathrm{~L} / \mathrm{min} / 100 \mathrm{~m}^{2}$ of utilization).

\begin{tabular}{|c|c|c|c|c|c|}
\hline \multirow[t]{2}{*}{$\begin{array}{l}\text { Return } \\
\text { Period }\end{array}$} & \multicolumn{2}{|c|}{ R-D System } & \multicolumn{2}{|c|}{$\begin{array}{l}\text { R-S-U-D System } \\
\left(10 \mathrm{~m}^{3} / 100 \mathrm{~m}^{2} \text { and }\right. \\
\left.10 \mathrm{~L} / \mathrm{min} / 100 \mathrm{~m}^{2}\right)\end{array}$} & \multirow[t]{2}{*}{$\begin{array}{l}\text { Peak } \\
\text { Reduction } \\
\text { (\%) }\end{array}$} \\
\hline & $\begin{array}{l}Q_{\text {peak }} \\
\left(m^{3} / h\right)\end{array}$ & $Q_{\text {peak }} / Q_{\text {sewer }}$ & $\begin{array}{l}Q_{\text {peak }} \\
\left(m^{3} / h\right)\end{array}$ & $Q_{\text {peak }} / Q_{\text {sewer }}$ & \\
\hline 100 & 26.0 & 2.36 & 10.2 & 0.93 & 60.8 \\
\hline 50 & 23.4 & 2.13 & 9.0 & 0.82 & 61.5 \\
\hline 30 & 21.6 & 1.96 & 8.2 & 0.75 & 62.1 \\
\hline 10 & 17.7 & 1.61 & 3.9 & 0.35 & 78.0 \\
\hline 5 & 15.0 & 1.36 & 0 & 0.0 & 100 \\
\hline 2 & 11.0 & 1 & 0 & 0.0 & 100 \\
\hline
\end{tabular}

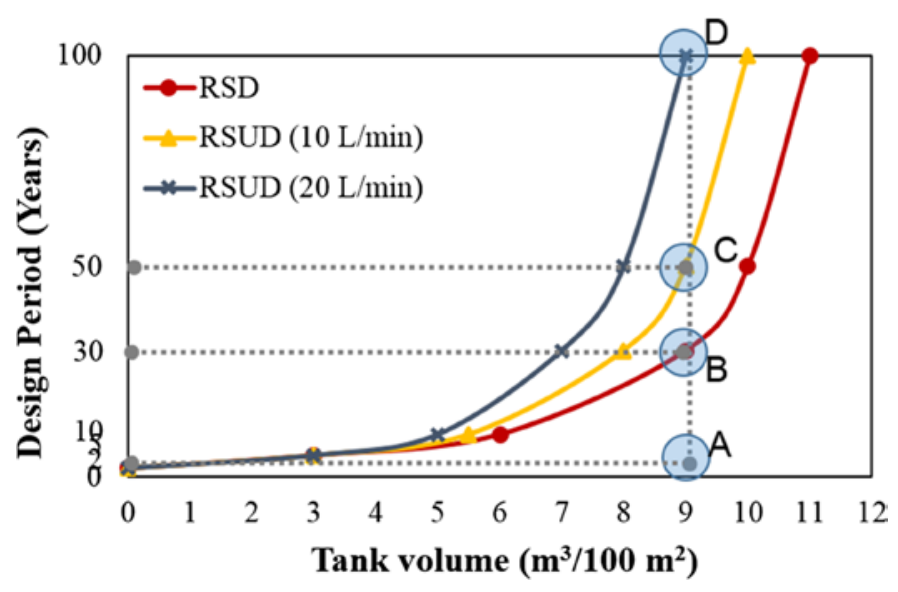

Figure 3.18 TD (Tank volume - Design period) curves for R-S-U-D system (using Seoul rainfall data and Huff method, normalized for $100 \mathrm{~m}^{2}$ catchment area). 
78 Hydrological Design of Multipurpose Micro-catchment RWM

\subsubsection{Rainwater utilization ratio}

R-S-U-D system contributes not only in flood mitigation, but also in water saving. Stored rainwater in the tank can be conserved and supplied to meet the water demand of the buildings. Rainwater utilization ratio (RUR) is defined as a ratio (\%) of yearly utilized rainwater volume to the total annual rainwater volume that falls on the roof.

Figure 3.19 shows the RUR (\%), which was calculated by the daily water balance simulation which will be discussed in detail in Chapter 4. This model considers Seoul daily rainfall conditions under different utilization rates in the case that the L.W.L is set at $25 \%$ of the total rainwater tank height. With a tank size of $5 \mathrm{~m}^{3} / 100 \mathrm{~m}^{2}$, the annual rainwater utilization ratio (RUR) of an R-S-U-D system is $71.6 \%$ (Point A) and $83.8 \%$ (Point B) $\left(100.3 \mathrm{~m}^{3}\right.$ and $117.3 \mathrm{~m}^{3}$ annual water saving per $100 \mathrm{~m}^{2}$ roof catchment area) with a utilization rate of 5 and $20 \mathrm{~L} / \mathrm{min} / 100 \mathrm{~m}^{2}$, respectively. The more the rainwater is conserved, the more the tap water is saved. In areas where freshwater resources are limited and sometimes seriously under threat, water conservation from widespread R-S-U-D systems is significantly needed.

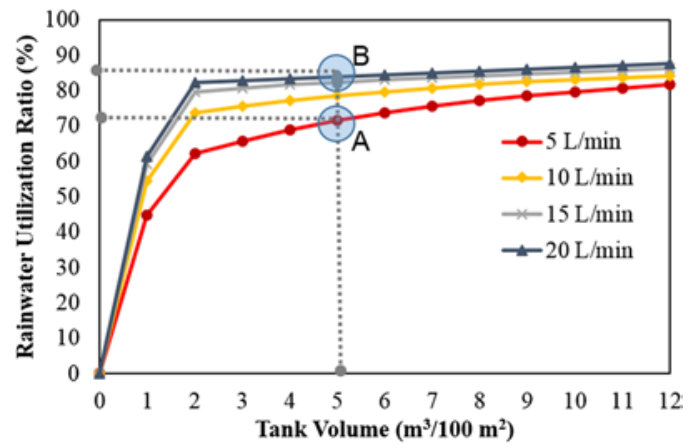

Figure 3.19 Rainwater utilization ratio for R-S-U-D system (using Seoul daily rainfall data, normalized for $100 \mathrm{~m}^{2}$ catchment area; L.W.L is set at $25 \%$ of the total rainwater tank height). 
Hydrological design of multipurpose micro-catchment RWM $\mathbf{7 9}$

\subsubsection{ES (Emergency Storage)}

An R-S-U-D system can also provide ES to save rainwater for using at emergency cases. The water volume stored below the L.W.L can be used for emergencies at any time. Depending on the needs of emergency, flood mitigation and water supply, the L.W.L can bet set accordingly by the designers or operators.

\subsection{RAINFALL-STORAGE-INFILTRATION- DISCHARGE (R-S-I-D) MODEL}

In some urban areas, groundwater is depleted because more groundwater is pumped out than infiltrated rainwater. After all the rainwater is drained away, the dried land cover will generate urban heat waves by reduced evaporative cooling effect. In this case, infiltration facilities can be installed as part of a RWM system for groundwater recharge. Timely infiltration of rainwater can also reduce the peak runoff flows. The Rainfall-StorageInfiltration-Discharge (R-S-I-D) model can be used for the design and analysis of the RWMS for flood control by installing both rainwater tank and infiltration box (Figure 3.20) (Nguyen, 2017). The infiltration component of the R-S-I-D system captures a portion of the runoff and allows it to percolate downward into the groundwater. Accordingly, the total rainwater runoff and peak flows will be reduced while groundwater is recharging.

To optimize the effect of the infiltration, the infiltration water level (outlet from rainwater tank to the infiltration box) should be set at the L.W.L. The amount of flow to the infiltration box can be controlled by a valve, which is always open and only closed when the maintenance of the infiltration box is needed. The water above the L.W.L. will slowly move to the infiltration box and percolated to the ground. Once the stored water level reaches the L.W.L, the water does not flow to the infiltration box. Therefore, the water volume stored below the L.W.L can be saved at any time and used for emergencies. 
Hydrological Design of Multipurpose Micro-catchment RWM

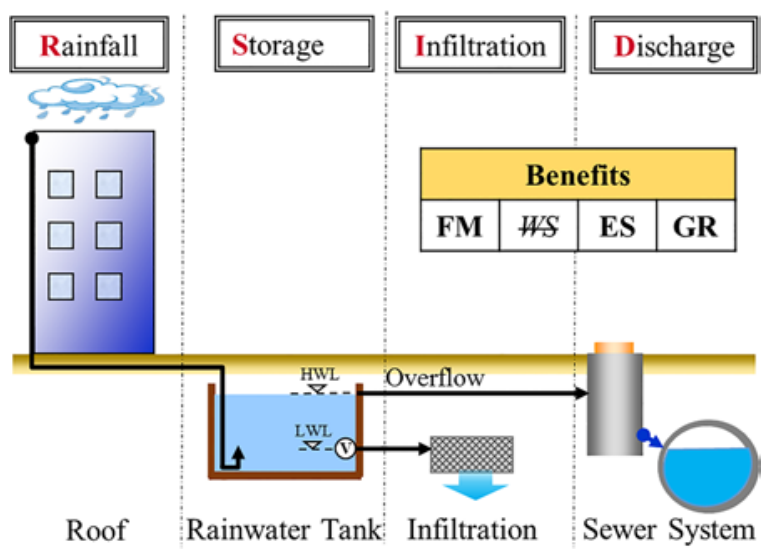

Figure 3.20 Rainfall-Storage-Infiltration-Discharge (R-S-I-D) system.

\subsubsection{Modeling of R-S-I-D system}

\subsubsection{Diagram}

The R-S-I-D system consists of a rooftop, downpipe, storage tank, infiltration box, low and high water levels and the overflow from the rainwater tank to the nearby sewer system (Figure 3.21). Figure 3.22 shows a typical polyethylene infiltration box $(0.5 \mathrm{~m}$ (Width) $\times 1.0 \mathrm{~m}$ (Length) $\times 0.4 \mathrm{~m}$ (Height), overall void ratio $=0.95)$. It can be wrapped with permeable sheet so that water can flow out, while soil particles are kept outside. One or more boxes can be connected each other depending on the required infiltration flowrate.

\subsubsection{Equations}

To simulate water flow in an R-S-I-D system, the water balance can be set up with respect to the conditions of rainwater tank and infiltration box (Figure 3.21). The water balance for the rainwater tank is described as follows:

$$
V_{t}=V_{t-1}+\left(Q_{\mathrm{in}, t}-Q_{I, t}-Q_{\mathrm{out}, t}\right) \Delta_{t}
$$


Hydrological design of multipurpose micro-catchment RWM 81

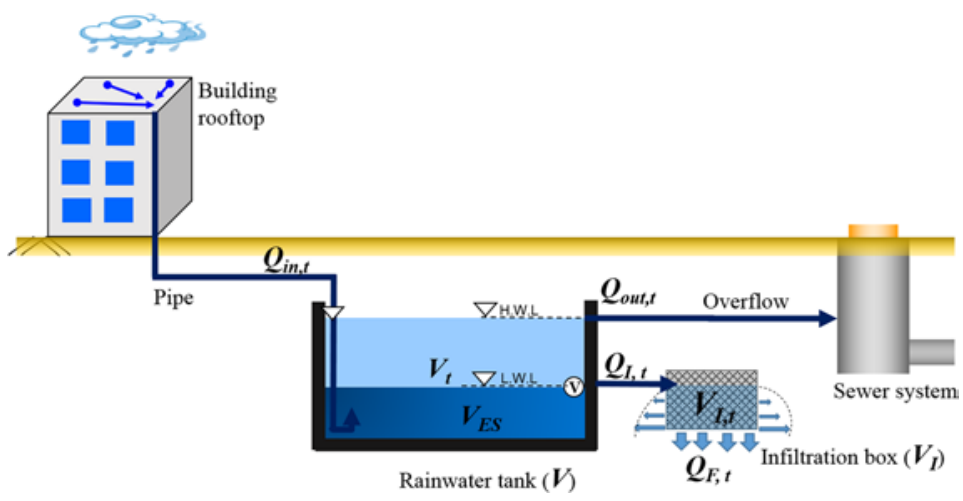

Figure 3.21 Notation and water flow of an R-S-I-D system.

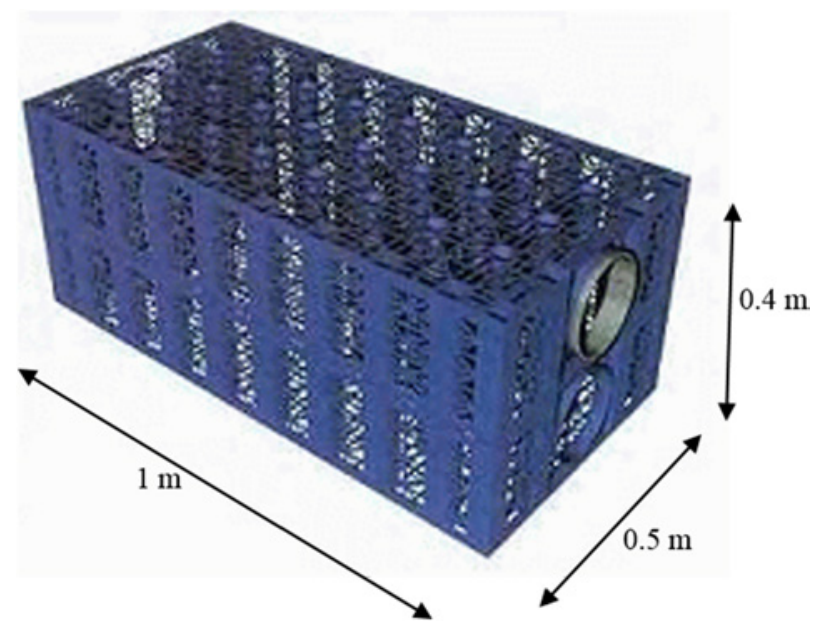

Figure 3.22 A typical infiltration box.

$Q_{I, t}$ is the inflow rate from the rainwater tank to the infiltration box $\left(\mathrm{m}^{3} / \mathrm{h}\right)$ at time $t$. In the system as shown in Figure 3.21, infiltration valve and pipe are designed so that $Q_{I, t}$ is controlled so that it is not larger than the infiltration rate. Therefore, $Q_{I, t}$ can 
be determined based on the water level in the rainwater tank with respect to the L.W.L and the water level in the infiltration box. It can be mathematically described as follows:

$$
\text { If } V_{t}<V_{\mathrm{ES}}, \quad Q_{I, t}=0
$$

$V_{\mathrm{ES}}$ is the water volume stored below the L.W.L $\left(\mathrm{m}^{3}\right)$

If $V_{t}=V_{\mathrm{ES}}$, rainwater in the tank flows to the infiltration box. The water balance in the infiltration box is described as follows:

$$
V_{I, t}=V_{I, t-1}+Q_{I, t} \Delta_{t}-Q_{F, t} \Delta_{t}
$$

$V_{I, t}$ is the volume of water remaining in the infiltration box $\left(\mathrm{m}^{3}\right)$ at time $t . V_{I, t-1}$ is the volume of water stored in the infiltration box $\left(\mathrm{m}^{3}\right)$ at time $t-1 . Q_{F, t}$ is the infiltration rate out from the infiltration box $\left(\mathrm{m}^{3} / \mathrm{h}\right)$. Several equations have been developed to estimate the infiltration rate depending on the soil properties, among which Horton's equation is used in this analysis. In this section, infiltration rate of $1 \mathrm{~L} / \mathrm{min}$ per one infiltration box is assumed as an example, which is reasonable for general soil condition. For different soil conditions, proper infiltration rate should be selected based on the field measurement of infiltration rate. Infiltration boxes are used in combination up to 20 units.

When the infiltration box is not full, the inflow rate to the infiltration box is the same as inflow rate to the rainwater tank.

$$
\text { If } V_{I, t} \leq V_{I}, \quad Q_{I, t}=\min \left(Q_{\mathrm{in}, t} ; Q_{\text {Infiltration }}\right)
$$

The infiltration rate is determined by the water remaining in the tank and the inflow quantity in the infiltration box.

$$
\begin{aligned}
& V_{I, t-1}+Q_{I, t} \Delta_{t}<Q_{\text {Infiltration }} \Delta_{t} \rightarrow Q_{F, t} \Delta_{t}=V_{I, t-1}+Q_{I, t} \Delta_{t} \\
& V_{I, t-1}+Q_{I, t} \Delta_{t} \geq Q_{\text {Infiltration }} \Delta_{t} \rightarrow Q_{F, t}=Q_{\text {Infiltration }}
\end{aligned}
$$

Or

$$
Q_{F, t} \Delta_{t}=\min \left(V_{I, t-1}+Q_{I, t} \Delta_{t} ; Q_{\text {Infiltration }} \Delta_{t}\right)
$$


Hydrological design of multipurpose micro-catchment RWM 83

$V_{I}$ is the volume of the infiltration box $\left(\mathrm{m}^{3}\right) . Q_{\text {Infiltration }}$ is the infiltration rate $\left(\mathrm{m}^{3} / \mathrm{h}\right)$.

If $V_{I, t}>V_{I}, \quad$ the infiltration is full

$Q_{I, t}=Q_{F, t}=Q_{\text {Infiltration }}$

$Q_{\text {out }, t}$ can be determined based on the water level in the rainwater tank with respect to the maximum water level.

If $V_{t}>V, \quad Q_{\text {out }, t} \Delta_{t}=V_{t-1}-V+\left(Q_{\mathrm{in}, t}-Q_{I, t}\right) \Delta_{t}$

$V$ is the volume of the rainwater tank $\left(\mathrm{m}^{3}\right)$.

\subsubsection{Flow chart}

The outflows from the rainwater tank under various conditions are calculated by the simulation based on the flow chart (Figure 3.23). The R-S-I-D model requires inputs of design parameters including runoff coefficient $(C)$, catchment area (A) $\left(\mathrm{m}^{2}\right)$, rainwater tank volume $(V)\left(\mathrm{m}^{3}\right)$, infiltration box volume $\left(V_{I}\right)\left(\mathrm{m}^{3}\right)$, emergency storage $\left(V_{\mathrm{ES}}\right)\left(\mathrm{m}^{3}\right)$, infiltration rate of the infiltration box $\left(Q_{\text {Infiltration }}\right)\left(\mathrm{m}^{3} / \mathrm{h}\right)$, and design rainfall $\left(i_{p, d, t}\right)(\mathrm{mm} / \mathrm{h})$. Outputs are the outflow presented by TP (Tank volume - Peak runoff) curves and TD (Tank volume - Design return period) curves, Groundwater Utilization Ratio (GRR) and Emergency Storage (ES).

\subsubsection{Results and discussion}

\subsubsection{TP (Tank volume - Peak runoff) curve}

If the rainwater tank is emptied slowly by percolating the stored rainwater for groundwater recharge, the runoff can be reduced, and flood mitigation capacity will increase. Figure 3.24 shows TP curves under different number of infiltration boxes for a 100-year design period in Seoul. In this figure, the 
84 Hydrological Design of Multipurpose Micro-catchment RWM

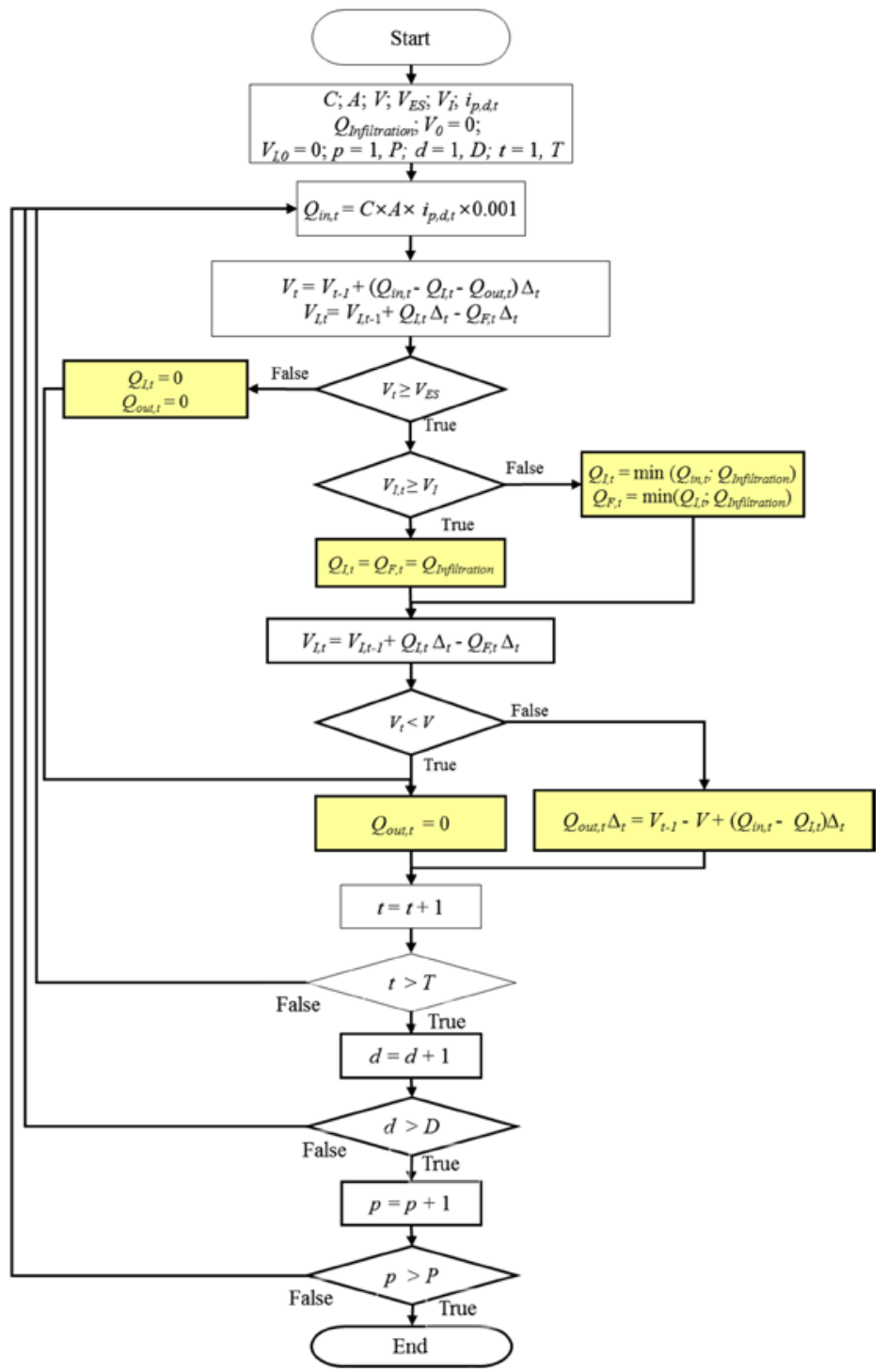

Figure 3.23 Flow chart figure for R-S-I-D model, $P$ (Design period), $D$ (Rainfall duration), $T$ (Simulation period). 
'No infiltration' line represents the R-S-D model. The larger the rainwater tank is, and the more infiltration box is used, the less will discharge flow be. The solid horizontal line represents the peak runoff flow $\left(11 \mathrm{~m}^{3} / \mathrm{h}\right)$ for the 2-year design rainfall. The minimum tank volume without infiltration to control a 100-year peak runoff for 2 years is $11 \mathrm{~m}^{3} / 100 \mathrm{~m}^{2}$ (Point A). The tank volume can be reduced to 9 (Point B), 8 (Point C), 6 (Point D) and 5 (Point E) $\mathrm{m}^{3} / 100 \mathrm{~m}^{2}$ with infiltration box numbers of 5, 10, 15 and 20 boxes, respectively.

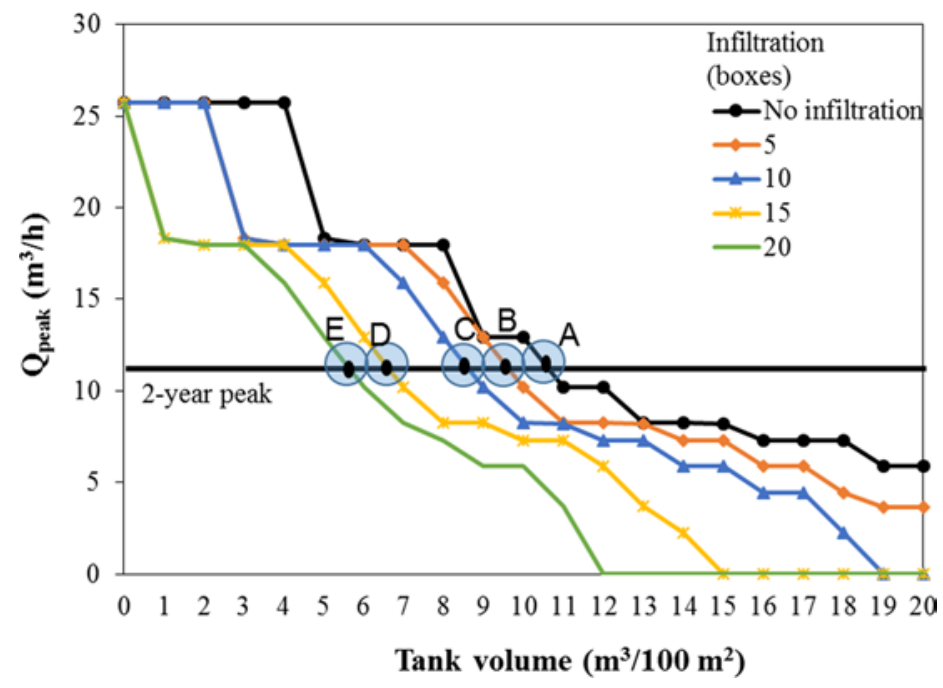

Figure 3.24 TP (Tank volume - Peak runoff) curves for R-S-I-D system (using 100-year design return period rainfall in Seoul, normalized for $100 \mathrm{~m}^{2}$ catchment area).

Table 3.5 shows the comparison between the peak runoff of R-D and R-S-I-D system, and peak reduction ratio. By installing a combination of rainwater tank of $10 \mathrm{~m}^{3} / 100 \mathrm{~m}^{2}$ and 10 infiltration boxes, the sewer system can be ensured for a heavier rainfall of 
86 Hydrological Design of Multipurpose Micro-catchment RWM 100 -year return period. It is also found that with the R-S-I-D system, the peak runoff can be reduced by $68.5-100 \%$ for a combination of $10 \mathrm{~m}^{3} / 100 \mathrm{~m}^{2}$ rainwater tank and 10 infiltration boxes.

Table 3.5 Peak reduction of R-S-I-D system $\left(10 \mathrm{~m}^{3} / 100 \mathrm{~m}^{2}\right.$ of rainwater tank and 10 boxes of infiltration).

\begin{tabular}{|c|c|c|c|c|c|}
\hline \multirow[t]{2}{*}{$\begin{array}{l}\text { Return } \\
\text { Period }\end{array}$} & \multicolumn{2}{|c|}{ R-D System } & \multicolumn{2}{|c|}{ 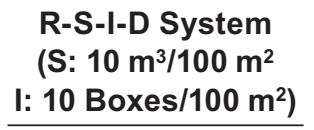 } & \multirow[t]{2}{*}{$\begin{array}{l}\text { Peak } \\
\text { Reduction } \\
(\%)\end{array}$} \\
\hline & $\begin{array}{l}Q_{\text {peak }} \\
\left(\mathrm{m}^{3} / \mathrm{h}\right)\end{array}$ & $Q_{\text {peak }} / Q_{\text {sewer }}$ & $\begin{array}{l}Q_{\text {peak }} \\
\left(\mathrm{m}^{3} / \mathrm{h}\right)\end{array}$ & $Q_{\text {peak }} / Q_{\text {sewer }}$ & \\
\hline 100 & 26.0 & 2.36 & 8.2 & 0.75 & 68.5 \\
\hline 50 & 23.4 & 2.13 & 6.5 & 0.59 & 72.2 \\
\hline 30 & 21.6 & 1.96 & 4.8 & 0.44 & 77.8 \\
\hline 10 & 17.7 & 1.61 & 0 & 0.0 & 100 \\
\hline 5 & 15.0 & 1.36 & 0 & 0.0 & 100 \\
\hline 2 & 11.0 & 1 & 0 & 0.0 & 100 \\
\hline
\end{tabular}

\subsubsection{TD (Tank volume - Design return period) curve}

Figure 3.25 shows TP (Tank volume - Design return period) curves. If a sewer system is designed for a 2-year return period rainfall, a rainwater tank of $9 \mathrm{~m}^{3} / 100 \mathrm{~m}^{2}$ (Point A) is required to control a 100-year return period rainfall. Similarly, the sewer system can be safe even with a smaller tank volume of $7 \mathrm{~m}^{3} / 100 \mathrm{~m}^{2}$ (Point B) or $3 \mathrm{~m}^{3} / 100 \mathrm{~m}^{2}$ (Point C) if 5 or 20 infiltration boxes are integrated, respectively.

\subsubsection{Groundwater recharge ratio}

R-S-I-D systems can contribute to both flood mitigation and groundwater recharge. Groundwater recharge ratio (GRR) is 
defined as the ratio of the total amount of water recharged to the ground to the total annual rainwater volume from the roof. Figure 3.26 shows the annual GRR from the R-S-I-D system in Seoul rainfall and assumed soil conditions and under different number of infiltration boxes. At the larger rainwater tank volume and higher infiltration volume, more groundwater will be recharged. With the rainwater tank volume of $5 \mathrm{~m}^{3}$, the annual GRR of an R-S-I-D system is $77 \%$ (Point A) and $88 \%$ (Point B) $\left(107.8 \mathrm{~m}^{3}\right.$ and $122.5 \mathrm{~m}^{3}$ annual groundwater recharge) with the infiltration box of 5 and 20 boxes, respectively.

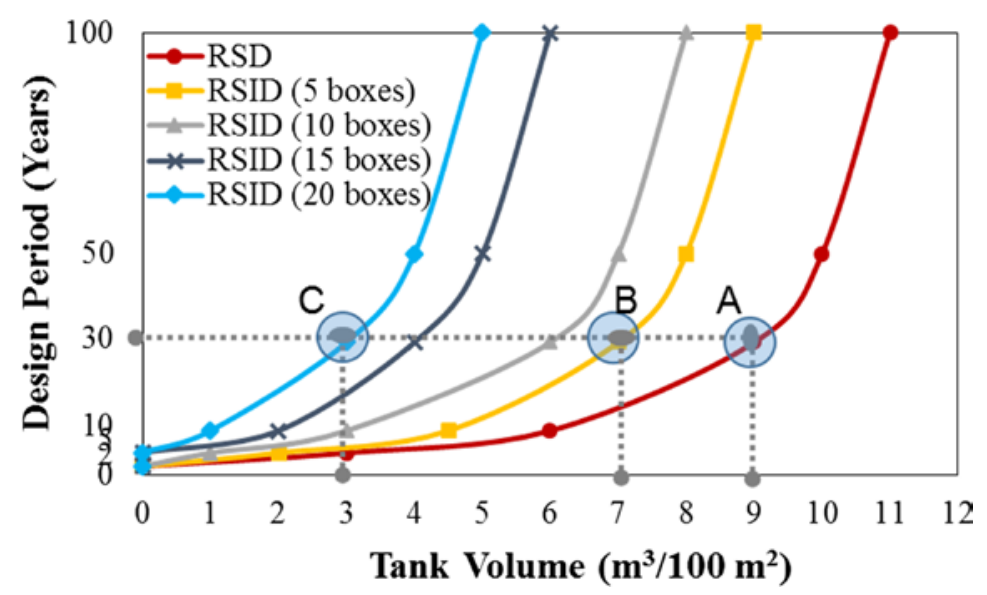

Figure 3.25 TD (Tank volume - Design period) curves for R-S-I-D system (using Seoul rainfall data and Huff method, normalized for $100 \mathrm{~m}^{2}$ catchment area).

\subsubsection{ES (Emergency Storage)}

Similar to previous systems, the R-S-I-D system can also provide ES to save rainwater for emergency cases. The water volume stored below the L.W.L can be used for emergency at any time. 


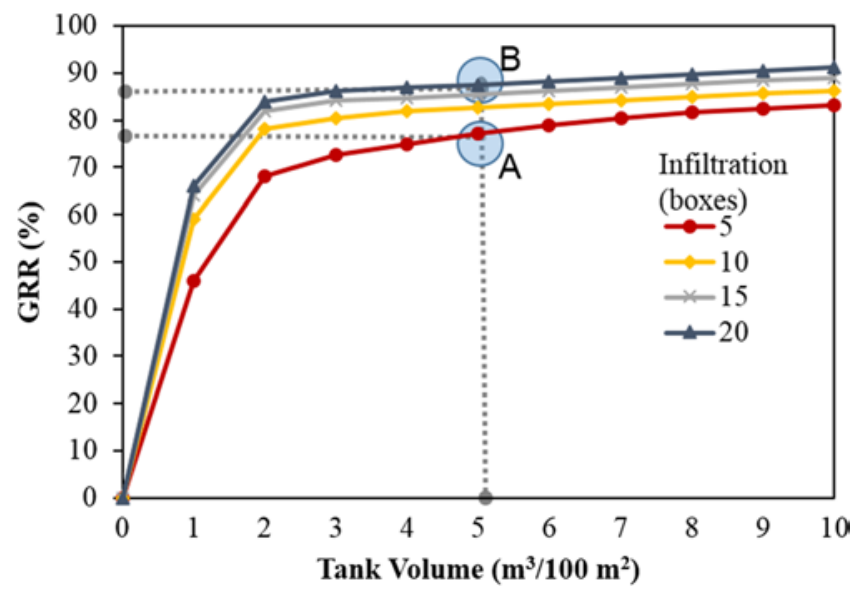

Figure 3.26 Groundwater Recharge Ratio for R-S-I-D system (using Seoul daily rainfall data, normalized for $100 \mathrm{~m}^{2}$ catchment area).

\subsection{RAINFALL-STORAGE-UTILIZATION- INFILTRATION-DISCHARGE (R-S-U-I-D) MODEL}

Figure 3.27 shows a scheme of an R-S-U-I-D system, which consists of rainwater tank, utilization pump, infiltration, and connection pipe to the nearby sewer system. The R-S-U-I-D model can be used for the analysis and design of RWMS with multiple benefit of flood mitigation, water saving, emergency storage and groundwater recharge (Nguyen, 2017).

When it rains, rainwater flows into the tank and water level increases until it reaches H.W.L., where overflow begins to discharge to the sewer. Stored rainwater is used for the domestic non-drinking purposes in the building until the water level reaches at L.W.L., after which utilization pump stops. The water volume stored below the L.W.L can be used for emergencies.

In this system, infiltration water level (I.W.L.) is introduced, which is the water level connected to the infiltration boxes through a control valve. When the water level is higher than 
I.W.L, infiltration occurs until the water level reaches at I.W.L, which can be set up at any level between L.W.L and H.W.L. The depth ratio $H(\%)$ is defined as the level difference between I.W.L and L.W.L. to the water depth between H.W.L and L.W.L.

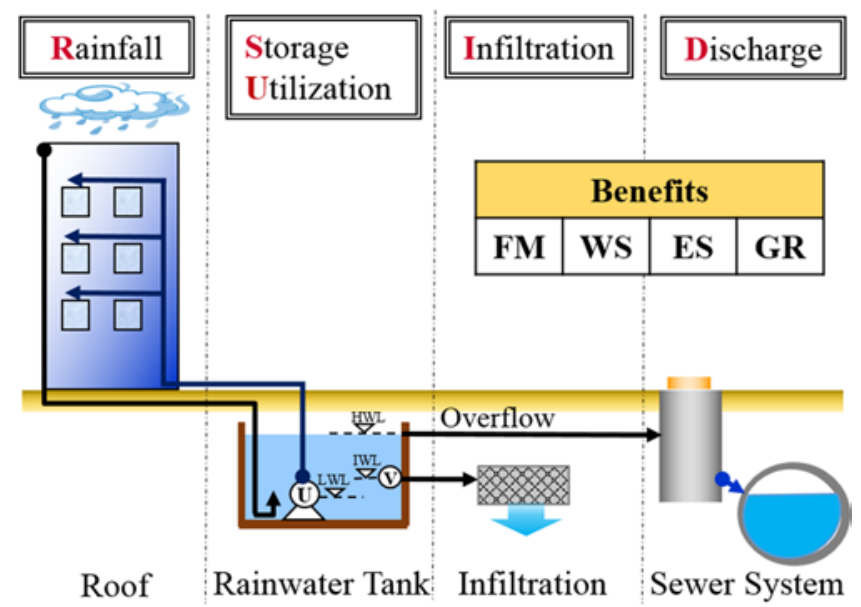

Figure 3.27 Rainfall-Storage-Utilization-Infiltration-Discharge (R-S-U-I-D) system.

\subsubsection{Modeling of R-S-U-I-D system}

\subsubsection{Diagram}

The R-S-U-I-D system consists of a rooftop, downpipe, rainwater tank, utilization pump, water supply facility, infiltration boxes, the low and high water levels and infiltration water level and the overflow from rainwater tank to the nearby sewer system (Figure 3.28).

\subsubsection{Equations}

To simulate water flow in an R-S-U-I-D system, the water balances can be set up around the rainwater tank and infiltration 
90 Hydrological Design of Multipurpose Micro-catchment RWM box (Figure 3.28). The water balance for the rainwater tank is described as follows:

$$
V_{t}=V_{t-1}+\left(Q_{\mathrm{in}, t}-Q_{\mathrm{sup}, t}-Q_{I, t}-Q_{\mathrm{out}, t}\right) \Delta t
$$

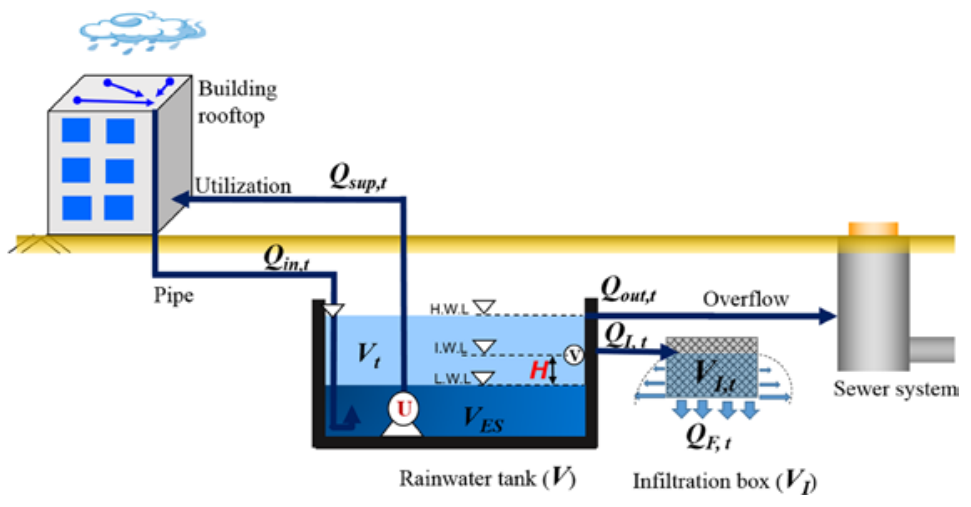

Figure 3.28 Notation and water flow of an R-S-U-I-D system.

$Q_{\mathrm{in}, t}$ is the inflow to the rainwater tank from the roof. $Q_{\text {sup }, t}$ is the water supply rate to the building from the rainwater tank $\left(\mathrm{m}^{3} / \mathrm{h}\right)$ at time $t . Q_{I, t}$ is the inflow rate from the rainwater tank to the infiltration box $\left(\mathrm{m}^{3} / \mathrm{h}\right)$ at time $t$. When the water level reaches at L.W.L., the pump stops.

If $V_{t}<V_{\mathrm{ES}}, \quad Q_{\text {sup }, t}=0$,

If $V_{t}>V_{\mathrm{ES}}$, the water supply is limited by the water remaining and inflow quantity in the tank.

$$
\begin{aligned}
& V_{t-1}-V_{\mathrm{ES}}+Q_{\mathrm{in}, t} \Delta_{t}-Q_{I, t} \Delta_{t}<Q_{\text {utilization }} \Delta_{t} \rightarrow Q_{\text {sup }, t} \Delta_{t} \\
& \quad=V_{t-1}-V_{\mathrm{ES}}+Q_{\mathrm{in}, t} \Delta_{t}-Q_{I, t} \Delta_{t} \\
& V_{t-1}-V_{\mathrm{ES}}+Q_{\mathrm{in}, t} \Delta_{t}-Q_{I, t} \Delta_{t} \geq Q_{\text {utilization }} \Delta_{t} \rightarrow Q_{\text {sup }, t}=Q_{\text {utilization }}
\end{aligned}
$$

$Q_{\text {uilization }}$ is the utilization rate $\left(\mathrm{m}^{3} / \mathrm{h}\right) . V_{\mathrm{ES}}$ is the water volume stored below the L.W.L $\left(\mathrm{m}^{3}\right)$. 
$Q_{\text {out }, t}$ is the discharge rate to the sewer, which can be determined based on the water level in the rainwater tanand rainwater inflow and utilization rate.

$$
\text { If } V_{t}>V, \quad Q_{\text {out }, t} \Delta t=V_{t-1}-V+\left(Q_{\text {in }, t}-Q_{\text {sup }, t}-Q_{I, t}\right) \Delta t
$$

$V$ is the volume of the rainwater tank $\left(\mathrm{m}^{3}\right)$.

$Q_{I, t}$ can be determined based on the I.W.L. and the water balance condition in the infiltration box.

If $V_{t} \leq H \times V+V_{\mathrm{ES}}$, then, $Q_{I, t}=0$,

If $V_{t}>H \times V+V_{\mathrm{ES}}$, rainwater flows to the infiltration box.

The water balance in the infiltration box is described as follows:

$$
V_{I, t}=V_{I, t-1}+Q_{I, t} \Delta_{t}-Q_{F, t} \Delta_{t}
$$

$V_{I, t}$ is the water remaining in the infiltration box $\left(\mathrm{m}^{3}\right)$ at time $t$. $V_{I, t-1}$ is the water remaining in the infiltration box $\left(\mathrm{m}^{3}\right)$ at time $t-1$. $Q_{F, t}$ is the infiltration rate from the infiltration box $\left(\mathrm{m}^{3} / \mathrm{h}\right)$.

When the infiltration box is not full, the inflow rate from the rainwater tank to the infiltration box $\left(Q_{I, t}\left(\mathrm{~m}^{3} / \mathrm{h}\right)\right)$ is equal to the inflow rate in the rainwater tank.

$$
\text { If } V_{I, t} \leq V_{I}, \quad Q_{I, t}=Q_{\text {in }, t}
$$

And the infiltration rate $\left(Q_{F, t}\left(\mathrm{~m}^{3} / \mathrm{h}\right)\right)$ is limited by the water remaining and the inflow quantity in the infiltration box.

$$
\begin{aligned}
& \text { If } V_{I, t} \leq V_{I}, \quad Q_{I, t}=Q_{\mathrm{in}, t} \\
& V_{I, t-1}+Q_{I, t} \Delta_{t}<Q_{\text {Infiltration }} \Delta_{t} \rightarrow Q_{F, t} \Delta_{t}=V_{I, t-1}+Q_{I, t} \Delta_{t} \\
& V_{I, t-1}+Q_{I, t} \Delta t \geq Q_{\text {Infiltration }} \Delta t \rightarrow Q_{F, t}=Q_{\text {Infiltration }} \\
& \text { Or } \\
& Q_{F, t} \Delta t=\min \left(V_{I, t-1}+Q_{I, t} \Delta t ; Q_{\text {Infiltration }} \Delta t\right)
\end{aligned}
$$


92 Hydrological Design of Multipurpose Micro-catchment RWM

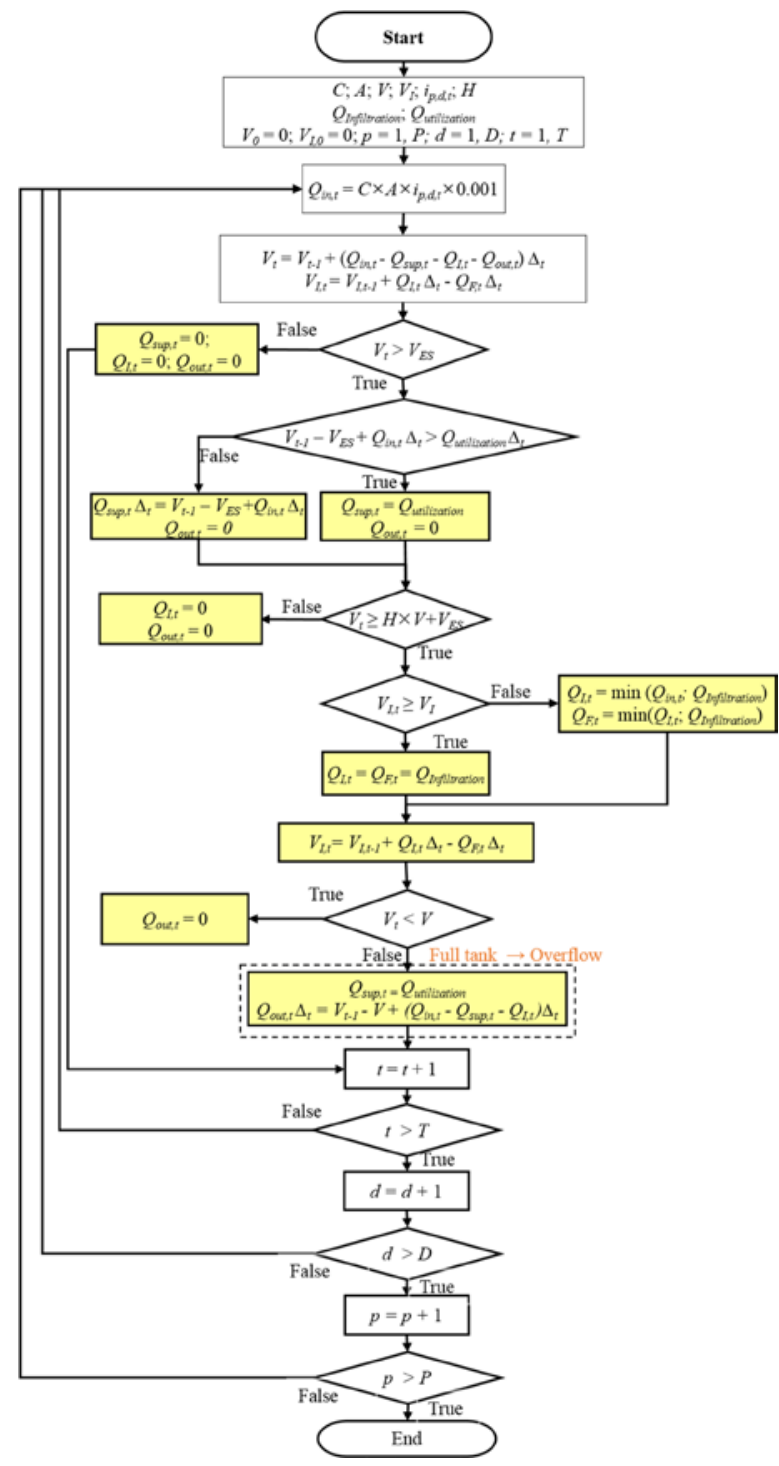

Figure 3.29 Flow chart figure, $P$ (Design period), $D$ (Rainfall duration), $T$ (Simulation period). 
Hydrological design of multipurpose micro-catchment RWM 93

If $V_{I, t}>V_{I}, \quad$ the infiltration is full.

$Q_{I, t}=Q_{F, t}=Q_{\text {Infiltration }}$

$V_{I}$ is the volume of the infiltration box $\left(\mathrm{m}^{3}\right) . Q_{\text {Infiltration }}$ is the infiltration rate $\left(\mathrm{m}^{3} / \mathrm{h}\right)$.

\subsubsection{Flow chart}

The outflow from the R-S-U-I-D system under various conditions is calculated by simulations based on the flow chart shown in Figure 3.29. The R-S-U-I-D model requires inputs of design parameters including design rainfall $\left(i_{p, d, t}\right)(\mathrm{mm} / \mathrm{h})$, runoff coefficient $(C)$, catchment area $(A)\left(\mathrm{m}^{2}\right)$, rainwater tank volume $(V)\left(\mathrm{m}^{3}\right)$, utilization rate $\left(Q_{\text {utilization }}\right)\left(\mathrm{m}^{3} / \mathrm{h}\right)$, infiltration box volume $\left(V_{I}\right)\left(\mathrm{m}^{3}\right)$, emergency storage $\left(V_{\mathrm{ES}}\right)\left(\mathrm{m}^{3}\right)$ and infiltration rate of the infiltration box $\left(Q_{\text {Infiltration }}\right)\left(\mathrm{m}^{3} / \mathrm{h}\right)$. Outputs are the outflow presented by TP (Tank volume - Peak runoff) curves and TD (Tank volume - Design return period) curves, Rainwater Utilization Ratio (RUR), Groundwater Recharge Ratio (GRR), and Emergency Storage (ES).

\subsubsection{Results and discussion}

\subsubsection{TP (Tank volume - Peak runoff) curve}

If the stored water is emptied by both utilization and infiltration, the runoff can be further reduced, which can contribute more to flood mitigation. Figure 3.30 shows TP curves for the utilization of $5 \mathrm{~L} / \mathrm{min} / 100 \mathrm{~m}^{2}$ plus different numbers of infiltration boxes for a 100-year design return period in Seoul (case of $V_{\mathrm{ES}}=H=25 \%$ $V)$. As shown in Figure 3.34, when the tank volume becomes larger and the number of infiltration boxes increases, peak flow will be reduced. The solid horizontal line represents the peak runoff flow $\left(11 \mathrm{~m}^{3} / \mathrm{h}\right)$ for the 2 -year design rainfall. The minimum tank volume to control a 100-year peak runoff for 2 years without infiltration is $11 \mathrm{~m}^{3} / 100 \mathrm{~m}^{2}$ (Point A). However, the tank volume 
94 Hydrological Design of Multipurpose Micro-catchment RWM can be reduced to 9 (Point B), 7 (Point C), 6 (Point D) and 5 (Point E) $\mathrm{m}^{3} / 100 \mathrm{~m}^{2}$ when infiltration numbers of 5, 10, 15 and 20 boxes are installed, respectively.

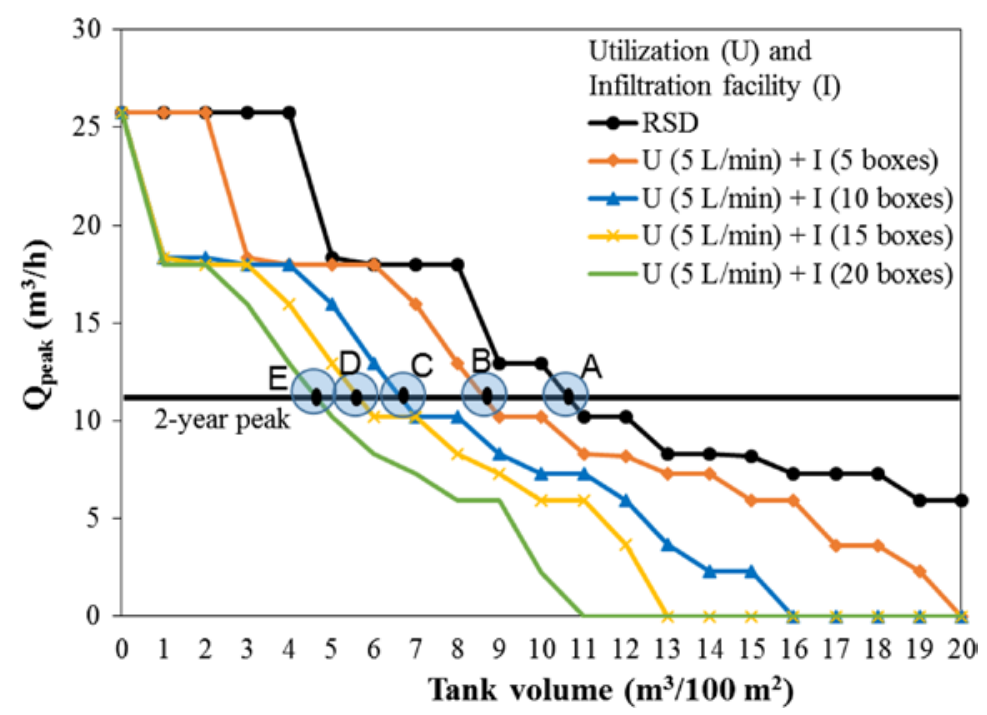

Figure 3.30 TP (Tank volume - Peak runoff) curves for R-S-U-I-D system (using 100-year design return period rainfall in Seoul, normalized for $100 \mathrm{~m}^{2}$ catchment area, $V_{\mathrm{ES}}=H=25 \% \mathrm{~V}$ ).

Table 3.6 shows the comparison of peak runoff of R-D and R-S-U-I-D systems, and peak reduction ratio. By installing a combination of rainwater tank of $10 \mathrm{~m}^{3} / 100 \mathrm{~m}^{2}$ and $5 \mathrm{~L} /$ $\mathrm{min} / 100 \mathrm{~m}^{2}$ utilization and 10 boxes of unit infiltration, the sewer system can resist even a heavier rainfall of 100-year return period. It is also found that with the R-S-U-I-D system, the peak runoff can be reduced by $71.9-100 \%$ for a combination of $10 \mathrm{~m}^{3} / 100 \mathrm{~m}^{2}$ rainwater tank and 10 boxes of the unit infiltration. 
Hydrological design of multipurpose micro-catchment RWM 95

Table 3.6 Peak reduction of R-S-U-I-D system $\left(10 \mathrm{~m}^{3} / 100 \mathrm{~m}^{2}\right.$ of rainwater tank with $5 \mathrm{~L} / \mathrm{min} / 100 \mathrm{~m}^{2}$ utilization and 10 boxes of infiltration, $V_{E S}=H=25 \% V$ ).

\begin{tabular}{|c|c|c|c|c|c|}
\hline \multirow[t]{2}{*}{$\begin{array}{l}\text { Return } \\
\text { Period }\end{array}$} & \multicolumn{2}{|c|}{ R-D System } & \multicolumn{2}{|c|}{$\begin{array}{l}\text { R-S-U-I-D System } \\
\text { (S: } 10 \mathrm{~m}^{3} / 100 \mathrm{~m}^{2} \\
\text { U: } 5 \mathrm{~L} / \mathrm{min} / 100 \mathrm{~m}^{2} ; \\
\left.\text { I: } 10 \text { Boxes } / 100 \mathrm{~m}^{2}\right)\end{array}$} & \multirow[t]{2}{*}{$\begin{array}{l}\text { Peak } \\
\text { Reduction } \\
\text { (\%) }\end{array}$} \\
\hline & $\begin{array}{l}Q_{\text {peak }} \\
\left(\mathrm{m}^{3} / \mathrm{h}\right)\end{array}$ & $Q_{\text {peak }} / Q_{\text {sewer }}$ & $\begin{array}{l}Q_{\text {peak }} \\
\left(\mathrm{m}^{3} / \mathrm{h}\right)\end{array}$ & $Q_{\text {peak }} / Q_{\text {sewer }}$ & \\
\hline 100 & 26.0 & 2.36 & 7.3 & 0.66 & 71.9 \\
\hline 50 & 23.4 & 2.13 & 5.6 & 0.51 & 76.1 \\
\hline 30 & 21.6 & 1.96 & 3.9 & 0.35 & 81.9 \\
\hline 10 & 17.7 & 1.61 & 0 & 0.0 & 100 \\
\hline 5 & 15.0 & 1.36 & 0 & 0.0 & 100 \\
\hline 2 & 11.0 & 1 & 0 & 0.0 & 100 \\
\hline
\end{tabular}

\subsubsection{TD (Tank volume - Design period) curves}

Figure 3.31 shows TD curves for the R-S-U-I-D system. If a rainwater tank with $5 \mathrm{~m}^{3} / 100 \mathrm{~m}^{2}$ volume of an R-S-D system (Point A) is installed, the sewer system can remain safe for a 7 -year return period of rainfall. Moreover, the sewer system can even sustain the stronger rainfall of 20 (Point B), 30 (Point C), 50 (Point D) or 100 (Point E)-year return periods if the stored rainwater is designed to be utilized at the rate of $5 \mathrm{~L} / \mathrm{min} / 100 \mathrm{~m}^{2}$ and integrated with infiltration of $5,10,15$ or 20 boxes, respectively.

\subsubsection{Rainwater utilization ratio and groundwater recharge ratio}

An R-S-U-I-D system can greatly contribute to not only the flood mitigation, but also to water conservation and groundwater recharge. Figure 3.32 shows the annual rainwater utilization 
96 Hydrological Design of Multipurpose Micro-catchment RWM

ratio and groundwater recharge ratio for the R-S-U-I-D system under different infiltration water level (I.W.L.) for the case of 5 infiltration boxes and utilization rate of $5 \mathrm{~L} / \mathrm{min} / 100 \mathrm{~m}^{2}$. The higher the I.W.L. is (i.e., higher values of $H$ ), more water savings and reduced groundwater recharge are expected. Similarly, the larger the tank size is, the more water saving and the less groundwater recharge is expected. With a rainwater tank size of $5 \mathrm{~m}^{3} / 100 \mathrm{~m}^{2}$ and $H$ is $25 \%$, the annual rainwater utilization ratio(RUR) and groundwater recharge ratio (GRR) of an R-S-U-I-D system are $61.0 \%$ and $21.7 \%\left(85.4 \mathrm{~m}^{3}\right.$ and $30.4 \mathrm{~m}^{3}$ ), respectively. When the I.W.L. is the same as L.W.L. $(H=0 \%)$, the water supply becomes zero and the R-S-U-I-D system works as an R-S-I-D system. Meanwhile, when the I.W.L is the same as H.W.L. $(H=75 \%)$, groundwater recharge becomes zero and thus, the R-S-U-I-D system works as an R-S-U-D system alone.

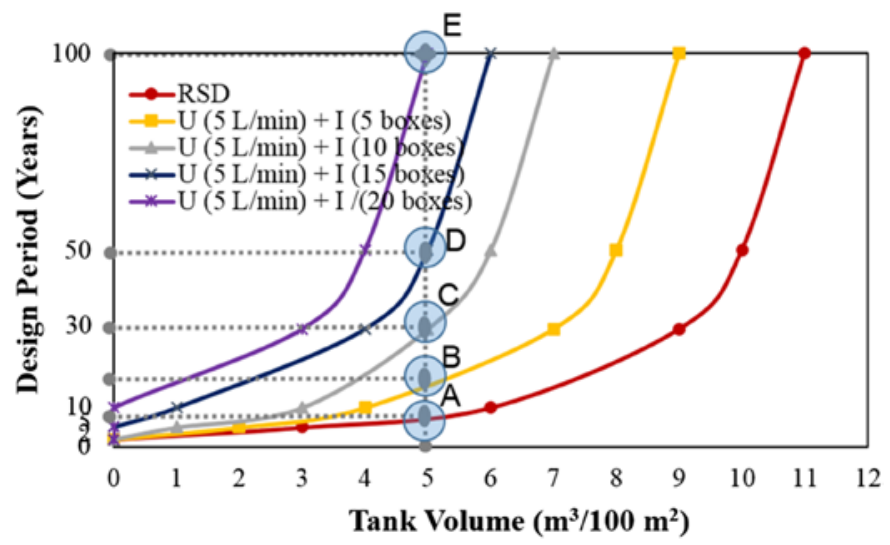

Figure 3.31 TD (Tank volume - Design period) curves for R-S-U-I-D system (using 100-year design return period rainfall in Seoul, normalized for $100 \mathrm{~m} 2$ catchment area, Utilization ratio $=5 \mathrm{~L} / \mathrm{min} / 100 \mathrm{~m}^{2}, V_{\mathrm{ES}}=$ $H=25 \% V)$. 
Hydrological design of multipurpose micro-catchment RWM 97

(a)

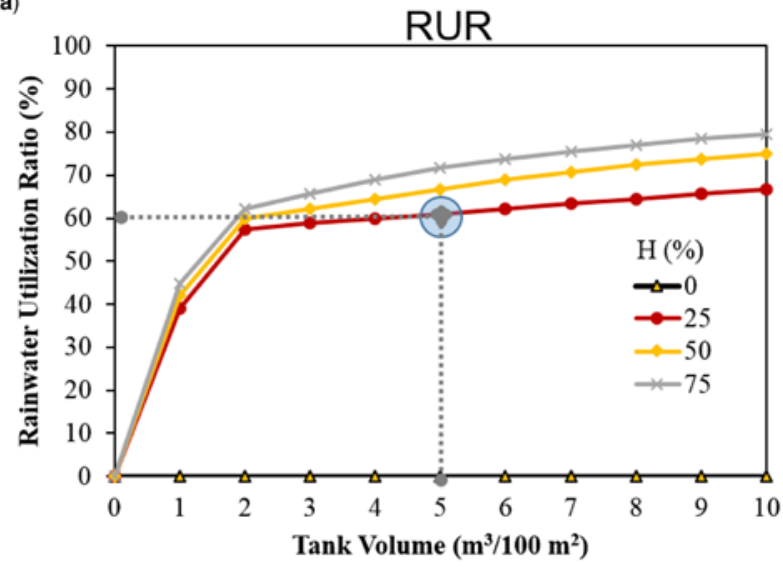

(b)

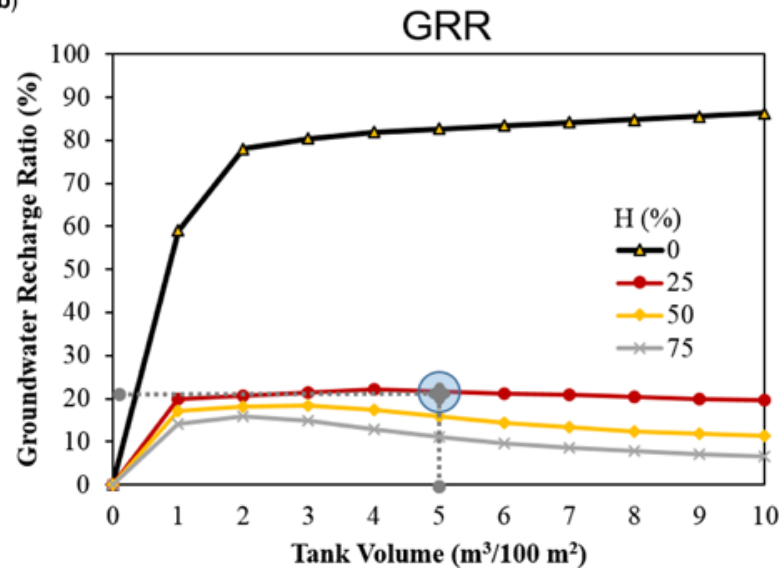

Figure 3.32 (a) RUR and (b) GRR for R-S-U-I-D system (Utilization rate = $5 \mathrm{~L} / \mathrm{min}$ and 5 infiltration boxes) for different infiltration positions.

\subsubsection{ES (Emergency Storage)}

Similar to previous systems, the R-S-U-I-D system can provide ES to save rainwater for emergency cases. The water volume stored below the L.W.L can be used for emergencies at any time. 
98 Hydrological Design of Multipurpose Micro-catchment RWM

\subsection{DESIGN EXAMPLE OF RWMS FOR SEOUL CITY, KOREA}

Based on the development of different RWM models introduced in this chapter, we wish to design and analyze different models for the case of Seoul city with a building rooftop of $2000 \mathrm{~m}^{2}$ and to compare the results among different models. The detailed procedure, calculation method and the results are shown and discussed.

\subsubsection{Design procedure}

Figure 3.33 shows step by step procedure for hydrological design of different RWMs: First find input design rainfall (i), and then find runoff flow $(Q)$ from building rooftop, and finally find discharge flow $(D)$ to the sewer system depending on the choice of RWMS

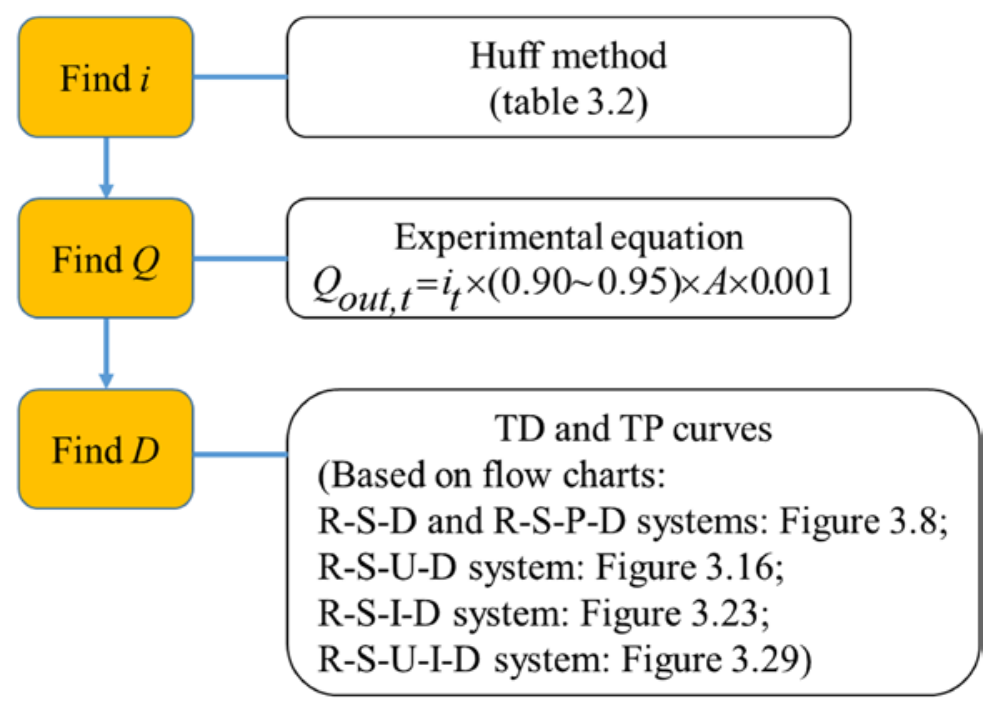

Figure 3.33 Produce of hydrological design of RWMS. 
The design rainfall hyetograph (i) can be constructed by using Huff method and local rainfall conditions following the instruction in Chapter 2 which is summarized in table 3.2.

The runoff $(Q)$ from building rooftop can be estimated using the experimental formula (Kim et al. 2009):

$$
Q_{\text {out }, t}=i_{t} \times(0.90 \sim 0.95) \times A \times 0.001
$$

$Q_{\text {out }, t}$ is the runoff from building rooftop catchment area $\left(\mathrm{m}^{3} / \mathrm{h}\right)$ at time $t . A$ is the catchment area $\left(\mathrm{m}^{2}\right) .0 .90-0.95$ is the runoff coefficient. $i_{t}$ is the rainfall intensity $(\mathrm{mm} / \mathrm{h})$ at time $t$.

Discharge flow $(D)$ to sewer system from RWMS can be calculated using the modeling methods for each design option which are summarized in flow chart figures (R-S-D and R-S-P-D systems: Figure 3.8; R-S-U-D system: Figure 3.16; R-S-I-D system: Figure 3.23; and R-S-U-I-D system: Figure 3.29). The results and discharge flow can be presented in TP (Tank volumePeak discharge) and TD (Tank volume-Design period) curves.

\subsubsection{Example calculation}

The first step is to develop normalized hydrological graphs for a unit area of $100 \mathrm{~m}^{2}$ using normalized input design parameters. And then in the second step, the results are multiplied by the ratio $(R a)$ of the actual catchment area to the unit catchment area. The normalized input design parameters are shown in Table 3.7.

Using input design parameters in Table 3.7 and following the procedures of hydrological design of RWMS, the TP and TD curves normalized for $100 \mathrm{~m}^{2}$ can be calculated. As the second step, the result are multiplied by the area ratio $R a$ $\left(R a=2000 \mathrm{~m}^{2} / 100 \mathrm{~m}^{2}=20\right)$. Table 3.8 shows the actual design parameters for a building of $2000 \mathrm{~m}^{2}(R a=20)$.

Figures 3.34 and 3.35 show the TP and TD curves for different RWM models for the 100-year design return period rainfall in Seoul, respectively. As shown in the figures, the required tank 
100 Hydrological Design of Multipurpose Micro-catchment RWM volume to control a rainfall of 30-year return period are 180, 180, 160, 120, and $100 \mathrm{~m}^{3}$ for R-S-D, R-S-P-D, R-S-U-D, R-S-I-D, and R-S-U-I-D systems, respectively.

Table 3.7 Normalized design parameters for a building rooftop of $100 \mathrm{~m}^{2}$ in Seoul.

\begin{tabular}{|c|c|c|}
\hline Region & & Seoul City, South Korea \\
\hline Rainfall & & Huff method \\
\hline $\begin{array}{l}\text { Existing sewer } \\
\text { system }\left(Q_{\text {Sewer }}\right)\end{array}$ & & $\begin{array}{l}\text { Sewer system is designed for } \\
\text { 2-year return period }\left(11 \mathrm{~m}^{3} / \mathrm{h}\right)\end{array}$ \\
\hline Design return period & & $2,5,10,30,50,100$ years \\
\hline Catchment area & & $100 \mathrm{~m}^{2}$ \\
\hline Tank size & & $0-20 \mathrm{~m}^{3}$ \\
\hline Utilization pump & & 0-20 L/ min; Standard $10 \mathrm{~L} / \mathrm{min}$ \\
\hline \multirow[t]{2}{*}{ Infiltration } & Types & $\begin{array}{l}\text { Unit volume: } 0.2 \mathrm{~m}^{3} ; \text { Unit } \\
\text { infiltration rate: } 1 \mathrm{~L} / \mathrm{min}\end{array}$ \\
\hline & Boxes & $0-10$ boxes \\
\hline
\end{tabular}

Table 3.8 Actual design parameters for a building rooftop of $2000 \mathrm{~m}^{2}$ in Seoul.

\begin{tabular}{|c|c|c|}
\hline Region & & Seoul City, South Korea \\
\hline Rainfall & & Huff method (same) \\
\hline $\begin{array}{l}\text { Existing sewer system } \\
\left(Q_{\text {Sewer }}\right)(\times R a)\end{array}$ & & $220 \mathrm{~m}^{3} / \mathrm{h}$ \\
\hline Design return period & & $2,5,10,30,50,100$ years \\
\hline Catchment area $(\times R a)$ & & $2000 \mathrm{~m}^{2}$ \\
\hline Tank size $(\times R a)$ & & $0-400 \mathrm{~m}^{3}$ \\
\hline Utilization pump $(\times R a)$ & & $\begin{array}{l}\text { 0-400 L/ min; Standard } \\
200 \mathrm{~L} / \mathrm{min}\end{array}$ \\
\hline \multirow[t]{2}{*}{ Infiltration } & Types & $\begin{array}{l}\text { Unit volume: } 0.2 \mathrm{~m}^{3} \text {; Unit } \\
\text { infiltration rate: } 1 \mathrm{~L} / \mathrm{min}\end{array}$ \\
\hline & Boxes $(\times R a)$ & $0-200$ boxes \\
\hline
\end{tabular}


Hydrological design of multipurpose micro-catchment RWM 101

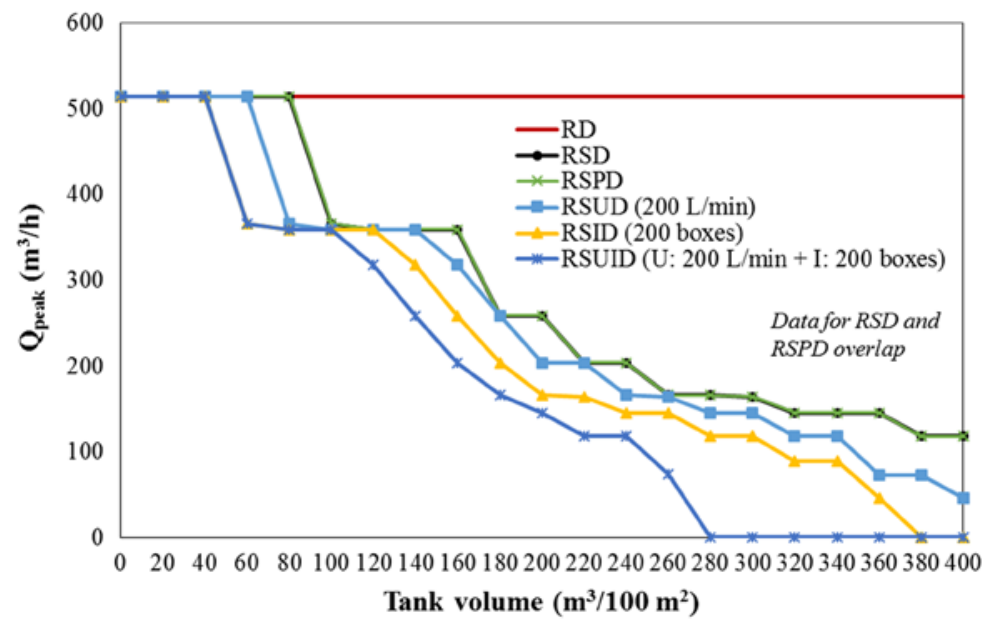

Figure 3.34 TP (Tank volume - Peak runoff) curves for various RWMSs (using 100-year design return period rainfall in Seoul).

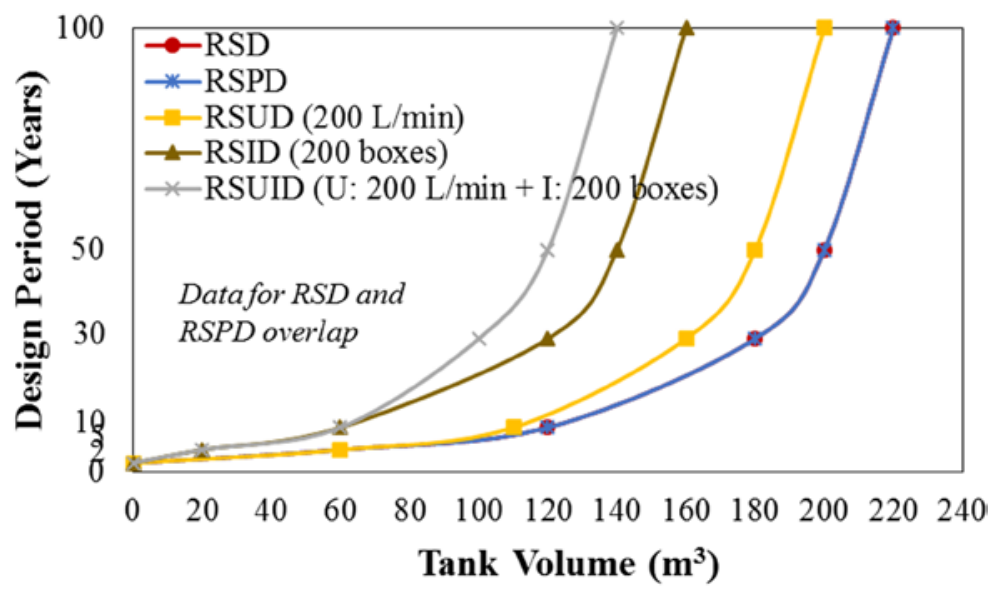

Figure 3.35 TD (Tank volume - Design period) curves for various RWMSs (using Seoul rainfall data and Huff method). 
102 Hydrological Design of Multipurpose Micro-catchment RWM

In addition, the total annual water conservation and groundwater recharge in R-S-U-D, R-S-I-D, and R-S-U-I-D systems can be calculated. Furthermore, all of these systems can also save water for emergencies, which is presented by ES (Emergency Storage). The multipurpose effects of different RWM models are comparatively demonstrated in Figure 3.35. Table 3.9 shows the extra benefits of each RWMS when the rainwater tank is designed as $180 \mathrm{~m}^{3}$.

Table 3.9 Extra benefits for each RWMS option (Area $=2000 \mathrm{~m}^{2}$, $V=180 \mathrm{~m}^{3}$, total yearly rainfall $=2800 \mathrm{~m}^{3}$ ).

\begin{tabular}{llccc}
\hline Models & $\begin{array}{l}\text { Peak Runoff Reduction Ratio } \\
\text { (\%) (For Rainfall of 100-y } \\
\text { Return Period) }\end{array}$ & $\begin{array}{l}\text { RUR } \\
(\%)\end{array}$ & $\begin{array}{l}\text { GRR } \\
(\%)\end{array}$ & $\begin{array}{l}\text { ES } \\
\left(\mathbf{m}^{3}\right)\end{array}$ \\
\hline RD & 0 & 0 & 0 & 0 \\
RSD & 49.6 & 0 & 0 & 45 \\
RSPD & 49.6 & 0 & 0 & 45 \\
RSUD & 50.1 & 82.1 & 0 & 45 \\
RSID & 60.6 & 0 & 85.7 & 45 \\
RSUID & 67.8 & 72.9 & 12.4 & 45 \\
\hline
\end{tabular}

\subsection{SUMMARY}

Due to climate change and surface change as the result of urbanization, it is expected that urban flooding will become more and more rampant. Therefore, design engineers and city planners all over the world might have several common questions as follows:

- What is the optimum size of rainwater tank at certain area for flood mitigation?

- How can a small rainwater tank reduce urban flooding?

- How to increase the resilience of sewer system without investing in much cost and time? 
- Are multipurpose RWMSs economically feasible compared to other conventional rainwater management systems?

- What would be the suitable rainwater tank volume to prevent flooding at a higher design return period rainfall?

- If we utilize the stored water or discharge rainwater by pumping out in advance, or install infiltration facilities and/or in combination, how much tank volume would be reduced?

- How much water would be saved in a year, how much water can be stored for emergency and how much water will be infiltrated to the ground?

- How can you monitor and encourage the participation of stake holders in the design and operation of many rainwater tanks?

In this chapter, six micro-catchment rainwater management (RWM) models are developed to give the answers to those above questions, which can quantitatively predict the multiple benefit of flood mitigation (FM), water saving (WS), emergency storage (ES) and groundwater recharge (GR) as shown in Figure 3.36. They can be used to calculate the peak runoff reduction when different combination of controllable and non-controllable measures are included. Moreover, they also provide a logical way to determine how to increase the resilience of sewer system without increasing the capacity of it.

All the logics and methodologies are taken from the already established hydrologic theory, with the only exception that the catchment area for RWM models is much smaller $\left(<2000 \mathrm{~m}^{2}\right)$ than that is assumed in the conventional hydrology models. Also, while the main concern of conventional hydrology is flood mitigation (FM) only, RWM models pursue multiple benefits. Due to unpredictable extreme weather events made by climate change, it will be more relevant to consider both flooding and drought in order to design hydraulic infrastructures more economically and wisely. 
104 Hydrological Design of Multipurpose Micro-catchment RWM

\section{R-D Model}

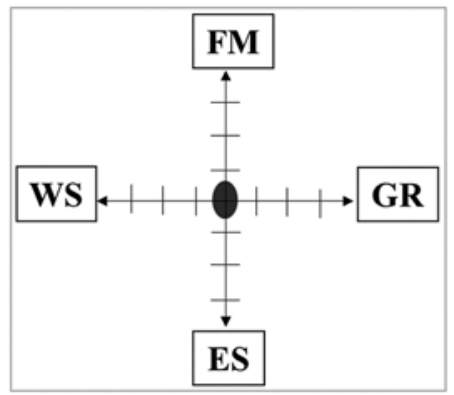

R-S-P-D Model

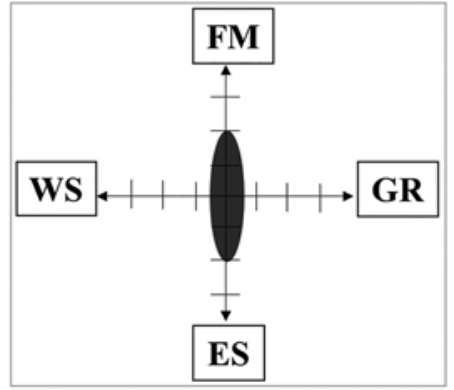

\section{R-S-I-D Model}

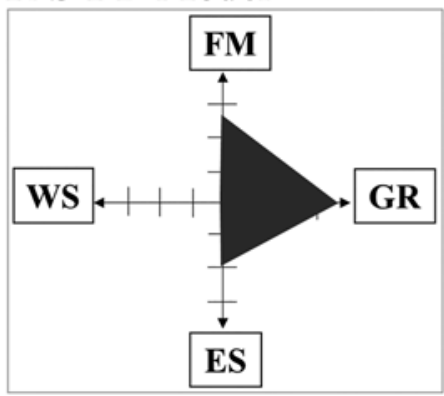

R-S-D Model

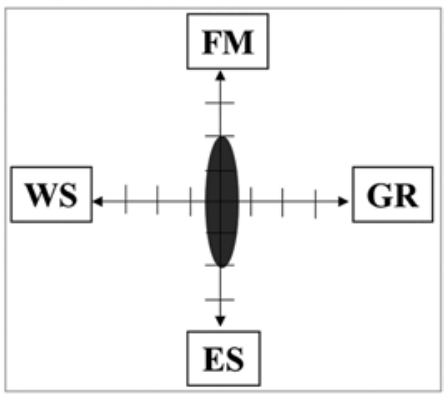

R-S-U-D Model

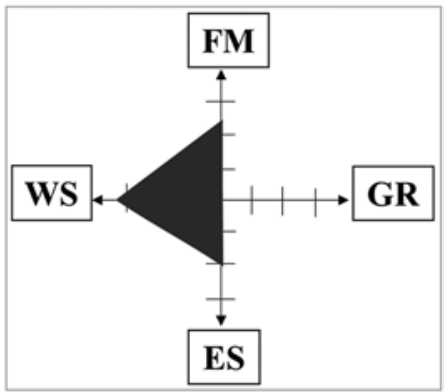

R-S-U-I-D Model

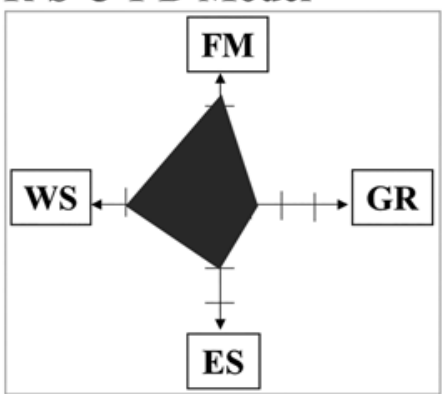

Figure 3.36 Comparison of multipurpose effects of different RWM models. (FM: flood mitigation, WS: water saving, ES: emergency storage, GR: groundwater recharge). 
The theoretical basis of various RWM models is R-D model which is the traditional way of rainwater management. In R-D model, the main goal is to drain rainwater as fast as possible and the sewer system is designed according to the peak runoff predicted by one of the currently available site-specific hydrological models. RWM models in this chapter used the same theories of rainfall modeling $(i)$ and runoff modeling $(Q)$ developed from current hydrology theory. Based on R-D model, several RWM models are developed progressively with or without controllable measures (i.e., utilization pump, discharge pump, infiltration), such as R-S-D, R-S-P-D, R-S-U-D, R-S-I-D, and R-S-U-I-D.

Because an RWM system is relatively easy to monitor and control, there are not many chances of system failure or malfunction. Even when some failures occur, the damage at RWM system is much smaller than that caused by failures at large-scale systems such as dams or pump stations. Therefore, RWMSs can be designed for much smaller design return period rainfall than other large-scale hydrology systems in order to get the same flood mitigation effect, which results in cost saving and enhanced resilience.

The developed micro-catchment hydrological models can be used to increase the resilience of existing sewer systems threatened by urbanization and climate change, which eventually help to find out the solutions for Sustainable Development Goals (SDGs 6 and 11). Also, by incorporating the new design concept of multipurpose RWM models, it is possible to make the solutions more economically viable and increase the resilience of the system by applying controllable measures.

\section{REFERENCES}

Kim Y. J. and Han M. Y. (2006). Development of RSD system for urban drain capacity improvement. The 6th International Workshop on Rainwater Harvesting \& Management Proceeding Book, Korea. 


\section{Hydrological Design of Multipurpose Micro-catchment RWM}

Kim Y. J., Han M. Y., Kim Y. H. and Mun J. S. (2009). An experimental runoff formula in building roof area for on-site rainwater management. Journal of Korea Water Resources Association, 42(2), 171-176.

Kim Y., Kim T., Park H. and Han M. (2014). Design method for determining rainwater tank retention volumes to control runoff from building rooftops. KSCE Journal of Civil Engineering, 1-6.

Nguyen, D. C. (2017). Micro-Scale Hydrology modeling for Multipurpose Rainwater Management. Doctoral Dissertation. Seoul National University, Seoul, Korea.

Nguyen D. C. and Han M. Y. (2017b). Rainfall-storage-utilization-discharge model for flood mitigation and water conservation. Water Science and Technology: Water Supply. In press. doi: 10.2166/ws.2017.184.

Nguyen D. C. and Han M. Y. (2017c) Rainfall-Storage-Pump-Discharge (RSPD) Model for Sustainable and Resilient Flood Mitigation. In: International Low Impact Development Conference China 2016. 


\section{Chapter 4}

\section{Hydrological design of rainwater harvesting system for water supply}

\subsection{INTRODUCTION}

Many communities in developing countries are suffering from water shortage due to several causes, such as the centralized water supply not always being available, pollution of surface water, groundwater being depleted or contaminated by heavy metals, and bottled water being too expensive to afford. The situation is expected to worsen in the future and may occur even in some remote areas in developed countries as well. Rainwater harvesting (RWH) from rooftops is drawing interest as an alternative source of safe drinking water in developing countries (Nguyen et al. 2013; Mwamila et al. 2015; Temesgen et al. 2015; Kim et al. 2016). If a RWH system (RWHS) is well designed and carefully operated, rainwater can be a potential source of drinking water with minor or even no treatment (Amin et al. 2009; Nguyen \& Han, 2014).

Figure 4.1 shows a typical rooftop RWHS, which consists of rooftop, connection pipe, filter, storage tank and water supply. In

C) IWA Publishing 2018. Hydrological Design of Multipurpose Micro-catchment Rainwater Management Mooyoung Han, Duc Canh Nguyen doi: 10.2166/9781780408712_107 
the design of such a RWHS, required input parameters include rainfall data $(i)$, roof catchment area $(A)$, surface runoff coefficient $(C)$, volume of storage tank $(V)$, and water demand $(D)$.

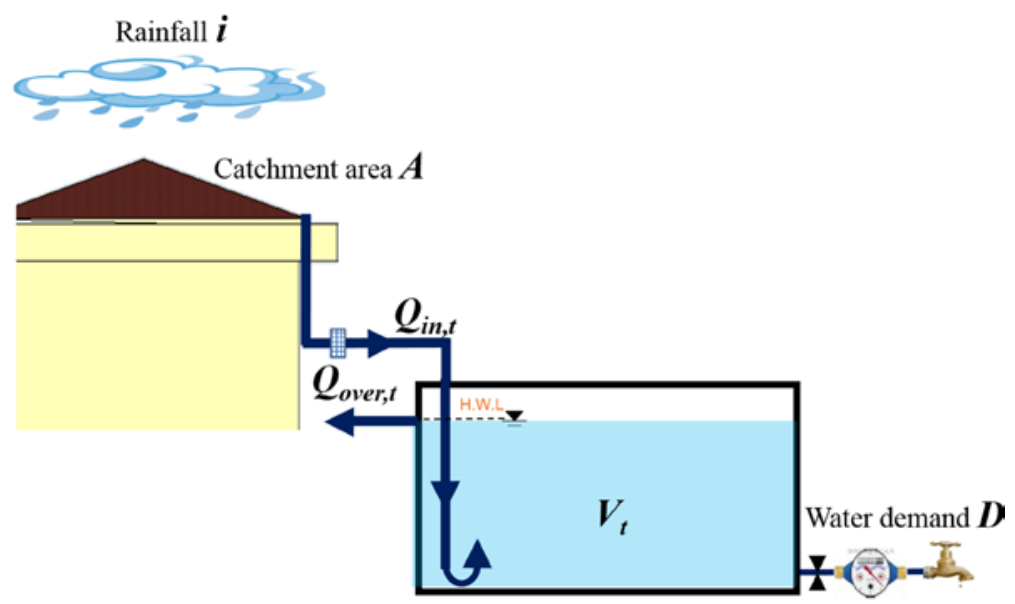

Tank volume $\boldsymbol{V}$

Figure 4.1 Schematic diagram of a typical RWHS.

Two parameters are suggested for the evaluation of the performance of a RWHS: the number of No Water Days (NWD) to define reliability and Rainwater Utilization Ratio (RUR) to define efficiency (Mun \& Han, 2012; Mwamila et al. 2015). Firstly, NWD (day) is the number of days in a year when the remaining water in the tank is less than one-day demand. In countries where the dry season lasts longer than usual, people suffer from water shortage for many days in a year (high NWD). An established RWHS will store rainwater for most of the days in a year and thus, have lower NWD.

Secondly, RUR (\%) is the ratio of the amount of rainwater supplied for water consumption to the total rainwater that has fallen on top of the roof catchment for a one-year period. If a 
large amount of rainwater overflows during the rainy season, the RUR may decrease. A higher RUR value means that the rainwater system is designed and operated efficiently.

Whereas roof catchment area $(A)$, volume of storage tank $(V)$ and water demand $(D)$ are easily determined, site-specific rainfall data $(i)$ may not be easily available or sometimes does not exist in sufficient detail for design purposes. Also, the required hydrological data for the design of a RWHS may be different from that of the conventional hydrological method, which is developed to design flood control measures. Due to the fact that a flood control system should be designed to cope with the worst case, hydrological data such as maximum rainfall for a short period in a shorter timestep is required. However, in the design of a RWHS for water supply, because the main concern is to maximize the yearly water supply with minimum NWD, the required hydrological data is the longer time-step for a one-year period.

In order to generalize the results of the hydrology model, the area, tank volume and water demand are normalized to $100 \mathrm{~m}^{2}$, which means that all of the results are calculated for the case of an area of $100 \mathrm{~m}^{2}$. If the actual area is $300 \mathrm{~m}^{2}$, for example, then the tank size and water demand can be multiplied by 3. By doing this, any systems with different catchment areas and water demand can be analyzed.

The proper selection of hydrological data for RHW for water supply is important, because it directly influences the performance as well as the sizing of the rainwater tank, which represent costs, benefits, and operation of the system. Also, daily rainfall data is required in order to provide accuracy in the simulation process because it best represents the precipitation phenomena over time. However, in many remote areas, especially in developing countries, daily rainfall data may not be available. Instead, rough monthly rainfall data may be obtained, such as monthly rainfall and the number of rainy days each month. It will be necessary to find a method which can 
simulate the performance reasonably well even though there is not sufficient hydrological data.

In this chapter, two design methods for RWHS for water supply are presented depending on the availability of sufficient rainfall data: one is when there is sufficient daily rainfall data (Section 4.2), the other is when there is not sufficient rainfall data (Section 4.3). Design example is presented in detail for each case.

In the following Section 4.4 the methods to improve the performance of the RWHS are suggested, such as by reducing the demand depending on the amount of remaining water in the tank, or by increasing the catchment area and/or volume of the storage tank.

\subsection{DAILY RAINFALL DATA MODEL}

\subsubsection{Modeling method}

A typical RWHS for water supply generally consists of roof catchment area, screen filter, downpipe, storage tank, supply facility and overflow unit (Figure 4.1). The daily rainfall data of one average year is used for simulation.

\subsubsection{Equations}

The performance efficiency is simulated on the basis of a water balance equation. At each time-step, the roof runoff during that time-step is added to the volume (mass) in the tank and the user's consumption and overflow is subtracted. Tests and corrections are applied to cover the three cases - 'full tank', 'empty tank', and 'demand exceeds the available stored water.'

$$
V_{t}=V_{t-1}+Q_{\text {in }, t} \Delta_{t}-Q_{\text {sup }, t} \Delta_{t}-Q_{\text {out }, t} \Delta_{t}
$$

$V_{t}$ is the cumulative water stored in the tank $\left(\mathrm{m}^{3}\right)$ at time $t . V_{t-1}$ is the cumulative water stored in the tank $\left(\mathrm{m}^{3}\right)$ at time $t-1 . \Delta_{t}$ is the time step (day). $Q_{\mathrm{in}, t}$ is the inflow rate of the rainwater tank 
$\left(\mathrm{m}^{3} / \mathrm{h}\right)$ at time $t$, which is the same as the runoff flow rate from the roof as in Eq. (2.9):

$$
Q_{\mathrm{in}, t}=i_{t} \times(0.90-0.95) \times A \times 0.001
$$

$0.90-0.95$ is the runoff coefficient $i_{t}$ is the rainfall intensity ( $\mathrm{mm} /$ day). $A$ is the catchment area $\left(\mathrm{m}^{2}\right)$.

$Q_{\text {sup }, t}$ is the water supply rate to the building from the rainwater tank ( $\mathrm{m}^{3} /$ day) at the $t$ th day. $Q_{\text {sup }, t}$ can be mathematically described as follows:

$$
\text { If } V_{t} \leq 0, \quad Q_{\text {sup }, t}=0
$$

If $V_{t}>0$, the water supply is limited by the cumulative water stored and inflow quantity in the tank.

$$
\begin{aligned}
& V_{t-1}+Q_{\mathrm{in}, t} \Delta_{t}<D \Delta_{t} \rightarrow Q_{\text {sup }, t} \Delta_{t}=V_{t-1}+Q_{\mathrm{in}, t} \Delta_{t} \\
& V_{t-1}+Q_{\mathrm{in}, t} \Delta_{t} \geq D \Delta_{t} \rightarrow Q_{\text {sup }, t}=D
\end{aligned}
$$

$D$ is the daily demand ( $\mathrm{m}^{3} /$ day). Outflow can be determined based on the water level in the RWH tank with respect to the High Water Level (H.W.L).

If $V_{t} \leq V, \quad Q_{\text {out }, t}=0$

If $V_{t}>V$, the tank is full,

$Q_{\text {out }, t} \Delta_{t}=V_{t-1}-V+Q_{\text {in }, t} \Delta_{t}-Q_{\text {sup }, t} \Delta_{t}$

The operational parameters of NWD and RUR can be mathematically described as follows:

$$
\begin{aligned}
& \mathrm{NWD}=T \times\left(1-\sum Q_{\text {sup }, t} \Delta_{t} / \sum D \Delta_{t}\right) \\
& \mathrm{RUR}=\sum Q_{\text {sup }, t} \Delta_{t} /\left(A \times \sum Q_{\text {in }, t} \Delta_{t}\right)
\end{aligned}
$$

\subsubsection{Flow chart}

Figure 4.2 shows a flow chart of a daily rainfall data model to design a typical RWHS for water supply. The RWH model requires input data of design parameters including runoff 
112 Hydrological Design of Multipurpose Micro-catchment RWM

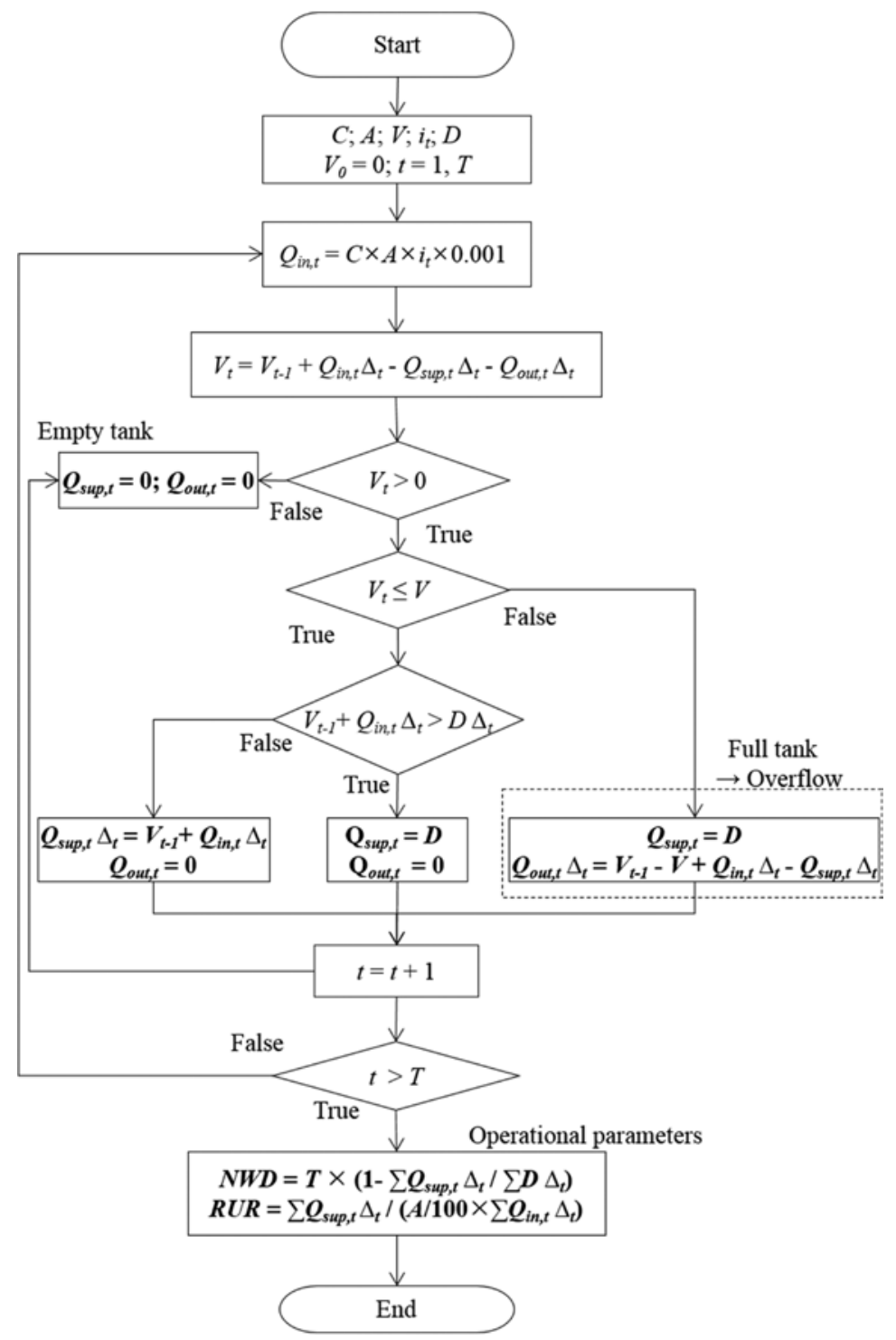

Figure 4.2 Flow chart to design and evaluate the performance of a typical RWHS. 
coefficient $(C)$, catchment area $(A)\left(\mathrm{m}^{2}\right)$, tank volume $(V)\left(\mathrm{m}^{3}\right)$, daily rainfall data $\left(i_{t}\right)(\mathrm{mm} /$ day) and daily water demand $(D)$ $\left(\mathrm{m}^{3} /\right.$ day). The model can evaluate operational parameters of RWHS, which are NWD (Number of No Water Days) and RUR (Rainwater Utilization Ratio).

\subsubsection{Design example for daily rainfall data model}

\subsubsection{Design condition}

This section presents how to design and evaluate the performance of a typical RWHS. The site is at an elementary school in $\mathrm{Cu}$ Khe Village, Hanoi, Vietnam. Before RWHS is introduced, two hundred students and teachers had to buy bottled water for drinking because the groundwater was contaminated by Arsenic, river water was polluted and centralized water supply system was not connected. A total of 100 Liter/day is required to supply 200 persons with an average supply ratio of $0.5 \mathrm{Liter} /$ person. The daily rainfall data is used for the year 2005 from Hanoi city, Vietnam (Figure 4.3). A unit roof area of $100 \mathrm{~m}^{2}$ and a range of tank sizes ranging from $0-10 \mathrm{~m}^{3}$ are considered. Four demand scenarios are selected: 50, 100, 150 and 200 Liter/day. The design parameters are summarized in Table 4.1.

\subsubsection{Results and discussion}

Figure 4.4 demonstrates the result of simulation of two operational parameters (NWD and RUR) as an example for different tank size and demand. It is found that for a specific tank volume, the RUR values increase and NWD becomes higher with higher water consumption.

With a lower demand (50 Liter/day), the NWD values decrease and become zero, which means that the RWHS can supply throughout the year. However, the RUR values are also reduced, which means much rainwater is wasted by overflow. 
114 Hydrological Design of Multipurpose Micro-catchment RWM

This is due to the monsoon rainfall pattern in Hanoi city. As the tank volume becomes smaller, the RWHS performance becomes worse which results in low RUR values and high NWD values. But as the tank volume becomes larger, the system performance is improved (RUR becomes higher, NWD becomes lower). During No Water Days, the school has to purchase bottled water at a cost of $\sim 0.5 \mathrm{USD} / 20 \mathrm{~L}$ bottle. A higher number of NWD means the school or the parents have to spend more money to purchase the bottled water.

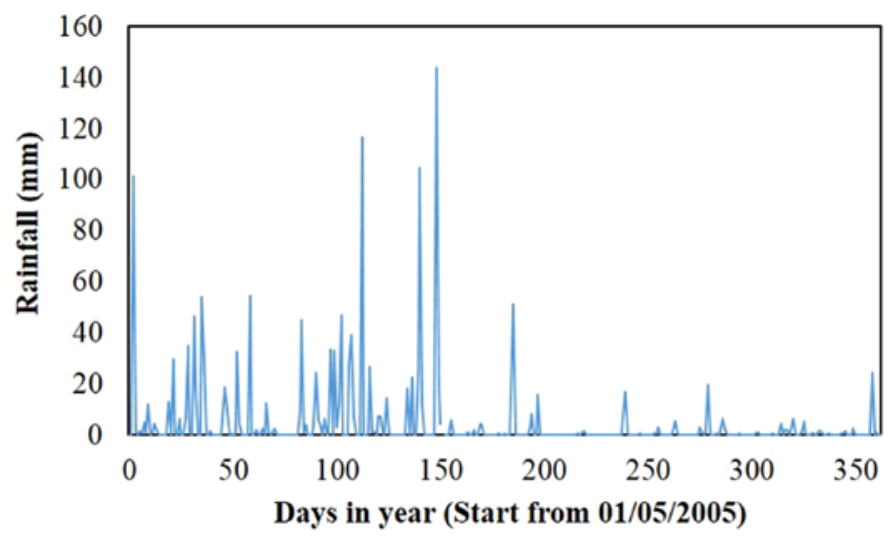

Figure 4.3 Daily rainfall data in Lang station, Hanoi, for the year 2005.

Table 4.1 Parameters used for daily rainfall data model.

\begin{tabular}{ll}
\hline Site & Cu Khe, Hanoi City, Vietnam \\
\hline Rainfall Data & Daily Data of 2005 (Figure 4.3) \\
Catchment area & $100 \mathrm{~m}^{2}$ \\
Tank size & $0 \sim 10 \mathrm{~m}^{3}$ \\
Water demand & $50,100,150$, and 200 Liter/day \\
Runoff coefficient & 0.9
\end{tabular}



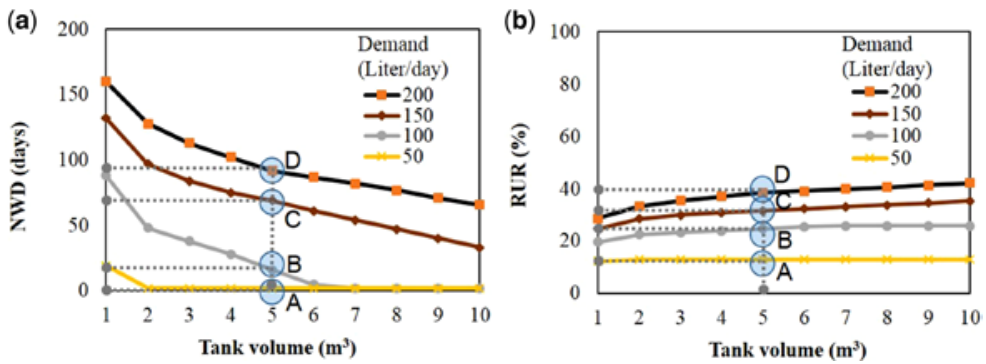

Figure 4.4 Performance of RWHS for different tank volume and demand scenarios: (a) NWD and (b) RUR.

The performance of a specific RWHS is easily observed from Figure 4.4. For example, for a typical RWHS of $100 \mathrm{~m}^{2}$ catchment area, and $5 \mathrm{~m}^{3}$ tank volume, the NWD values are $0,20,70$, and 95 days (Points A, B, C, D in Figure 4.4a) for 50, 100, 150, and 200 Liter/day demand, respectively; and the RUR values are 12, 24, 32 and $39 \%$ of the total amount of rainwater (Points A, B, C, $\mathrm{D}$ in Figure 4.4b), respectively.

\subsection{MONTHLY RAINFALL DATA MODEL (WHEN RAINFALL DATA IS INSUFFICIENT)}

In most developing countries, the daily rainfall data, which is used for the simulation as in Section 4.2, may not be available for the design site. Even though data may sometimes exist, gaining access to it may be too expensive. For example, a 10 -year daily rainfall record for Hanoi area costs even more than to build a small RWHS. However, in most developing countries and remote areas, monthly rainfall data and the number of wet days in a month are usually available and easily accessible, as shown in Table 4.2. Although the use of monthly rainfall data may lead to less accurate results because it is too raw and unable to show fluctuations, it is the only available data, and still useful. 
116 Hydrological Design of Multipurpose Micro-catchment RWM

Table 4.2 Monthly rainfall and number of wet days data for the year of 2005 in lang road area, Hanoi.

\begin{tabular}{|c|c|c|c|c|c|c|c|c|c|c|c|c|}
\hline Year & Jan & Feb & Mar & Apr & May & Jun & Jul & Aug & Sept & t Oct & Nov & Dec \\
\hline Rainfall & 11.4 & 35.6 & 27.4 & 32.9 & 221.2 & 278 & 108.2 & 377.2 & 366 & 17.8 & 91.9 & 26.8 \\
\hline $\begin{array}{l}\text { No. of } \\
\text { wet days }\end{array}$ & 8 & 13 & 18 & 12 & 19 & 15 & 13 & 18 & 12 & 9 & 6 & 6 \\
\hline
\end{tabular}

\subsubsection{Modeling method}

Figure 4.5 presents examples of how to present different rainfall data. Figure 4.5a shows the daily rainfall data for Hanoi city (S0). There are several methods to modify monthly data as an input to the simulation model.
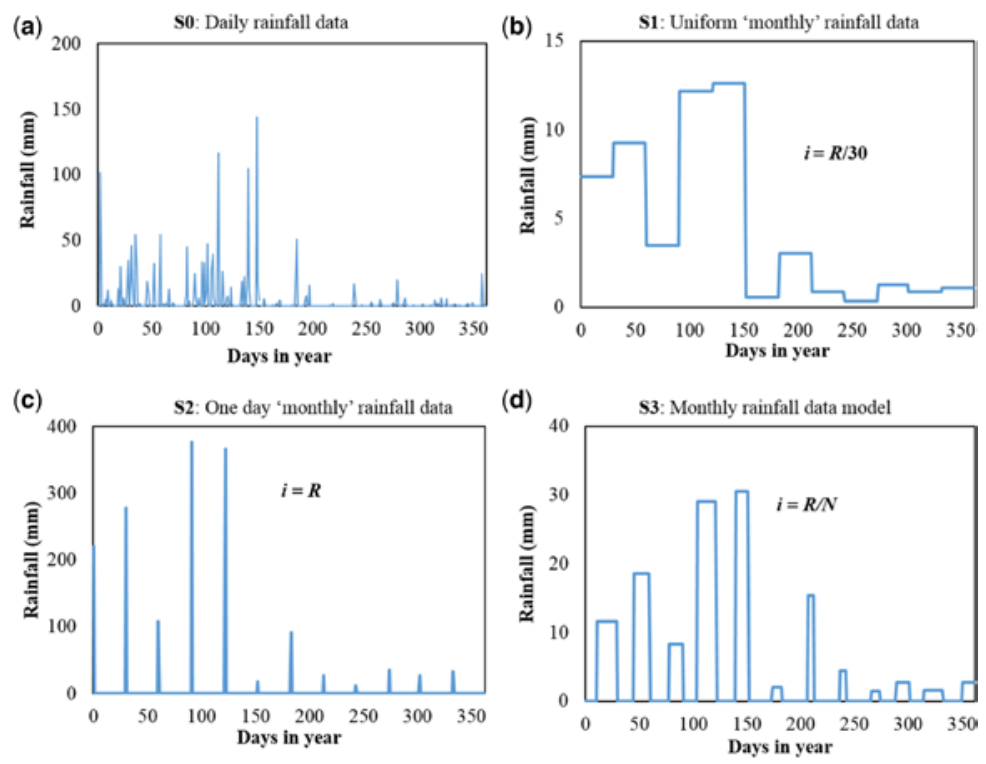

Figure 4.5 Different rainfall data: (a) daily rainfall data; (b) uniform 'monthly' rainfall data; (c) one day 'monthly' rainfall data; and (d) monthly rainfall data model. ( $R$ : monthly rainfall, $N$ : number of wet days in month). 


\subsubsection{Uniform 'monthly' rainfall data (S1)}

This model assumes that it rains uniformly every day for the whole month with the amount of monthly data divided by 30 days. This model has been the most popular method to design a RWHS from monthly data. With the uniform monthly data, it is assumed that the daily conditions throughout that month are constantly maintained for the running of a RWHS performance model (Figure 4.5b).

\subsubsection{One-day 'monthly' rainfall data (S2)}

Another way to use monthly data is to assume that each month's rainfall occurs in only one day during that month (Figure $4.5 \mathrm{c}$ ). It can be located either at the first day or last day of the month.

\subsubsection{Monthly rainfall data model (S3)}

The monthly rainfall data model is a simple and reasonable method to design a RWHS for water supply using monthly rainfall data. For simple and practical design of rainfall data from monthly data to predict RWHS performance, wet days are assumed to occur uniformly on consecutive days. To underline the importance of the rainfall data, it is noted that rainwater storage systems are relatively small and will overflow during sustained wet periods and will become empty during sustained dry periods. It is important that water managers understand the level of risk associated with such rainfall occurrences. In many areas of developing countries, rainwater may be the only water supply source. Therefore, tank size should be designed to conserve water even during dry days. Accordingly, in the monthly rainfall data model, these uniformly consecutive wet days are proposed to be distributed during the last days of that month, as shown in Figure 4.6. In most of the cases, the values of $N$ (number of wet days in the month) are available. However, when $N$ values are not available, they can be calculated 
118 Hydrological Design of Multipurpose Micro-catchment RWM

from the climate condition. More details of the calculation and usage of monthly rainfall data can be found in Nguyen and Han (2017). This scenario shows a critical situation, which is based on the worst-case assumptions considering the above-mentioned risk associated with rainfall occurrences.

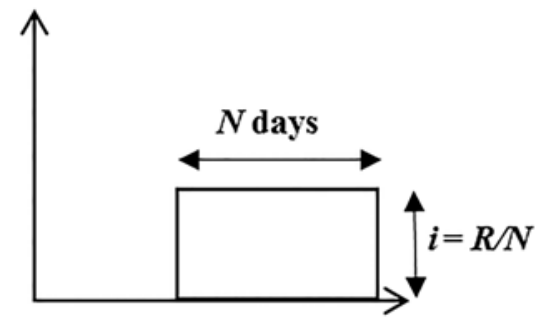

S3: Rainfall distributed in the last days

Figure 4.6 Monthly rainfall data model ( $R$ : monthly rainfall; $N$ : number of wet days).

The monthly rainfall data model uses the same logic as the daily rainfall data model. The only difference is the use of input data of (1) monthly rainfall in $i$ th month, $R_{i}$; (2) number of wet days in $i$ th month, $n_{i}$; and other design parameters of the RWHS. The model can generate uniformly consecutive wet days distributed during the last days of the month.

\subsubsection{Design example for monthly rainfall data model}

\subsubsection{Design condition}

The case study of an elementary school with 200 students in $\mathrm{Cu}$ Khe, Hanoi, Vietnam, is selected for this design example. Two demand scenarios are selected, namely: (a) low demand $(200 \times 0.3$ Liter/day) and (b) high demand $(200 \times 1$ Liter/day). Daily rainfall data (S0) and numbers of wet days were collected for the site in 2005; the uniform (S1) and one-day (S2) 'monthly' rainfall data, 
and monthly rainfall data model (S3) are generated from the data and shown in Figure 4.7. The design conditions are summarized in Table 4.3.
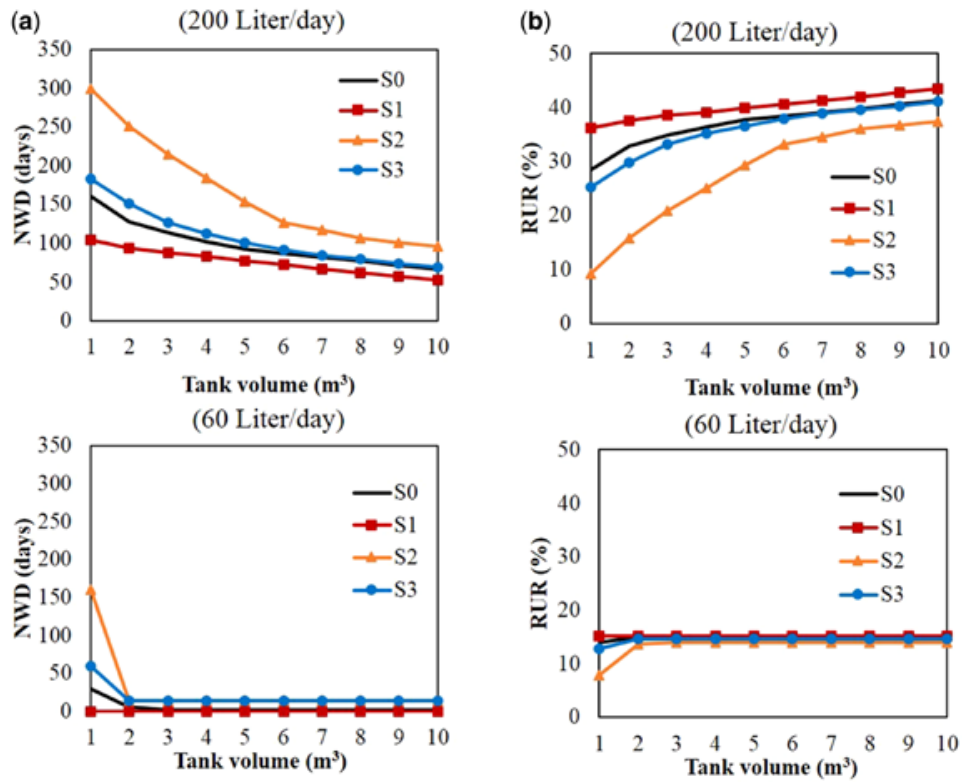

Figure 4.7 Comparison of different rainfall data: (a) NWD and (b) RUR for high demand scenario (top) and low demand scenario (bottom). (S0: daily rainfall data model, S1: uniform monthly model, S2: one-day monthly model, S3: monthly rainfall data model).

\subsubsection{Results and discussion}

The simulation results of NWD and RUR when using different monthly models (S1, S2, S3) are compared to provide a more accurate daily rainfall data model (S0) as shown in Figure 4.7. While the two models which assume uniform or one-day 'monthly' data show a large error, the monthly rainfall data model (S3) shows a relatively small error as compared with daily rainfall data model 
(S0). For the small tank size, the use of both uniform monthly and one-day monthly data results in significant error for both high and low demand scenarios. However, with a larger tank size, there is no significant difference among different models.

Table 4.3 Parameters used for monthly rainfall data model.

\begin{tabular}{ll}
\hline Site & Cu Khe, Hanoi City, Vietnam \\
\hline Rainfall data & Data of 2005 (S0; S1; S2; S3) (Figure 4.5) \\
Catchment area & $100 \mathrm{~m}^{2}$ \\
Tank size & $0 \sim 10 \mathrm{~m}^{3}$ \\
Water demand & Low demand: 60 L/day \\
& High demand: 200 L/day \\
Runoff coefficient & 0.9 \\
\hline
\end{tabular}

Particularly, for low demand, with a tank size larger than $2 \mathrm{~m}^{3}$, there is inconsiderable error introduced by using uniform monthly data instead of actual daily rainfall data. Using uniform monthly data overestimates RWHS performance as compared to using actual daily rainfall. A smaller value of NWD and higher value RUR are found in Figure 4.7 for both high and low demand scenarios. These results mean that using uniform 'monthly' data cannot clearly show the fluctuations of rainfall events. Meanwhile, using one-day 'monthly' data underestimates RWHS performance as compared with using daily rainfall data. A higher value of NWD and smaller value of RUR are predicted using one-day 'monthly' data in Figure 4.7 for both high and low demand scenarios.

Meanwhile, the results using the monthly rainfall data model (S3) are much closer to that of using daily rainfall data. That is, the monthly rainfall data model provides more accurate results compared to those of uniform and one-day 'monthly' rainfall data models. For small tank volumes, there is just a small error between the monthly rainfall data model and the daily rainfall data model for both high and low demand scenarios. For larger 
tank volumes, the results are even closer to the results using actual daily data.

As a conclusion, we can overcome the lack of daily data by using the monthly rainfall data model which assumes the uniform distribution of wet days at the end of each month.

Nguyen and Han (2017) also compared the monthly rainfall data model and random generation model which was developed by Thomas (2002). The random generation model generates pseudo daily rainfal data from monthly rainfall data, in which wet days are taken to be randomly spaced and can be assigned using a random number generator ('wet if $X<P$ (wet-day probability)' where $X$ is a random number that is uniformly distributed between 0 and 1). Transforming a uniform distributed random variable $X$ (range 0 to 1 ) by the equation $r=-R \ln (X)$ gives the generated rainfall $r$. It is found that the results introduced by using the random generation model may overestimate the actual RWHS performance. Meanwhile, the designed rainfall by the monthly rainfall data model showed acceptable results and a conservative underestimation of the actual RWHS performance which leads to a safer RWHS design. Moreover, the design method in the monthly rainfall data model is much simpler than random number generato model.

\subsection{HOW TO IMPROVE THE PERFORMANCE OF RWHS}

The performance of a RWHS used for water supply can be evaluated by two parameters, which are Number of No Water Days (NWD) and Rainwater Utilization Ratio (RUR). How to improve the performance of a RWHS is a major concern in the design and operation process. A higher value of NWD means that there are many days in a year ending up without stored rainwater. This will cause a serious problem, especially when and where there are no other alternatives for water supply, such as during the 
dry seasons in remote areas of developing countries. Meanwhile, a low value of RUR means that rainwater is used inefficiently. During the rainy season, because the inflow of the tank is larger than water consumption, rainwater is wasted by overflow. In other words, we are losing valuable resources and money.

Most RWHSs are reported to have problems related to high NWD and low RUR. Semra et al. (2011) also found that about one-third of the sampled households were reported as running out of rainwater during the six-month dry season in Vietnam. As a consequence, achieving low NWD and high RUR values is always the desirable target.

The system performance can be improved by applying a variable demand model, or increasing the catchment area or volume of tank. Lower NWD can be achieved by voluntarily reducing water consumption during or before the dry season. Higher RUR can be achieved by increasing the tank volume or catchment area.

\subsubsection{Variable demand model}

Most existing models evaluate the performance of RWHS assuming constant or fixed demand throughout the year without considering seasonal and local situations for water availability. In fact, using the same amount of water during or before the drought may not be a good idea, because the users will suffer from higher NWD. Instead, by reducing water consumption to some degree during and before the dry season, the users may suffer less drought (as NWD becomes lower).

During the rainy season, when the tank is full and the inflow is larger than the demand, overflow will occur, which will lower the RUR value. In this case, the demand may be increased, which will eventually increase the value of RUR. During this time, water can be used for non-drinking purposes or groundwater recharge instead of wasting it. 
Nguyen and Han (2014) and Mwamila et al. (2015) introduced a different approach with a consideration of variable demands in which daily demands are varied by the rainfall variance and/ or the remaining water in the tank. For example, when the water level is in the range of the first quarter from the top, the water demand is set to normal. When the water level is lowered to second, third and fourth quarters, the water demand can be set to $75 \%, 50 \%$ and $25 \%$, respectively. By reducing water consumption during the dry seasons, the NWD period can be shortened. This can be included in the logic of flow chart. Other site-specific operation logics are possible and can be included in the flow chart. The most recent one will be a logic based on a water sensor and IT, which will determine the optimum usage depending on the remaining water and seasonal trend.

A variable demand model has been developed (Nguyen \& Han, 2014) which included an algorithm to determine daily demand based on the rainfall variance for the best use of a RWHS. In the other words, the RWHS would secure the water supply in the dry season and utilize the excess amount of rainwater in the rainy season. If the cumulative water stored in the rainwater tank after the end of $t$ th day $\left(V_{t}\right)$ is lower than the capacity of rainwater tank $(V)$, rainwater supply should be limited to meet the minimum demand $\left(D_{\min }\right)$ at the $t$ th day. If $V_{t}$ is higher than $V$, it means that the amount of rainwater is excessive. Hence, rainwater can be supplied for multiple uses within the maximum demand $\left(D_{\max }\right)$ in the days before the $t$ th day. The daily demand can be mathematically described as follows:

$$
\begin{aligned}
& \text { If } V_{t} \leq V, \quad D_{t}=D_{\min }, \\
& \text { If } V_{t}>V, D_{t-j}=D_{\max },(j=1, a) ; V_{t-a}=V_{t-a-1}=Q_{t-a}-D_{t-a} \\
& V_{t}^{\prime}=V_{t-a-1}+\sum\left(Q_{k}-D_{k}\right), \quad(k=t-a, t)<V
\end{aligned}
$$


124 Hydrological Design of Multipurpose Micro-catchment RWM

In the above descriptions, $V_{t-a}$ is the cumulative water stored in the rainwater tank after the end of the $(t-a)$ th day; $V_{t-a-1}$ is the storage in the tank $\left(\mathrm{m}^{3}\right)$ at the beginning of the $(t-a)$ th day; $a$ is the number of the days before the $t$ th day when the re-calculated cumulative water stored in the rainwater tank after the end of the $t$ th day $\left(V_{t}^{\prime}\right)$ is lower than $V . Q_{k}$ and $D_{k}$ are the harvested rainwater and the daily water demand of the household of the $k$ th day, respectively; and, $k$ is the number of runs from $(t-a)$ and $t$.

\subsubsection{Flow chart}

The flow chart for the variable demand model is demonstrated in Figure 4.8. The algorithm to calculate variable demand is included in the constant demand model. The variable demand model requires input data of minimum demand $\left(D_{\text {min }}\right)$, which is the minimum necessary required water consumption (L/day) (generally for drinking purposes); maximum demand $\left(D_{\max }\right)$, which is the maximum water consumption (generally for all purposes) (L/day); and the design parameters of the RWHS. The model can simulate the system performance such as NWD and RUR. Also, daily demand for each day in a year can be calculated from the model.

\subsubsection{Design example for RWHS performance improvement}

\subsubsection{Design condition}

Daily rainfall data is collected in Hanoi city for a typical dry year of 2005. Although the typical roof area is $100 \mathrm{~m}^{2}$, it is possible to expand the roof area by using canvas fabric catchment or locally available materials (Nguyen et al. 2013). The roofs of nearby buildings can be used to increase the catchment area. 


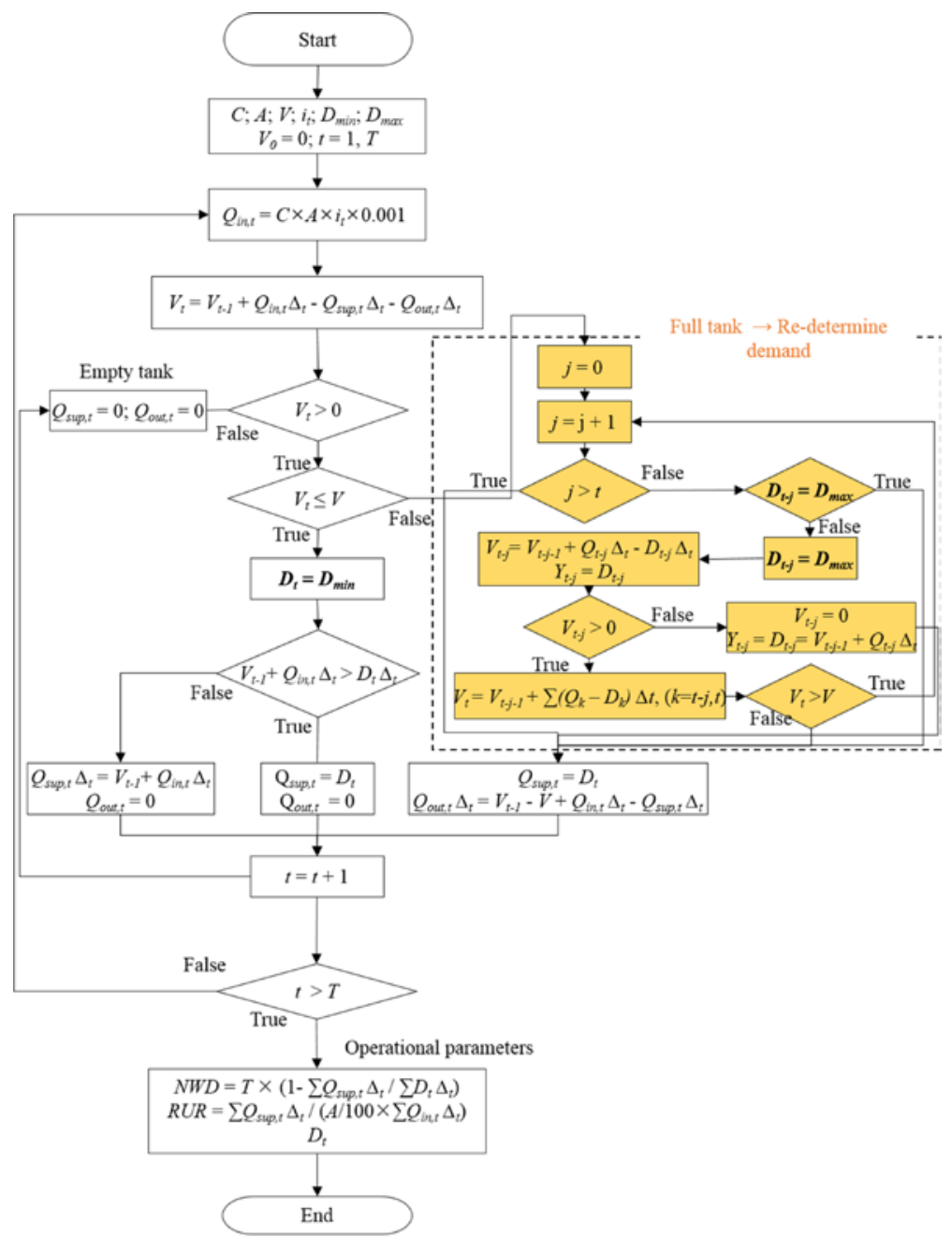

Figure 4.8 Flow chart to design and evaluate the performance of a RWHS using variable demand model. 
126 Hydrological Design of Multipurpose Micro-catchment RWM

Roof areas ranging $0-350\left(\mathrm{~m}^{2}\right)$ and tank sizes ranging $0-10 \mathrm{~m}^{3}$ are considered. The minimum demand is 60 Liter/day and the maximum demand is 200 Liter/day. RWHS performances are calculated using the daily rainfall data model and variable demand model. A summary of the design parameters is shown in Table 4.4.

Table 4.4 Parameters used for performance improvement.

\begin{tabular}{ll}
\hline Site & Cu Khe, Hanoi City, Vietnam \\
\hline Rainfall data & Daily data of 2005 (figure) \\
Catchment area & $100 \mathrm{~m}^{2}, 0-350 \mathrm{~m}^{2}$ \\
Tank size & $4 \mathrm{~m}^{3}, 0-10 \mathrm{~m}^{3}$ \\
Minimum demand & 60 Liter/day \\
Maximum demand & 200 Liter/day \\
Runoff coefficient & 0.9 \\
\hline
\end{tabular}

\subsubsection{Results and discussion}

(a) Performance improvement by using variable demand model

The performance of different scenarios of water consumption is compared in Figure 4.9. Using normal constant high demand of 200 Liter/day, NWD is 75 days and RUR is $38 \%$ for a RWHS with $4 \mathrm{~m}^{3}$ of tank volume and $100 \mathrm{~m}^{2}$ of catchment area. If the demand is reduced to the low demand of 60 Liter/day, then the NWD will become zero, but the RUR is also reduced to $18 \%$. However, if we use the variable demand model, then the RUR can increase up to $38 \%$ while keeping the NWD at zero.

(b) Performance improvement by increasing tank size (at fixed catchment area of $100 \mathrm{~m}^{2}$ )

The performance of the RWHS when the tank size is increased is shown in Figure 4.10. The NWD is zero for a tank size larger 
than $2 \mathrm{~m}^{3}$ at the low demand (60 Liter/day) or variable demand scenarios. But it never reaches zero even with a larger tank with normal consumption of 200 Liter/day. The RUR value is the same if the tank size is larger than $2 \mathrm{~m}^{3}$ for the low demand. However, RUR increases slightly with tank size for the normal consumption of 200 Liter/day or variable demand.

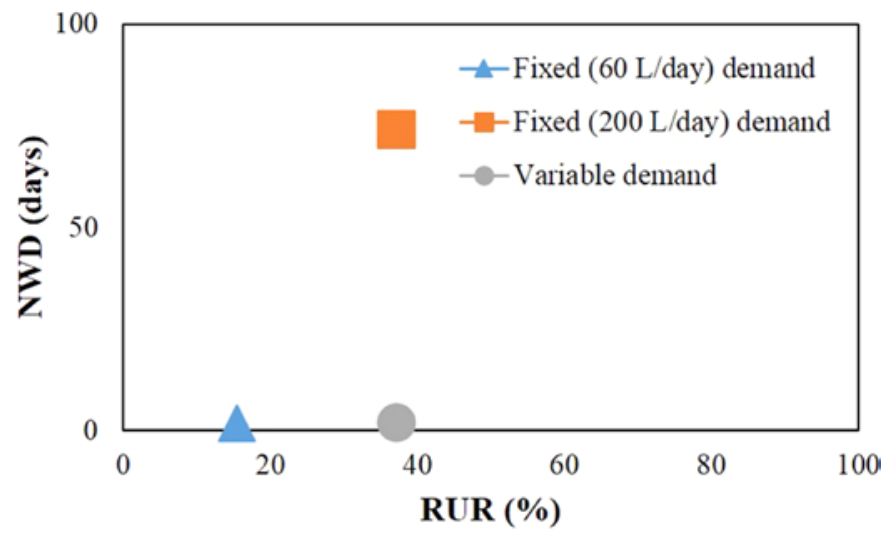

Figure 4.9 Comparison of operational parameters by different demand scenarios (Tank volume: $4 \mathrm{~m}^{3}$; catchment area: $100 \mathrm{~m}^{2}$ ).
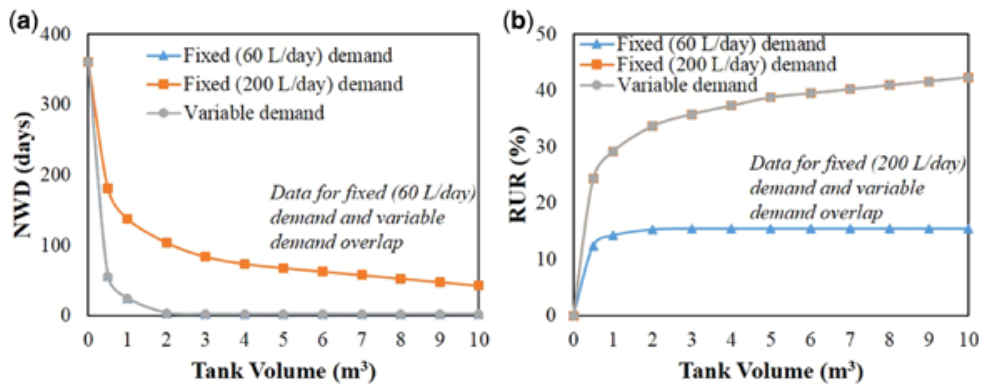

Figure 4.10 Change of operational parameters by changing tank size (catchment area is fixed at $100 \mathrm{~m}^{2}$ ) (a) NWD, (b) RUR. 
128 Hydrological Design of Multipurpose Micro-catchment RWM

(c) Performance improvement by increasing catchment area (at fixed tank size of $4 \mathrm{~m}^{3}$ )

The performance of RWHS with the increase of catchment area is shown in Figure 4.11. The NWD is zero for a catchment area larger than $100 \mathrm{~m}^{2}$ at the low demand (60 Liter/day) or variable demand scenarios. But it never reaches zero even when the catchment area increases to $350 \mathrm{~m}^{2}$ with normal consumption of 200 Liter/day. The RUR value is the same when the catchment area is larger than $50 \mathrm{~m}^{2}$ for the low demand. However, RUR increases slightly with the catchment area for the high demand or variable demand scenarios.
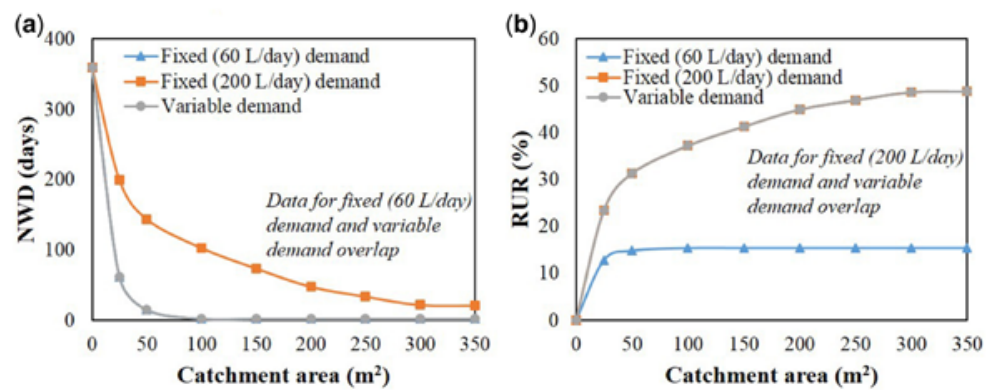

Figure 4.11 Change of operational parameters by changing catchment area (tank size is fixed at $4 \mathrm{~m}^{3}$ ) (a) NWD, (b) RUR.

Both variable demand and system improvement can be easily developed for other cities using site-specific conditions. They can be used for designing and operating RWHSs for water supply purposes.

\subsection{SUMMARY}

To sum up, the design and performance evaluation of a typical RWHS can be carried out by a simple water mass balance equation using input parameters of daily rainfall data. The 
system performance can be evaluated by operational parameters of NWD and RUR, which present the reliability and efficiency of the water supply system. The daily rainfall data model can be used to design and analyze a typical RWHS when daily rainfall data is available.

When hydrological data is insufficient, monthly rainfall data with the number of wet days can be used. The monthly rainfall data model which generates daily rainfall for each month with a distribution of uniformly wet days in the last days of the month will help provide performance prediction, which is quite similar to that of using the daily rainfall data model.

Several methods to improve the system performance are suggested such as: using the variable demand model, which is to reduce water consumption during or before a drought period, and increasing tank volume and/or catchment area.

It is hoped that people can design and predict the RWHS for any specific site using the design methods introduced in this chapter, regardless of the availability of a detailed rainfall database.

\section{REFERENCES}

Amin M. T. and Han M. Y. (2009). Roof-harvested rainwater for potable purposes: Application of solar collector disinfection (SOCO-DIS). Water Research, 43(20), 5225-5235.

Kim Y., Han M., Kabubi J., Sohn H. G. and Nguyen D. C. (2016). Communitybased rainwater harvesting (CB-RWH) to supply drinking water in developing countries: Lessons learned from case studies in Africa and Asia. Journal of Water Science and Technology: Water Supply, 16(4), $1110-1121$.

Mun J. and Han M. (2012). Design and operational parameters of a rooftop rainwater harvesting system: definition, sensitivity and verification. Journal of Environmental Management, 93(1), 147-153.

Mwamila T., Han M. and Ndomba P. (2015). Tackling rainwater shortages during dry seasons using a socio-technical operational strategy. Water Science \& Technology: Water Supply, 15(5), 974-980.

Nguyen D. C. and Han M. Y. (2014). Design of dual water supply system using rainwater and groundwater at arsenic contaminated area in Vietnam. 


\section{Hydrological Design of Multipurpose Micro-catchment RWM}

Journal of Water Supply: Research and Technology-AQUA, 63(7), $578-585$.

Nguyen D. C. and Han M. Y. (2017). Proposal of simple and reasonable method for design of rainwater harvesting system from limited rainfall data. Resources, Conservation \& Recycling, 126, 219-227.

Nguyen D. C., Dao A. D., Kim C. and Han M. Y.(2013). A sustainability assessment of the rainwater harvesting system for drinking water supply - A case study of Cukhe Village, Hanoi, Vietnam. Environmental Engineering Research Journal, 18(2), 109-114.

Temesgen T., Han M. Y., Park H. J. and Kim T. (2015). Design and technical evaluation of improved rainwater harvesting system on a University Building in Ethiopia. Water Science \& Technology: Water Supply, 15(6), 1220-1227. 


\section{Chapter 5}

\section{Case studies}

\subsection{DESIGN AND OPERATION OF A MULTIPURPOSE RWHM PROJECT IN AN URBAN AREA - CASE STUDY IN STAR CITY, SOUTH KOREA}

\subsubsection{Introduction}

Star City - located in the north-eastern part of Seoul, near the Han River, South Korea - is a major real-estate development project of more than 1300 apartments (Figure 5.1). The Star City rainwater harvesting system (RWHS) has been operating since 2007 and is receiving worldwide attention as a model water management system that supplements the existing centralized water infrastructure as a Climate Change Adaptation (CCA) strategy (International Water Association [IWA], 2008).

Several innovative concepts have been applied in implementing the Star City RWHS: (1) the concept of a multipurpose system: the system is used in flood mitigation, water conservation, and

C IWA Publishing 2018. Hydrological Design of Multipurpose Micro-catchment Rainwater Management Mooyoung Han, Duc Canh Nguyen doi: 10.2166/9781780408712_131 
emergency response; (2) the proactive management of flooding: the Star City RWHS has a remote-control system for monitoring and controlling tank water level. The three different tanks also store water separately according to water quality. The risk of flooding is mitigated with the remote-control system by emptying or filling the tanks appropriately; and (3) the city government's incentive program for the developer to alleviate fear of any economic disadvantage. The developer was permitted to construct three percent more floor space than would normally be allowed. Considering the price of real estate in Seoul, that is a remarkable incentive.

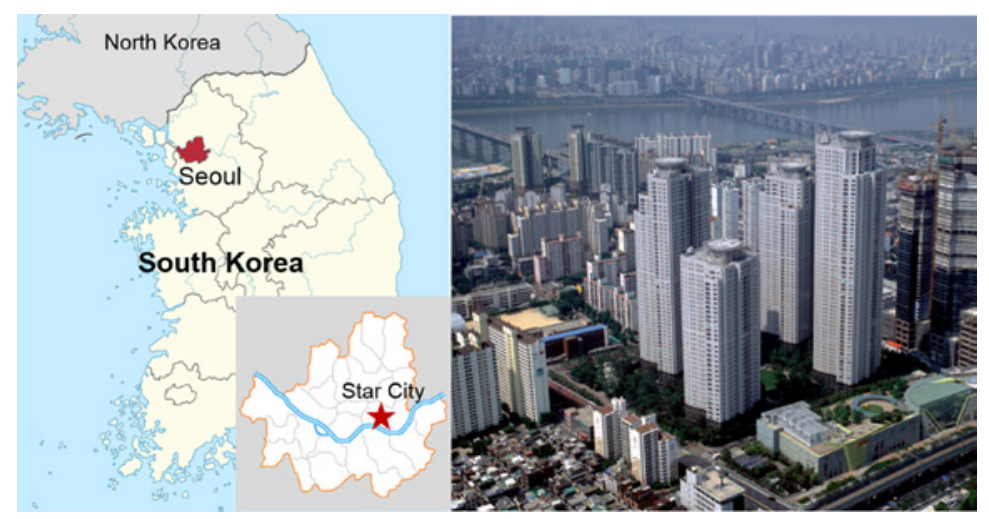

Figure 5.1 Location of Star City in Seoul, Korea.

This section introduces the Star City RWHS, and analyzes its operational data from various viewpoints, such as those of water saving, rainwater quality and flood mitigation for short-term CCA, and energy saving potential for long-term CCA. The social effect of the project on decentralized rainwater management systems (DRWMSs) promotion is also discussed. Finally, we suggest that DRWMSs are a simple and efficient measure for addressing climate change issues and are applicable to most cities around the world. 


\subsubsection{Materials and methods}

Figure 5.2 is a schematic diagram of the Star City RWHS. A total of $3000 \mathrm{~m}^{3}$ of water is stored in three separate tanks with a total floor area of $1500 \mathrm{~m}^{2}$. The capacity of each tank is $1000 \mathrm{~m}^{3}$. Two of the tanks are used to store rainwater from the rooftops and the ground. Garden irrigation is achieved efficiently by ground infiltration, which is recycled to the tank for multiple uses. The third tank stores emergency tap water. Fresh tap water is maintained by regular replenishment after decanting half of the old water to the rainwater tank.

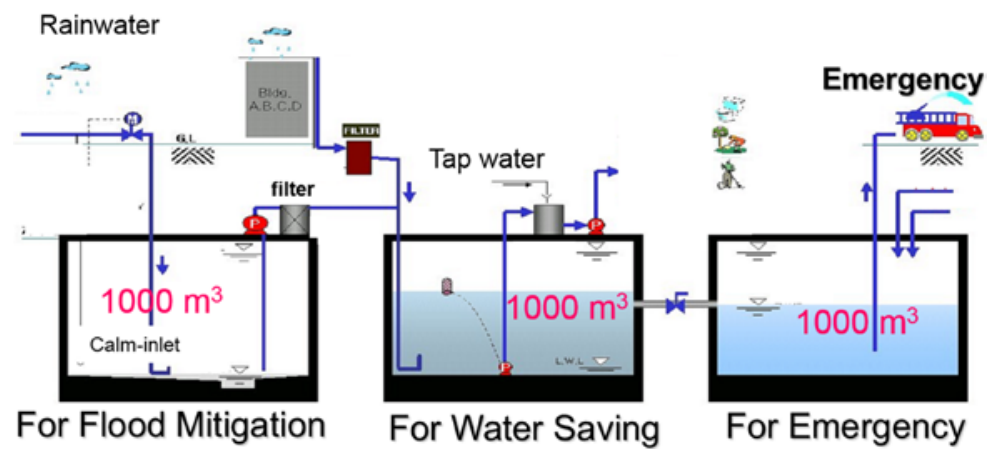

Figure 5.2 Schematic diagram of the Star City RWHS.

Rainwater supply is monitored using the flowmeter. Turbidity and $\mathrm{pH}$ are measured and compared with the Korean Gray Water Standard (KGWS) and the Korean Drinking Water Standard (KDWS). The rainwater management model in Chapter 3 can be used for the evaluation of flood mitigation during the RWHS operation in the Star City complex. Further, the energy consumed for water supply from the existing Seoulwide water supply system (WSS) and the Star City RWHS are also calculated, and the energy saving by DRWMSs is evaluated from the results. 
134 Hydrological Design of Multipurpose Micro-catchment RWM

\subsubsection{Results and discussion}

\subsubsection{Water saving and flood mitigation potential}

Monthly rainfall and rainwater supply from June 2007 to May 2008 are presented in Figures 5.3a, b. Most rainfall is concentrated from summer to early autumn as shown in the figure. Rainwater is mostly used for gardening in summer and autumn, not in winter due to low temperature and freezing. Based on operating the system for a year, we found the volume of water conserved to be approximately $26,000 \mathrm{~m}^{3}$ per year, which results in an RUR of $\sim 47 \%$ (the annual amount of rainfall over the Star City complex). The ratios of the volume of water conserved per month to monthly amount of rainfall, ranged widely from $18 \%$ in July to over $200 \%$ in November. Over $200 \%$ could be achieved by supplying stored rainwater left from the previous month and by irrigation, which is recycled to the rainwater tank.

The turbidity of stored rainwater is maintained below 1.5 NTU, as shown in Figure 5.4. The dotted line in the figure represents the KGWS. The $\mathrm{pH}$ of the rainwater ranged from 6 to 8.4, which meets the KDWS (Figure 5.5). The dotted lines in Figure 5.5 represent the KDWS.

The total area of the Star City complex is around $51,200 \mathrm{~m}^{2}$, comprising $6200 \mathrm{~m}^{2}$ of rooftop and $45,000 \mathrm{~m}^{2}$ of terrace and garden. When considering the infiltration capacity of the garden, the runoff coefficient of the terrace is assumed to be $60 \%$ of that of the roof. The total equivalent area thus becomes $\sim 34,550 \mathrm{~m}^{2}$. The Tank volume - Catchment area ratio is $5.8 \mathrm{~m}^{3} / 100 \mathrm{~m}^{2}$. As the Utilization rate - Catchment area ratio is small (ranging from 0-0.3 L/min/100 $\mathrm{m}^{2}$ ), the Star City RWMS can be designed and analyzed using R-S-D model. These factors can be plotted on the TP (Tank volume - Peak runoff) curves for the R-S-D system as described in Chapter 3, and the flood mitigation potential can be evaluated. As shown in Figure 5.6, a 100-year-frequency peak runoff of $26 \mathrm{~m}^{3} / \mathrm{h}$ (Point A) can be reduced to $18 \mathrm{~m}^{3} / \mathrm{h}$ (Point B) 
through a rainwater tank installation with a Tank volume Catchment area ratio of $5.8 \mathrm{~m}^{3} / 100 \mathrm{~m}^{2}$. The peak runoff of $18 \mathrm{~m}^{3} / \mathrm{h}$ indicates a 10 year-frequency peak runoff (Point $\mathrm{C}$ ). Therefore, the Star City complex, which has a storage array with a 10-year design period, would provide protection from a 100year flood.

(a)

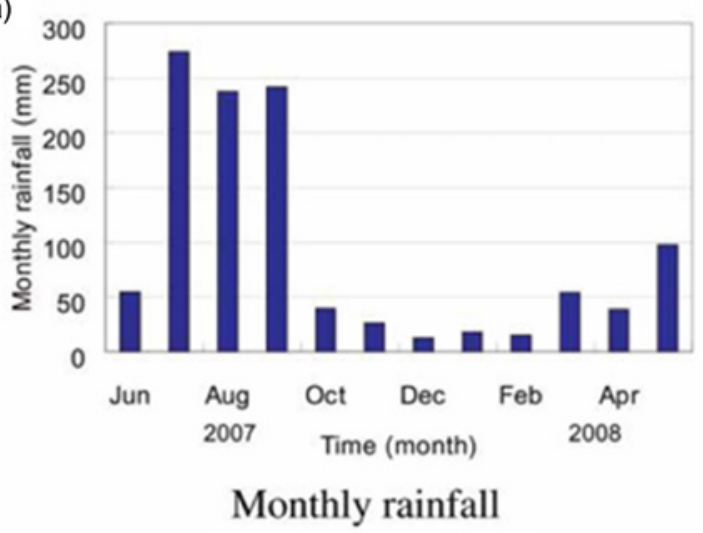

(b)

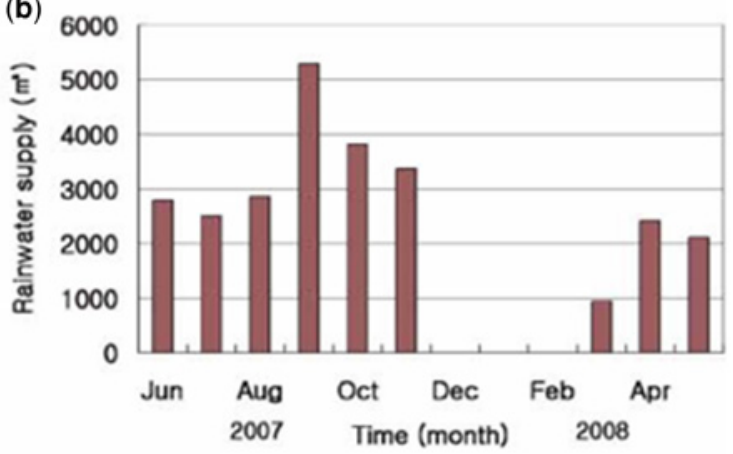

Monthly rainwater supply

Figure 5.3 Rainfall and rainwater supply at the Star City RWHS from 2007 to 2008. 
136 Hydrological Design of Multipurpose Micro-catchment RWM

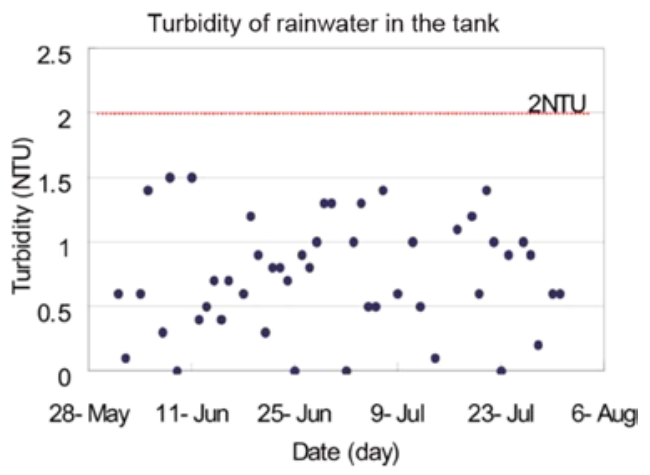

Figure 5.4 Turbidity of rainwater in the tank.

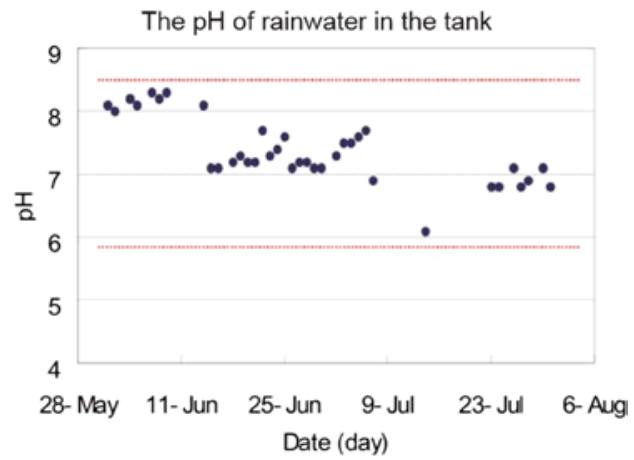

Figure 5.5 The $\mathrm{pH}$ of rainwater in the tank.

\subsubsection{Energy saved by using rainwater supply}

The energy consumed in supplying drinking water is mainly used in water purification and transmission. The average unit energy requirement for $1 \mathrm{~m}^{3}$ water supply is around $0.38 \mathrm{kWh} / \mathrm{m}^{3}$ for the case of Seoul City Water Supply System. However, when the collected rainwater is used for irrigation, the energy required for purification is zero. And assuming a $10 \mathrm{~m}$ elevation difference and $100 \mathrm{~m}$ transmission distance, the total amount of energy required 
is around $0.039 \mathrm{kWh} / \mathrm{m}^{3}$, which is $\sim 10 \%$ of the energy consumed by conventional means of supplying drinking water. Based on the foregoing calculations, $8.9 \mathrm{MWh}$ of electricity is expected to be saved per year by rainwater use in the Star City project. For more details, please refer to Han and Mun (2011).

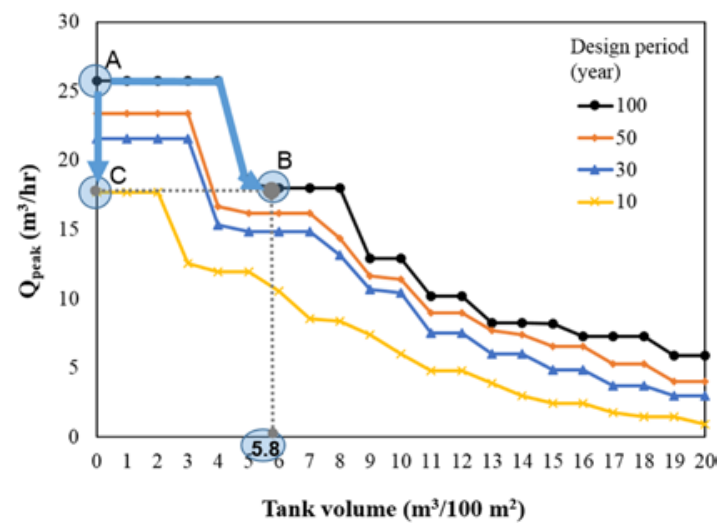

Figure 5.6 TP (Tank volume - Peak runoff) curves for R-S-D system using different design return periods (using Seoul rainfall data and Huff method, normalized for $100 \mathrm{~m}^{2}$ catchment area).

\subsubsection{Social impact}

The success of the Star City project serves as a model for enacting regulations aimed at rainwater harvesting and management in Seoul. In December 2004, the city authority announced new rules to enforce the installation of RWHSs, with the main purpose of mitigating urban flooding and a secondary purpose of conserving water and extending energy savings. These measures are expected to ensure the safety of the city from future flooding. A special feature of the new system is the provision of a network for monitoring water levels in all water tanks at the central disaster prevention agency in the City Office (Figure 5.7). Data will be gathered from each $\mathrm{Gu}$ or district office. Depending on the expected amount of rainfall, the 
central disaster prevention agency may issue an order to building owners to either fully or partially empty their rainwater tanks. An incentive program is planned to reward those who follow the order and penalize those who do not. After a storm event, the stored water can be used for fire fighting and non-drinking purposes, such as toilet flushing and gardening.

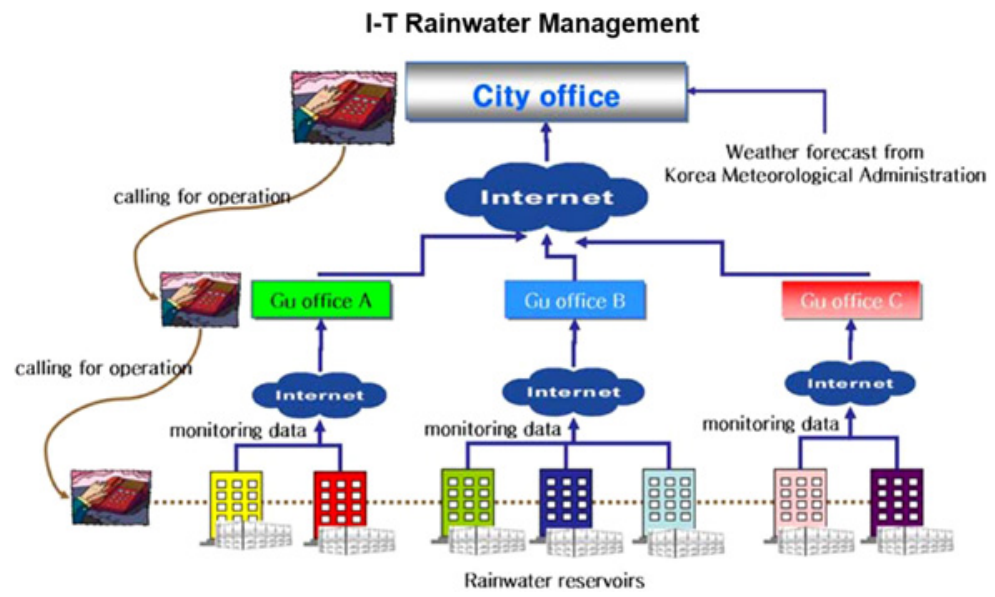

Figure 5.7 A diagram showing the monitoring of a multiple rainwater tank system for the prevention of urban flooding and for water conservation.

The buildings included in the regulations are as follows:

- All public buildings. Compulsory for new buildings and recommended to the possible extent for existing buildings.

- New public facilities, such as parks, parking lots, and schools, to the possible extent.

- Private buildings. Recommended for new buildings, subject to the buildings' permission (floor area larger than $2000 \mathrm{~m}^{2}$ ).

- Large development plans, such as new town projects. A rainwater management system is a first priority. 
By October 2016, 59 local authorities in South Korea had made regulations on rainwater management to promote DRWMSs by providing financial incentives and subsidies, and by establishing operating rainwater committees. Several cities have proposed rules for the publication of comprehensive rainwater management reports every 10 years. Many other cities are planning to make rainwater regulations under the Green Growth Policy of the South Korean government.

\subsection{DESIGN AND OPERATION OF A RAINWATER FOR DRINKING (RFD) PROJECT IN A RURAL AREA - CASE STUDY IN CU KHE ELEMENTARY SCHOOL, VIETNAM}

\subsubsection{Introduction}

A safe and affordable drinking water supply, which is one of the targets in Sustainable Development Goal 6 (SDG6), is essential for life. However, millions of people around the world still do not have access to this necessity, especially in rural areas in developing countries.

Community-based rainwater harvesting (CB-RWH) is recommended as a promising solution to the drinking-water challenges in developing countries (Kim et al. 2016). However, the common concerns of rainwater for drinking projects which have generally prohibited the spread of RWH are (1) a lack of sufficient rainfall data in remote areas to design the system, (2) uncertainty of water quality, and (3) uncertainty of public acceptance.

In July 2014, we installed a $12 \mathrm{~m}^{3} \mathrm{RWH}$ system at $\mathrm{Cu}$ Khe Elementary School, which is located in a rural area near Hanoi, Vietnam, and operated it to overcome these concerns. Several innovative technologies have been applied in implementing the $\mathrm{Cu}$ Khe Elementary School RWHS. Local rainfall data were gathered using a simple rain gauge to compare the simplified method using monthly rainfall data and real data in the design of 
140 Hydrological Design of Multipurpose Micro-catchment RWM

the RWHS. Measuring rainfall data and water consumption data is helpful for the democratic operation and self-control of RWH systems, and was suggested to be a good model for 'governing of the commons,' proposed by Ostrum (1990), who later won the 2009 Nobel Prize in Economics.

This section shows a successful case study of a RFD project at $\mathrm{Cu}$ Khe Elementary School in overcoming the commonly encountered challenges, such as system modeling with insufficient rainfall data, water quality of the rainwater system, and public acceptance (Dao et al. 2017).

\subsubsection{Materials and methods}

\subsubsection{Site description}

$\mathrm{Cu}$ Khe Elementary School is located in $\mathrm{Cu} \mathrm{Khe}$, a remote village in the southern part of Hanoi, Vietnam (Figure 5.8). As briefly introduced in Chapter 4, people in $\mathrm{Cu}$ Khe village do not have access to a safe water supply for many reasons. The only safe drinking water is bottled water, which is too expensive for many villagers to afford. The school, however, had to supply expensive bottled water for the young students, paid for by their parents. In 2014, the school had 200 students, 15 teachers, and 3 buildings, with relatively secure and suitable roofs. The average annual rainfall is $1680 \mathrm{~mm}$.

\subsubsection{Rainwater harvesting system}

In July 2014, the $\mathrm{Cu}$ Khe Elementary School rainwater harvesting system was installed as a corporate social responsibility (CSR) activity, having been donated by Lotte Department Store, South Korea, in collaboration with Seoul National University College of Engineering. The construction was carried out by local labor and using locally available materials in order to be technically independent, so that the operation and repair could later be performed by local people. 
(a)

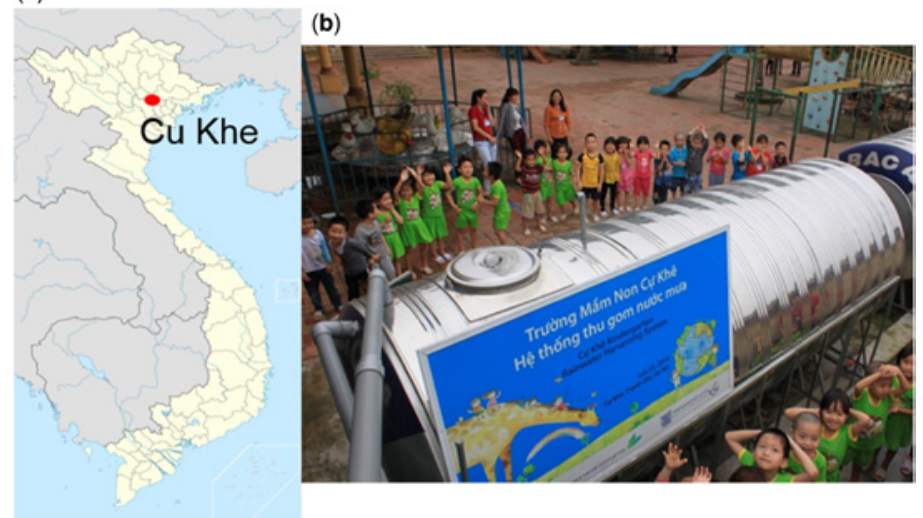

Figure 5.8 (a) The location and (b) picture of RFD system of $\mathrm{Cu}$ Khe Elementary School, Vietnam.

Figure 5.9 is a schematic diagram of the $\mathrm{Cu}$ Khe Elementary School RWH system. Rainwater is stored in two separate $6 \mathrm{~m}^{3}$ stainless steel tanks to enhance the sedimentation capacity. In the storage tank a simple ' $\mathrm{J}$ ' shaped pipe, called a calm-inlet, is installed to avoid the re-suspension of bottom sludge. To ensure rainwater quality for safe drinking, a simple UV filter is installed near the tap to treat microorganisms. Here, water level gauges and water meters are installed to monitor remaining rainwater volume and cumulative water consumption.

\subsubsection{Analysis of operational data}

The design of a RWHS is usually completed using a simple water balance equation using daily rainfall data and water consumption. However, $\mathrm{Cu}$ Khe village did not have daily rainfall data to enable a precise RWH design but had monthly rainfall data. The solution was to install a simple rain gauge, which is the same design as was developed by King Sejong the Great of the Joseon Dynasty, a kingdom before the Republic of Korea (Kings' Annal for Sejong, 
142 Hydrological Design of Multipurpose Micro-catchment RWM

1441). A science student group monitored the rainfall data each day and kept the records via a website (Figure 5.10). Daily rainfall data were measured with the rain gauge from 02/2015-12/2015. Moreover, rainwater supply was monitored using a water meter for 1 year in 2015. In this section, the recorded data are used to evaluate RWHS performance and to compare the monthly rainfall data model (Nguyen \& Han, 2017a).

\begin{tabular}{ccc}
\hline School & Area & Volume of Tank \\
\hline $\begin{array}{c}\text { Cu Khe } \\
\text { elementary }\end{array}$ & $150 \mathrm{~m}^{2}$ & $6,000 \mathrm{~L} \times 2=12,000 \mathrm{~L}$ \\
\hline
\end{tabular}
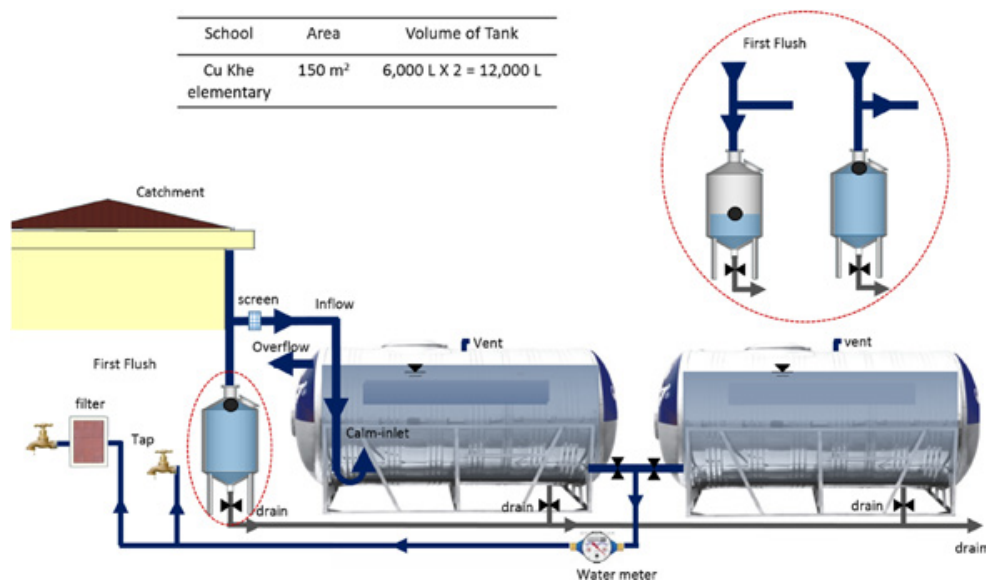

Figure 5.9 Schematic of the rainwater tank at $\mathrm{Cu}$ Khe Elementary School in Vietnam.

In addition, the rainwater quality was checked. The public acceptance of the RFD project in $\mathrm{Cu}$ Khe Elementary School also underwent an evaluation process, in which those who used the RDF system were interviewed by questionnaire about their satisfaction.

\subsubsection{Results and discussion}

\subsubsection{Verification of monthly rainfall data model with operational data}

After installation, the school used $59.7 \mathrm{~m}^{3}$ of water for 1 year. Assuming consistent usage, the average daily demand is 0.55 
Liter/day which can save $\sim 0.5$ USD/day in comparison to purchasing bottled water. According to an interview with the school's principal, there had been no empty day of the storage since the installation. This suggests that the RWH system has satisfied all drinking water demand.

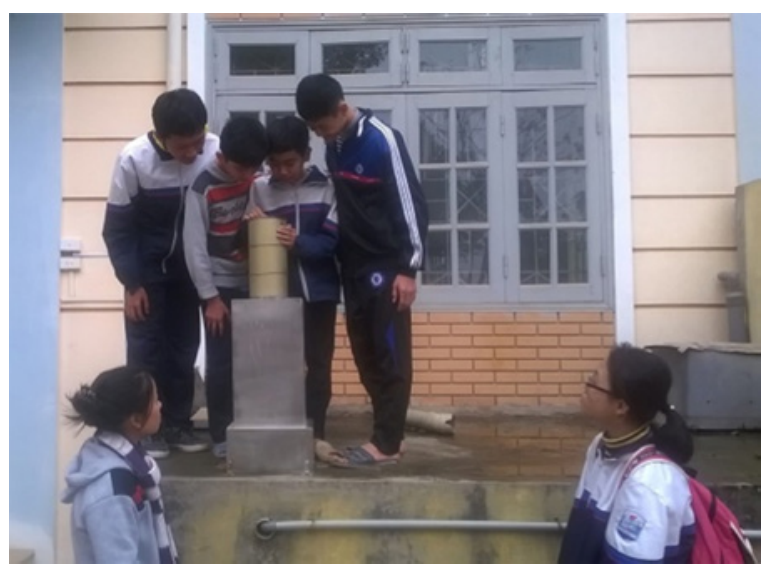

Figure 5.10 The rain gauge installed at $\mathrm{Cu}$ Khe Elementary School in Vietnam (Kim et al. 2016).

Daily rainfall was measured using the rain gauge and recorded by students. Figure 5.11 shows recorded daily rainfall from 02/2015-12/2015. Most rainfall was concentrated in the summer.

A benefit of local data collection is that it can result in a democratic decision of operation that can be used as reference for the design and operation of a RWHS. Figure 5.12 compares the RWHS performance by employing the recorded daily rainfall and the monthly rainfall data model. These results prove the accuracy of the monthly rainfall data model to design RWHSs with a small error where there is a lack of sufficient rainfall data. 
144 Hydrological Design of Multipurpose Micro-catchment RWM

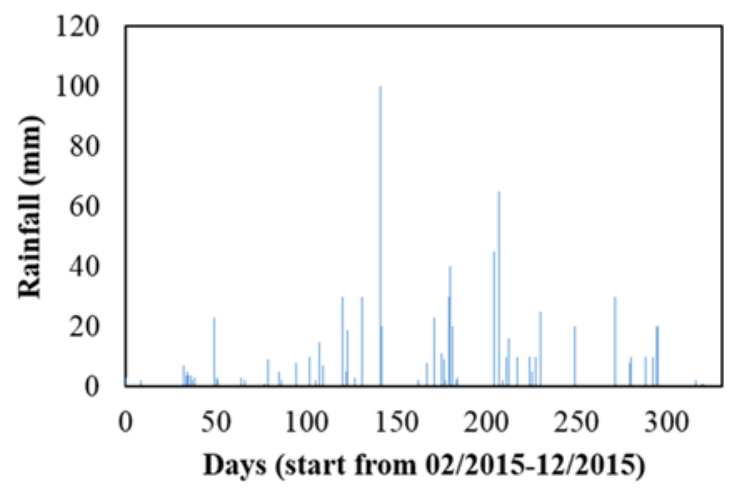

Figure 5.11 Recorded daily rainfall data in Cu Khe Elementary School from 02/2015-12/2015.
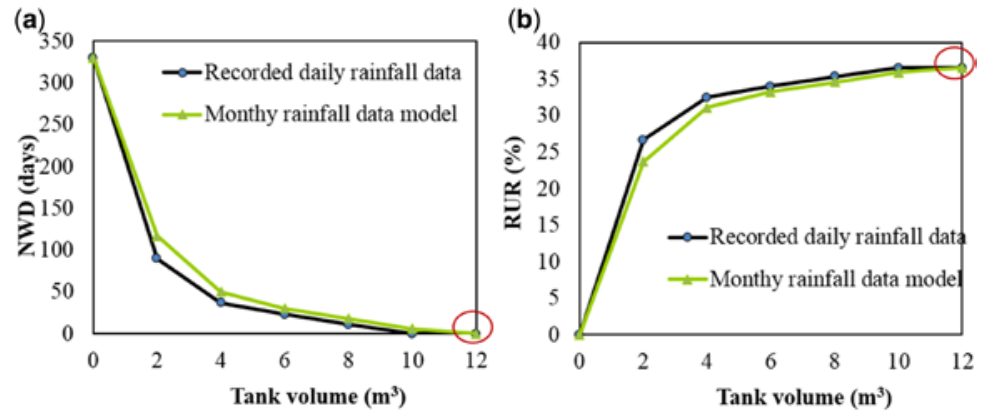

Figure 5.12 Variation of (a) number of No Water Days (NWD) and (b) Rainwater Utilization Ratio (RUR) by using recorded daily rainfall data and the monthly rainfall data model as the input.

\subsubsection{Water quality}

Table 5.1 shows the water quality of stored and treated rainwater. As shown, all chemical and physical parameters are much lower than Vietnam drinking water quality standards (VDWQS) and World Health Organization (WHO) drinking water quality guidelines over the year. Similar results can be achieved from other well-designed RWH systems. 
Table 5.1 Water quality of stored and treated rainwater.

\begin{tabular}{lllll}
\hline Variables & VDWQS & WHO & $\begin{array}{l}\text { Stored } \\
\text { Rainwater }\end{array}$ & $\begin{array}{l}\text { Treated } \\
\text { Rainwater }\end{array}$ \\
\hline $\mathrm{pH}$ & $6.5-8.5$ & - & $6.3-7.9$ & $6.36-7.24$ \\
TDS (mg/L) & 1000 & - & $26-53.8$ & $23-47.6$ \\
Turbidity (NTU) & 2 & - & $0.05-1.2$ & 0.6 \\
As (mg/L) & 0.01 & 0.01 & $<0.005$ & $0-0.005$ \\
Iron (mg/L) & 0.3 & - & $0.025-0.084$ & 0.05 \\
Lead (mg/L) & 0.01 & 0.01 & $<0.001$ & $0-0.001$ \\
Zinc (mg/L) & 3 & - & $0.046-0.05$ & 0.01 \\
Al (mg/L) & 0.2 & 0.2 & $<0.001$ & $0-0.001$ \\
Total Coliform & 0 & 0 & $0-78,000$ & 0 \\
(MPN/100 mL) & & & & \\
E. coli (MPN/100 mL) & 0 & 0 & $0-3200$ & 0 \\
\hline
\end{tabular}

The stored rainwater before filtration can meet VDWQS and WHO drinking water quality guidelines except for the microbiological parameters.

At the point of use after filtration, all the parameters including both total coliforms and E. coli parameters satisfy VDWQS and WHO drinking water quality guidelines, confirming that UV filter is safe enough to disinfect rainwater. In rural areas in developing countries, UV filter is recommended to eliminate microbiological contamination from rainwater due to its long duration and low cost. These results prove that RWH can safely be used for drinking with a POU treatment system.

\subsubsection{Public acceptance}

Table 5.2 shows the opinions of the teachers, students and their parents about the RFD system in $\mathrm{Cu}$ Khe Elementary School. Through the surveys and the interviews, it is shown that the 
146 Hydrological Design of Multipurpose Micro-catchment RWM community people have a positive perception toward the RFD project. They consider rainwater to be a safe and clean source of drinking water. Furthermore, they also showed high satisfaction with the RFD project's economic benefits, which were proved to prevent the need to purchase costly bottled water.

Table 5.2 Stakeholders' opinions about the RFD project at Cu Khe Elementary School, based on questionnaire.

\begin{tabular}{|c|c|c|c|c|c|}
\hline & $\begin{array}{l}\text { Very } \\
\text { Disappointed } \\
\text { (\%) }\end{array}$ & $\begin{array}{l}\text { Disappointed } \\
\text { (\%) }\end{array}$ & $\begin{array}{l}\text { Normal } \\
(\%)\end{array}$ & $\begin{array}{l}\text { Good } \\
\text { (\%) }\end{array}$ & $\begin{array}{l}\text { Very } \\
\text { Good } \\
(\%)\end{array}$ \\
\hline $\begin{array}{l}\text { Are you satisfied } \\
\text { with the taste of } \\
\text { rainwater? }\end{array}$ & 3 & 1 & 51 & 35 & 9 \\
\hline $\begin{array}{l}\text { Are you } \\
\text { satisfied with } \\
\text { the rainwater } \\
\text { quality? }\end{array}$ & 2 & 4 & 41 & 42 & 11 \\
\hline $\begin{array}{l}\text { Do you think } \\
\text { the RDF is } \\
\text { convenient for } \\
\text { use? }\end{array}$ & 3 & 0 & 45 & 41 & 11 \\
\hline $\begin{array}{l}\text { Do you think } \\
\text { the system is } \\
\text { economical? }\end{array}$ & 2 & 1 & 36 & 35 & 26 \\
\hline
\end{tabular}

The public acceptance and success of the RFD project at the $\mathrm{Cu}$ Khe Elementary School can be widely transferred to their communities and villages, since many of the stakeholders were involved in the RFD project. This may hopefully result in the promotion and awareness of the replication potential of RFD to achieve resilient and sustainable drinking water supplies in rural areas in developing countries that facing water shortages. It also suggests that RFD should be promoted as an important means to achieve SDG6. 


\subsection{EFFECT OF FLOOD REDUCTION BY DECENTRALIZED RAINWATER MANAGEMENT SYSTEM (DRWMS) - A CASE STUDY IN SUWON CITY, SOUTH KOREA}

\subsubsection{Introduction}

In recent years, increased runoff coefficient $(C)$ caused by urbanization coupled with heavier precipitation $(i)$ caused by climate change has resulted in more flooding events in many cities around the world. Technically speaking, flooding occurs when the increased runoff $(Q)$ is larger than the design capacity of the existing sewer system. Increasing the capacity of an existing sewer system costs a lot of money and is time consuming.

In Suwon city, flooding occurred at a small town named Munnae in 2007 and 2010. The National Emergency Management Agency (NEMA) and Suwon City wished to solve this problem by installing one large centralized storm water management system using a traditional method with the single purpose of flooding mitigation. As an alternative, decentralized rainwater management systems (DRWMSs) are suggested, which involve building several small rainwater tanks with the same total volume for the multiple purposes of flood mitigation, water saving and emergency storage. The comparison of centralized and decentralized rainwater management systems is illustrated in Figure 5.13.

(a) Centralized management

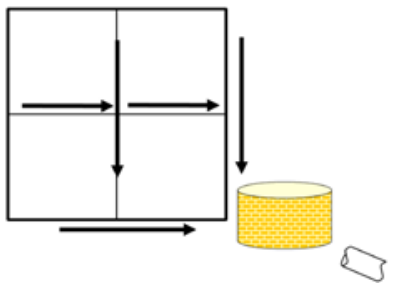

(b) Decentralized management

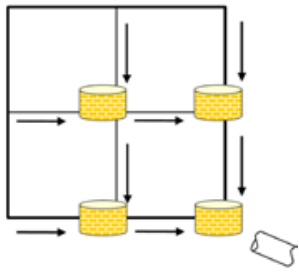

Figure 5.13 Comparison of (a) centralized and (b) decentralized Rainwater Management Systems. 
148 Hydrological Design of Multipurpose Micro-catchment RWM

In this case study, the volume of the storm water management system is calculated from the traditional centralized concept. For the design of DRWMSs, the same volume is divided into several tanks with the same total volume and located at several areas (upper part, middle part and lower part), and the peak runoff is calculated and compared with different options. The multiple benefits of using DRWMSs are discussed.

\subsubsection{Materials and methods}

Based on traditional centralized storm-water management, the capacity of the rainwater storage tank can be simply calculated by considering the building area following the Ministry of Land, Transport and Maritime Affairs (2009) method.

$$
V_{r}=A_{i} \times K
$$

$V_{r}:$ Storage tank capacity $\left(\mathrm{m}^{3}\right)$

$A_{i}$ : Architectural roof area (or the size of impervious area) $\left(\mathrm{m}^{2}\right)$

$K$ : Factor of reservoir capacity $(0.05 \sim 0.1)\left(\mathrm{m}^{3} / \mathrm{m}^{2}\right)$

The roof area in Munnae town is about $29,000 \mathrm{~m}^{2}$. As a rule of thumb, multiplying the factor of 0.1 by the area gives the required tank capacity of $2850 \mathrm{~m}^{3}$, approximated to $3000 \mathrm{~m}^{3}$. Land cover using the ArcGIS program is used to incorporate the land cover data, GIS is used to find the input data such as the sewage pipe network. Then, hydrologic simulation is carried out using XP-SWMM. Because Munnae town is located in a combined sewer area, water flow capacity of the pipe network is investigated to characterize the effluent.

In order to study the effects of the number of decentralized rainwater storage tanks with the same total volume of $3000 \mathrm{~m}^{3}$, the capacity of peak flow reduction is analyzed. Table 5.3 shows several combinations of tank installation. Case A shows the case 
before tank installation, Case B shows the centralized rainwater tank, and Cases C-F show the decentralized cases. Although there are more combinations of the location of small tanks such as upper, mid and low part of the area, in this example, the case of locating in the mid area is presented, as in Figure 5.14. For each case, the runoff is simulated and the peak runoff for each case is calculated. (For more details, please refer to Han et al. (2012)).

Table 5.3 Volume and number of rainwater tanks in each case.

\begin{tabular}{lllllll}
\hline Case & A & B & C & D & E & F \\
\hline Unit tank volume $\left(\mathrm{m}^{3}\right)$ & 0 & 3000 & 1500 & 1000 & 750 & 600 \\
No. of tanks & 0 & 1 & 2 & 3 & 4 & 5 \\
\hline
\end{tabular}

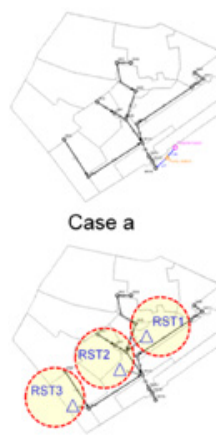

Case d

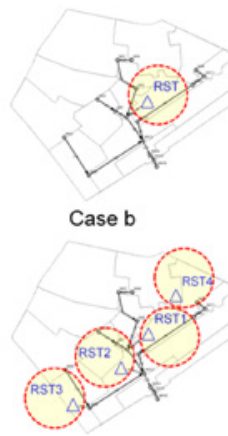

Case e
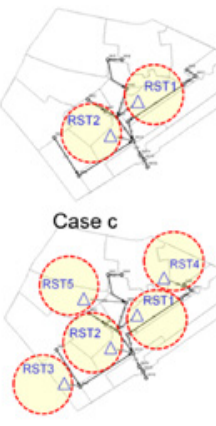

Case $f$

Figure 5.14 Cases for simulation of decentralized rainwater tank installation.

\subsubsection{Results and discussion}

Using the actual rainfall data in the year 2000, the results of peak runoff reduction for several alternatives of rainwater storage tank installation are shown in Figure 5.15. 


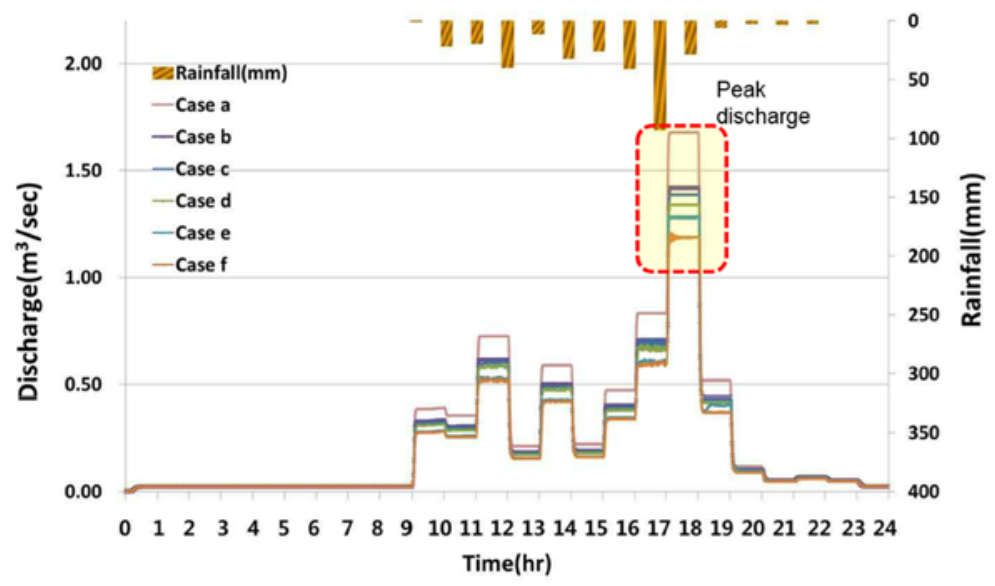

Figure 5.15 Discharge at outflow under different numbers of rainwater storage tanks with the same total volume.

As a result, installing one rainwater tank of $3000 \mathrm{~m}^{3}$ can reduce the peak flow rate by $15.5 \%$ compared to the case before the installation of a tank. It is clear that by installing a rainwater storage tank, we can increase the capacity for flood mitigation.

However, the larger the number of rainwater storage tanks, the higher the peak runoff reduction can be achieved. Installing five rainwater tanks of $600 \mathrm{~m}^{3}$ volume each in the area can further reduce the peak flow rate by $28 \%$. That is, by spreading largescale centralized rainwater management systems to many smallscale decentralized rainwater management systems with the same total volume, we can further improve the effect of flood reduction.

From the viewpoint of water saving, the rainwater that is collected at small scale DRWMSs has several advantages. Due to its short water mileage, it will be easier to collect than the rainwater collected at centralized system, which has a longer mileage. Also, because the consumers are located nearer, the cost associated with the transportation of the water, such as installation and operation, will be smaller. 


\subsection{SUMMARY}

The case studies have demonstrated the effect and application of decentralized RWHSs for multipurpose rainwater management in urban areas, providing drinking water from rainwater in rural areas, and a case of urban flooding mitigation by use of a decentralized rainwater management system.

The Star City RWHS is introduced here as a model water management system to address several water-related problems as well as a measure to respond to climate change. The RWHS is not only able to save the area from flooding, but also provides a water resource as well as saving energy. The Star City approach shows that DRWMSs can be a feasible supplement to the existing centralized system in a newly constructed residential complex, and can be achieved by installing a proactive and multipurpose RWHS.

A well-designed RFD (Rainwater For Drinking) project has been in operation at $\mathrm{Cu}$ Khe Elementary School in a rural area in Vietnam, a developing country, since June 2014. By monitoring rainfall data and water consumption, a community can democratically self-regulate its water consumption. It is possible to design a suitable system with a monthly rainfall data model. A well-designed RFD system ensures a relatively safe water source with good physicochemical quality. After applying point-of-use treatment, it provides safe drinking water that satisfy the WHO drinking water quality and VDWQS guidelines. Public acceptance of the RFD project was analyzed. It is suggested that CB-RWM has the potential to achieve a resilient and sustainable water supply for drinking.

By installing a rainwater storage tank, we can reduce the risk of flooding. However, the effect of flood reduction can be further improved by applying decentralized rainwater management systems. Many small-scale rainwater storage tanks can result in better performance compared to one large-scale rainwater storage 
tank with the same total volume. The collected rainwater can later be used by nearby consumers, thus resulting in saving water.

The success of these case study projects demonstrates the potential for promoting rainwater to resolve the global urban flooding and water shortage problems as well. It has also proved that proper RWMSs can contribute to sustainable flood mitigation and safe drinking water supply approaches, and increase the resilience of existing system against urbanization and climate change, resulting in a highly promising solution for SDGs 6 and 11.

\section{REFERENCES}

Dao A. D., Nguyen D. C. and Han M. Y. (2017). Design and operation of a rainwater for drinking (RFD) project in a rural area: case study at Cukhe Elementary School, Vietnam. Journal of Water Sanitation and Hygiene for Development, 07.4 (651-658) doi: 10.2166/washdev.2017.055

Han M. Y. and Mun J. S. (2011). Operational data of the Star City rainwater harvesting system and its role as a climate change adaptation and a social influence. Water Science and Technology, 63(12), 2796-2801.

Han M. Y., Kum S. Y., Mun J. S. and Kwak D. G. (2012). The effect of decentralized rainwater tank system on the reduction of peak runoff: a case study at M Village. Journal of Korea Water Resources Association, 45(1), 65-73.

International Water Association (IWA) (2008). Seoul's Star City: a rainwater harvesting benchmark for Korea. Water, 21, 17-18.

Kim Y., Han M., Kabubi J., Sohn H. G. and Nguyen D. C. (2016). Communitybased rainwater harvesting $(\mathrm{CB}-\mathrm{RWH})$ to supply drinking water in developing countries: lessons learned from case studies in Africa and Asia. Journal of Water Science and Technology: Water Supply, 16(4), 1110-1121.

Kings Annal for Sejong (1441). http://sillok.history.go.kr/popup/viewer.do?id= kda_12308018_004\&type=view\&reSearchWords=\&reSearchWords _ ime $=($ Accessed 30 November 2017).

Ministry of Land, Transport and Maritime Affairs (2009). A Study on Establishment of Rainwater Management Plan in Administrative Multi City. Report, 69 p.

Nguyen D. C. and Han M. Y. (2017a). Proposal of simple and reasonable method for design of rainwater harvesting system from limited rainfall data. Resources, Conservation and Recycling, 126(Suppl. C), 219-227. 
Nguyen D. C. and Han M. Y. (2017b). Rainfall-storage-utilization-discharge model for flood mitigation and water conservation. Water Science and Technology: Water Supply, In press, doi: 10.2166/ws.2017.184.

Ostrum E. (1990). Governing the Commons: The Evolution of Institutions for Collective Action. Cambridge University Press, Cambridge, UK. 
Downloaded from https://iwaponline.com/ebooks/book-pdf/651202/wio9781780408712.pdf

by IWA Publishing publications@iwap.co.uk 


\section{Index}

C

Controllable measures, 18, 50, 53-54,

103, 105

operation, 18, 19

Community-based

rainwater harvesting

(CB-RWH), 139

Climate change, 11, 13, 49, 54, 55,

103, 105, 147

D

Decentralized rainwater management systems

(DRWMSs), 13, 132, 133, 139, 147-150

\section{Design}

data, 52, 53-54, 55, 109

example for daily rainfall data model, 113-115

example for monthly rainfall data model, 118-121

example for RWHS performance improvement, 124-128 inflow and rainwater storage

tank, 31

procedure for hydrological design, 98

rainfall, 117

rainfall hyetograph for microcatchment RWMS, 36-41 rainfall hyetographs, 30, 33, 36-41, 57, 58, 59, 99

Design period, 58, 65, 67, 135

Developing countries, 107, 109, 115, 117, 122, 139-140, 146

Developed countries, 107

Discharge modeling, 17, 28, 33

Dong, 11

Drain city challenges, 4-7

philosophy, 7

to rain city, 11-14

Drinking water

challenges, 11

local or WHO, 54

resilient and sustainable, 146

safe, 11, 107, 140, 151 
156 Hydrological Design of Multipurpose Micro-catchment RWM

$\mathbf{E}$

Emergency storage (ES), 8, 36,

$51,61,62,67-68,75,79,83$,

87-88, 93, 97, 102, 103

Environment, 7, 10, 14, 50

F

Flood, 1, 2, 11

control, 34, 79, 109

flood-control infrastructure, 30

hydrograph, 26

prevention, 6

prone street or city, 69

reduction effect, 147-150

risk in local sewers, 12

Flood mitigation (FM), 13, 15, 18, 27 ,

$33,35-36,49,50,51,52,54,61$, $65,67,71,78,86-87,104,134$

G

Groundwater depletion, 1, 9, 50

Groundwater recharge (GR), 8, 15, 36, 50, 51, 79, 83, 85, 102, 103, 104 Groundwater recharge ratio (GRR),

86-87, 88, 93, 95-97

Gyeongbokgung Palace, 10

\section{H}

Hongik Ingan, 14

Hydrology

conventional, 17-19, 19-29

micro-catchment, 17-19, 29-36,

36-45

model, 17, 109

Hydrological modeling, 52-54

Hydrological design, 49-102, 107-128

$\mathbf{N}$

No water day (NWD), 108, 109, 111,

$113,114,119,120,121,122$,

$123,124,126,128,129,145$
$\mathbf{P}$

Peak runoff, 24, 30, 32, 33, 148

curves for R-D system, 59, 76, 85,94

flow rates, 58

flows, 71, 75, 79, 85, 93

line, 65

rate, 54,64

reduction, $64,103,149,150$

$\mathbf{R}$

Rain city

from drain city to, 11-14

philosophy, 10

solutions from, 7-10

Rainfall data

daily, 109, 110-115, 118-119, 120, $124,142,144$

local, 54, 140

monthly, 109, 115-121, 129, 139,

$142,143-144$

Rainfall-Discharge model (R-D model), 49, 50, 55-60, 105

Rainfall-Storage-Discharge model

(R-S-D model), 50, 60-68, 69,

75, 76-77, 134

Rainfall-Storage-Pumping-

Discharge model

(R-S-P-D model), 52, 68-71

Rainfall-Storage-Utilization-

Discharge model

(R-S-U-D model), 52, 71-79

Rainfall-Storage-Infiltration-

Discharge model

(R-S-I-D model), 52, 79-88

Rainfall-Storage-Utilization-

Infiltration-Discharge model

(R-S-U-I-D model), 52, 88-97

Rain gauge, 139, 142, 143

Rainwater harvesting system

(RWH system), 30, 107-128,

141-142 
$\mathrm{Cu}$ Khe Elementary School, 141

Star City, 131

Rainwater management (RWM), 1 by area, 8

by line, 5

decentralized, 132, 147-150

development, 50-52

measure, 36

micro-catchment, 17-18

multipurpose, 9, 49-102

new paradigm, 1-14

philosophy, 14

social responsibility, 7, 9-10

Rainwater management System

(RWMSs), 10, 15

R-S-D, 60

R-S-U-D, 72

Rainfall modeling, 19-24, 105

Rainwater utilization ratio (RUR),

75, 78, 93, 95-97, 108, 113, 121 annual, 78

for R-S-U-D system, 78

Rainwater for drinking (RFD), 139-146, 151

Runoff modeling, 17, 24-27,

$31-33,105$

Resilient, 50, 52, 146, 151

$\mathbf{S}$

Sewer system, 2, 17, 49, 67, 76, 147

capacity, 2, 6, 8, 12, 49

conventional, 16, 18, 19

design and operation, 5, 54 discharge flow to, 99

roof and, 50, 60

storm, 25

Sustainable development goal

(SDGs), 139

SDGs6, 139, 146

T

Tank volume, 33, 62, 64, 65, 75, 93, $113,114,115,120-121$

$\mathbf{U}$

Urban flooding, 49, 55, 102,

137-138, 151-152

Urban water, 49, 50

V

Variable demand, 122-124, 126, 127,128

W

Water resources, 27, 151

Water quality, 9, 132, 139, 144-146

Water saving (WS), 8, 36, 50, 71,

$78,88,103,104,134-136,150$

Water shortage, 1, 8, 13, 50, 107

Water supply, 52, 54, 67, 70

demand from municipal, 71

domestic, 52

emergency, 67

energy saving by using, 136

lack of, 50

RWHS for, 107-128 
Downloaded from https://iwaponline.com/ebooks/book-pdf/651202/wio9781780408712.pdf

by IWA Publishing publications@iwap.co.uk 


\section{“This publication can be a guide to transform the world into a Rain City"}

Professor Mooyoung Han, Director, Rainwater Research Center, Seoul National University

Rainwater as a resource has been underrated due to scientific misunderstandings about its quality, the lack of hydrologic design tools for small catchments, such as roofs, the preference for large infrastructures, and the small number of successful cases reported. This book summarizes seventeen years of scientific research, operational monitoring, and practical demonstration projects made at Seoul National University Rainwater Research Center.

A new paradigm of rainwater is proposed, which is to collect rainwater and use it, instead of draining it. Based on conventional hydrology and methodology, a hydrological modelling method for micro-catchment is suggested. By incorporating several controllable measures into the design, the system can solve several water-related problems such as flooding, water conservation, emergency water storage, and groundwater recharge.

Now is the time to adapt. Many good examples are reported from around the world, including South Korea. Fifty-nine South Korean cities have announced regulations and commitment to become 'Rain Cities' by offering financial incentives to rainwater management systems or subsidizing them.

This book is written to give hope to those who seek to transform their community from a 'Drain City' to a 'Rain City'. It has been prepared to clear the ambiguity about rainwater management and transform the experts as well as the citizens to become active proponents of rainwater. This book can be a guide to transform the world into Rain Cities, and become a viable solution toward Sustainable Development Goal Number 6.

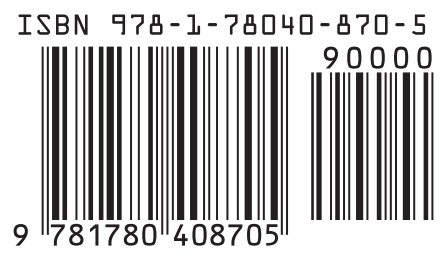

